University of Nebraska - Lincoln DigitalCommons@University of Nebraska - Lincoln

Student Research Projects, Dissertations, and

Theses - Chemistry Department

Chemistry, Department of

4-24-2015

\title{
The 8-Silyloxyquinoline Scaffold as a Versatile Platform for the Sensitive Detection of Aqueous Fluoride
}

Xinqi Zhou

University of Nebraska-Lincoln, ethanzhou@huskers.unl.edu

Follow this and additional works at: http://digitalcommons.unl.edu/chemistrydiss

Part of the Analytical Chemistry Commons, and the Organic Chemistry Commons

Zhou, Xinqi, "The 8-Silyloxyquinoline Scaffold as a Versatile Platform for the Sensitive Detection of Aqueous Fluoride" (2015).

Student Research Projects, Dissertations, and Theses - Chemistry Department. 57.

http://digitalcommons.unl.edu/chemistrydiss/57

This Article is brought to you for free and open access by the Chemistry, Department of at DigitalCommons@University of Nebraska - Lincoln. It has been accepted for inclusion in Student Research Projects, Dissertations, and Theses - Chemistry Department by an authorized administrator of DigitalCommons@University of Nebraska - Lincoln. 


\title{
The 8-Silyloxyquinoline Scaffold as a Versatile Platform for the Sensitive Detection of Aqueous Fluoride
}

\author{
by \\ Xinqi Zhou
}

\section{A THESIS}

\begin{abstract}
Presented to the Faculty of
The Graduate College at the University of Nebraska In Partial Fulfillment of Requirements

For the Degree of Master of Science
\end{abstract}

\author{
Major: Chemistry \\ Under the Supervision of Professor Cliff I. Stains
}

Lincoln, Nebraska

April 2015 


\title{
The 8-Silyloxyquinoline Scaffold as a Versatile Platform for the Sensitive Detection of Aqueous Fluoride
}

\author{
Xinqi Zhou, M.S. \\ University of Nebraska, 2015
}

Advisor: Cliff I. Stains

As one of the most essential elements in nature, fluoride has been well known and extensively studied since the $16^{\text {th }}$ century. Since then the two-edged nature of fluoride in biological systems has been well described. Specifically, moderate fluoride exposure can aid in tooth and bone development, while fluoride overexposure results in the depilating disease known as fluorosis. Because of the side effects upon overexposure of fluoride, there is a need to develop fast and straight forward methods to sensitively and selectively detect and quantify fluoride concentration in drinking water. With this goal in mind and by taking advantage of the high sensitivity of fluorescence, we designed fluorescent probes to selectively detect inorganic fluoride $(\mathrm{NaF})$ in aqueous sample using the novel 8-silyloxyquinoline scaffold. Our initial probe design is capable of detecting inorganic fluoride in aqueous solution, with a detection limit of $3.8 \mu \mathrm{M}(72 \mathrm{ppb})$, well below the EPA recommended levels for drinking water (4 ppm), placing the probe among the most sensitive inorganic fluoride sensors reported to date. Since the 8-silyloxyquinoline template showed high sensitivity to fluoride and the structure could be easily modified, we were able to design and synthesize a second fluoride probe that had a red-shifted excitation and emission wavelength and was capable of detecting aqueous fluoride concentrations as low as $50 \mu \mathrm{M}(0.95 \mathrm{ppm})$ utilizing a straightforward test-strip assay. In 
conclusion, this work provides a novel fluorogenic platform for detecting fluoride with high selectivity and sensitivity in the laboratory and in the field. 


\section{Table of Contents}

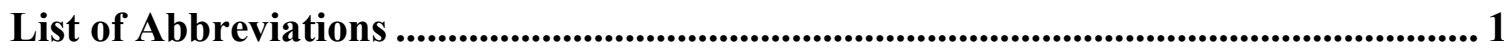

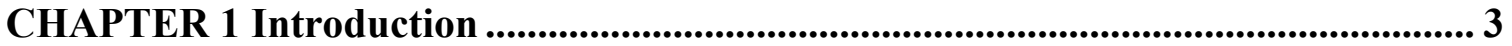

$1.1 \quad$ Fluoride - A Two-Edged Sword.................................................................................... 3

1.2 Fluorescent Sensors for fluoride - Principles, Design and Applications .................. 4

1.2.1 Sensors Based on Hydrogen-Bonding Interactions ................................................. 4

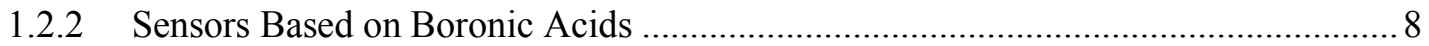

1.2.3 Sensors Based on Fluoride Promoted Desilylation .................................................... 11

CHAPTER 2 8-Silyloxyquinoline Platform for the Sensitive Detection of Aqueous

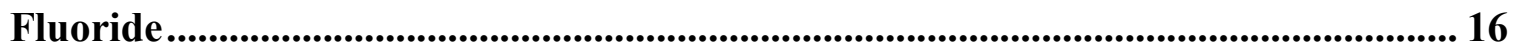

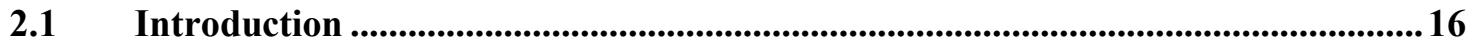

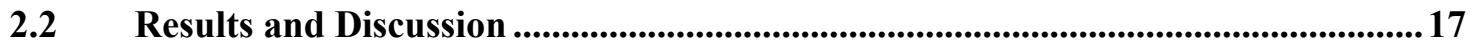

2.2.1 Rational Design of an 8-silyloxyquinoline-based Fluoride Sensor ......................... 17

2.2.2 Limit of Detection and Selectivity of Fluoride Sensor 2 2......................................22

2.2.3 Test-Strip-Based Sensing of Fluoride in Aqueous Samples. ...................................28

2.3 Experimental Procedures .......................................................................................................34

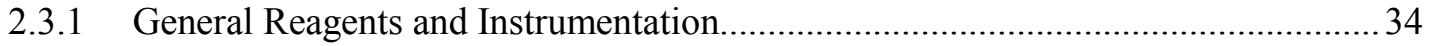

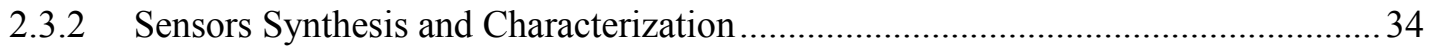

2.3.3 Determination of Molar Extinction Coefficient …................................................... 42

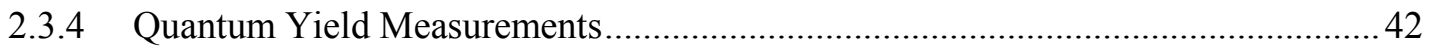

2.3.5 Absorbance and Fluorescence Assay Conditions......................................................... 42

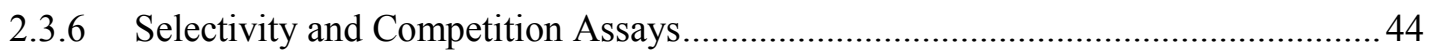

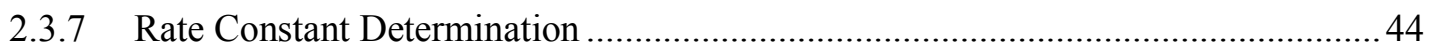

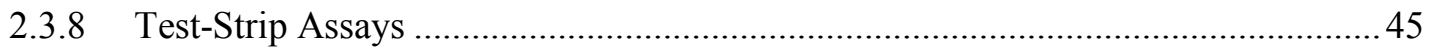

2.4 Conclusions and Future Directions..................................................................45

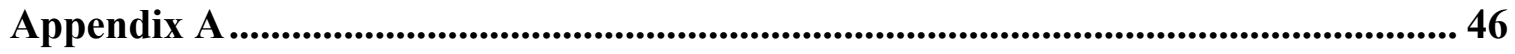

Appendix B ................................................................................................................................. 82

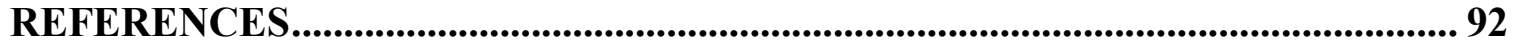




\section{List of Abbreviations}

\begin{tabular}{|c|c|}
\hline $\mathrm{ACN}$ & Acetonitrile \\
\hline $\mathrm{BDE}$ & Bond Dissociation Energy \\
\hline $\mathrm{CDC}$ & Center for Disease Control and Prevention \\
\hline CTAB & Cetyltrimethylammonium Bromide \\
\hline DCM & Dichloromethane \\
\hline DMF & Dimethylformamide \\
\hline DMSO & Dimethyl Sulfoxide \\
\hline DIPEA & N, N-Diisopropylethylamine \\
\hline EPA & the United States Environmental Protection Agency \\
\hline HATU & 1-[Bis(dimethylamino)methylene]-1H-1,2,3-triazolo[4,5-b]pyridinium \\
\hline & 3-oxid hexafluorophosphate) \\
\hline HEPES & 4-(2-hydroxyethyl)-1-piperazineethanesulfonic acid \\
\hline HOMO & Highest Occupied Molecular Orbital \\
\hline ICT & Intramolecular Charge Transfer \\
\hline LUMO & Lowest Unoccupied Molecular Orbital \\
\hline MES & 2-(N-morpholino)ethanesulfonic acid \\
\hline NMR & Nuclear Magnetic Resonance \\
\hline PBS & Phosphate Buffered Saline \\
\hline PET & Photo-induced Electron Transfer \\
\hline PHS & United States Public Health Service \\
\hline TBA & Tetra-n-butyl Ammonium \\
\hline TBAF & Tetra-n-butyl Ammonium Fluoride \\
\hline
\end{tabular}




\section{List of Abbreviations - Continued}

TBDPSCl Tert-butylchlorodiphenylsilane

THF Tetrahydrofuran

UV Ultra Violet

WHO World Health Organization 


\section{CHAPTER 1 Introduction}

\subsection{Fluoride - A Two-Edged Sword}

As one of the most important anions on planet, the chemistry and biology of fluoride have been extensively studied. Numerous studies have shown that fluoride in drinking water or tooth paste could help with the dental health. ${ }^{1,2}$ Also, fluoride can help increase the bone mass and hence has the potential for treating osteoporosis. ${ }^{3,4}$ Because of these benefits, water fluoridation became widely used by $1960 .{ }^{5}$ However, later studies have shown that overexposure of fluoride can be detrimental, especially to the teeth, ${ }^{6}$ brain, ${ }^{7}$ kidney ${ }^{8,9}$ and bone, ${ }^{10-12}$ resulting in a disease known as fluorosis. Taking this into account, WHO, HHS and EPA have given their recommended fluoride level as 0.5-1.0 ppm, $0.7-1.2 \mathrm{ppm}$ and $4.0 \mathrm{ppm}$, respectively. ${ }^{13}$ Fluoride is also a byproduct of the hydrolysis of sarin gas. As a result, it is of great value to monitor the fluoride levels in victims and the local environment after an incident involving sarin gas. ${ }^{14,15}$

Both the benefits and perniciousness of fluoride certainly make it extremely urgent to develop methods for detection. However, despite the increasing interest, the development of fluoride sensors still remains challenging. There are numerous traditional measurement methods, including ${ }^{19} \mathrm{~F}$ NMR analysis, ion selective electrode methods, and ion chromatography methods. ${ }^{16-19}$ These methods either rely on expensive and fragile equipment or are relatively time consuming, making it less applicable to measure and monitor fluoride levels in the field and in real time. Recently, colorimetric and fluorescent detection of fluoride using small organic molecules has drawn growing attention because of the simplicity, accuracy and low cost of the assay format. ${ }^{20-30}$ However, the sensors have to overcome the hydration enthalpy barrier of fluoride in 
water $(-121 \mathrm{kcal} / \mathrm{mol})$ so that it can be used in real world aqueous sample. As a consequence, although numerous sensor platforms have been reported in the literature, the fluoride detection limit of these sensors is generally in the mid micromolar range for aqueous samples. Given the recommended fluoride concentration in drinking water by the EPA (4 ppm or $211 \mu \mathrm{M})$ and the PHS $(0.7-1.2$ ppm or $37-63 \mu \mathrm{M})$, it still remains challenging and necessary to further develop sensors that are more sensitive to fluoride, especially in aqueous solutions.

\subsection{Fluorescent Sensors for Fluoride - Principles, Design and Applications}

Fluoride is known to have a hard Lewis base nature, the smallest ionic radius, and the highest charge density. Utilizing these unique chemical properties, chemists have been designing colorimetric and fluorescent sensors specific for fluoride. In general, most of the sensors reported to date can be divided into the following categories:

\subsubsection{Sensors Based on Hydrogen-Bond Interaction}

It has been well established and understood that fluoride can form strong hydrogen bonds compared to oxygen and nitrogen. ${ }^{31}$ Over the past decade, fluoride receptors like urea, thiourea, sulfonamide, amide, Schiff base, indole, tetrazole, and pyrrole have been utilized to design selective fluoride sensors. ${ }^{32-36}$ The sensors usually have a reporter consisting of a chromophore or a fluorophore, a fluoride receptor (hydrogen donor) and a spacer or linker to link the reporter and fluoride receptor. Binding of fluoride to these receptors will cause a change in the electron density surrounding the reporter, known as the PET process (Figure 1-1) ${ }^{37,38}$ and hence the absorption and emission spectrum of the reporter will change accordingly. Specifically, before binding with fluoride, the HOMO energy level of the receptor will be lower than that of the 
reporter. One electron is promoted to the LUMO upon excitation and can freely transition back to the ground state and release energy in the form of fluorescence. However, when fluoride binds at the receptor, the HOMO energy level of the receptor becomes higher. In that case, upon excitation, one electron on the receptor's HOMO will transfer to the empty position of the reporter's HOMO before the LUMO electron of the reporter can relax to the ground states significantly quenching fluorescence. The degree of fluorescence quenching can be monitored by instruments and correlated to the amount of fluoride in solution.

One of the earliest examples of a fluoride sensor based on the hydrogen bonding mechanism was developed by Yoon's group. ${ }^{39}$ As shown in Figure 1-2, the sensor is comprised of anthracene (fluorescent reporter), two ureas (fluoride receptor), and two $-\mathrm{CH}_{2}$ - groups to link them together. Upon binding with fluoride, the fluorescence of anthracene is significantly quenched due to PET. The selectivity of this sensor arises from the hydrogen donating properties of the two ureas. Due to the PET process, these types of fluoride sensors are usually "turn-off" sensors and hence the sensitivity is usually limited. Also, acetate and phosphate represent commonly observed false positives. 


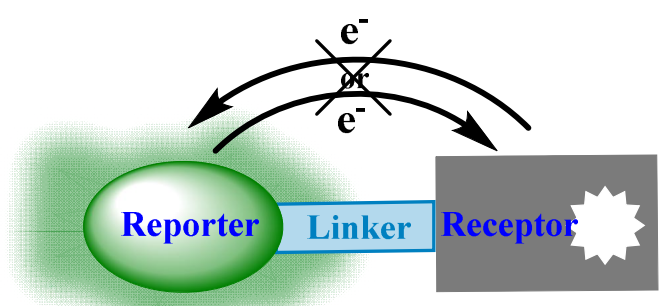

Strongly fluorescent

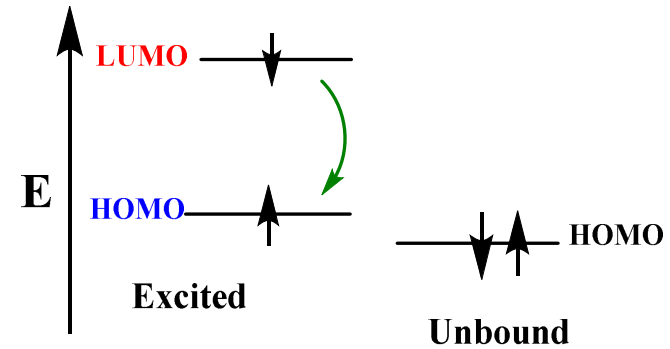

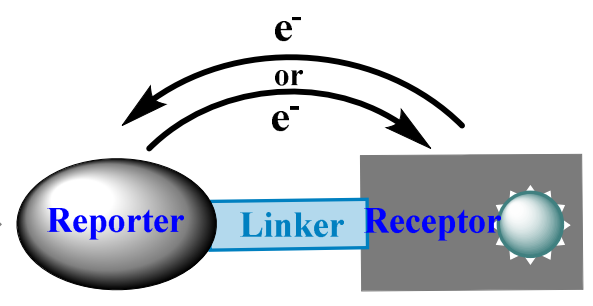

Weakly fluorescent

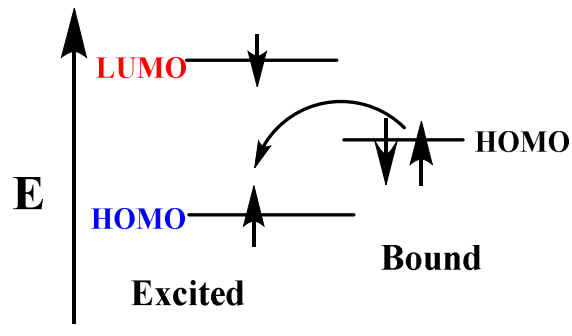

Figure 1-1. PET mechanism of hydrogen bond based fluoride sensor 

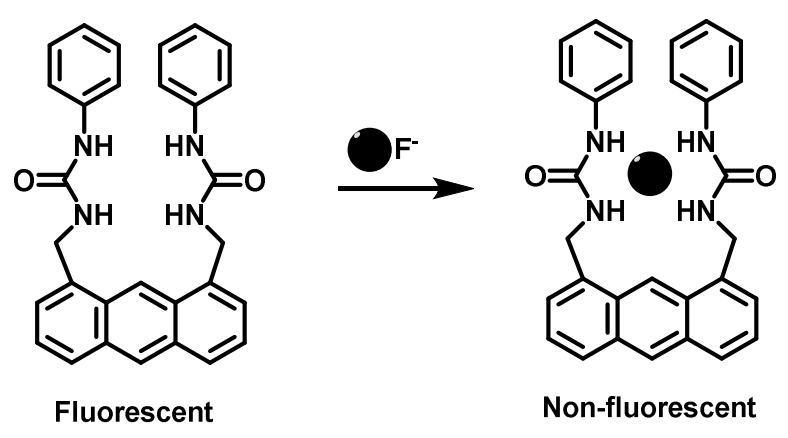

Figure 1-2. Example of a fluoride sensor based on the hydrogen bond mechanism 


\subsubsection{Sensors Based on Fluoride-Boronic Acid Moieties Interaction}

Because of the boronic acid group's affinity to hard bases, such as fluoride, sensors utilizing boronic acids have been cleverly designed by different groups. In general, the fluorescence or absorbance change is usually related to a change in the electronic properties of the boron center upon fluoride binding (Figure 1-3). ${ }^{40-44}$

One fluorescein boronic acid probe was designed and investigated for fluoride detection by Yoon's group (Figure 1-4). ${ }^{44}$ The fluorescence of the fluorescein derivative is initially quenched by PET. However, upon reacting with fluoride, the fluorescence can be turned on. Since this is an off-on sensor, the sensitivity of this sensor is greatly improved.

In this type of sensor, the boron center has to compete with water to react with fluoride and the concentration of the sensors used for the assay is usually in the low micromolar range, making competition with water (55 M) difficult. 


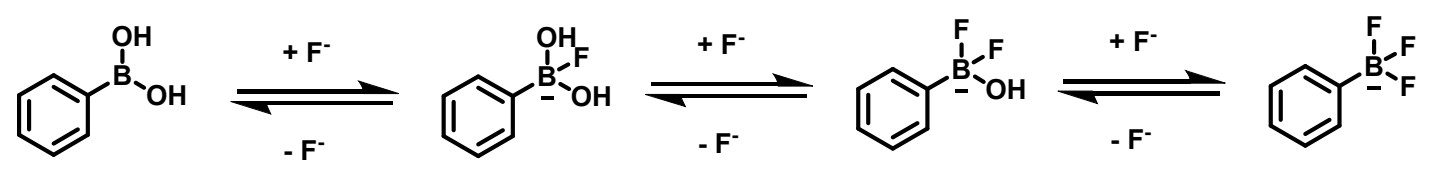

Figure 1-3. Mechanism for fluoride binding with boronic acids 


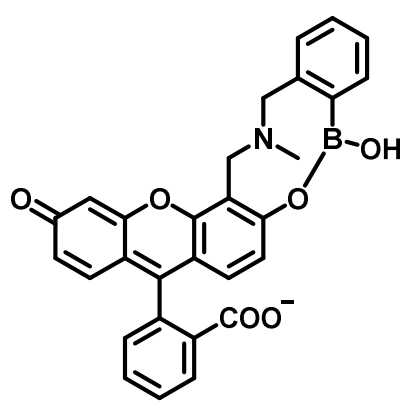

Fluorescence off

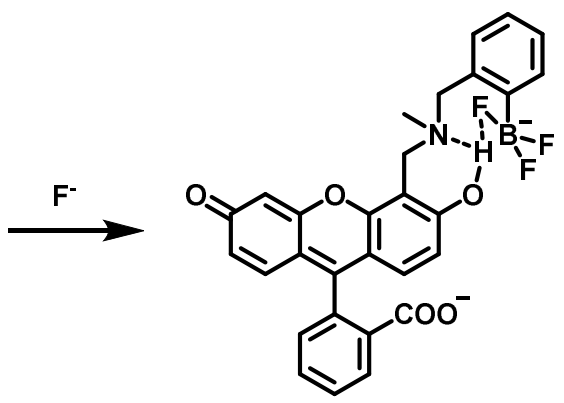

Fluorescence on

Figure 1-4. Example of fluoride sensor based on interaction with boronic acid 


\subsubsection{Sensors Based on Fluoride Promoted Desilylation}

Another characteristic that distinguishes fluoride from other anions is its strong affinity to silicon. Compared with the carbon-silicon bond (BDE: $69 \mathrm{kcal} / \mathrm{mol}$ ) and oxygen-silicon bond (BDE: $103 \mathrm{kcal} / \mathrm{mol}$ ), the fluoride-silicon bond is much more stable (BDE: $141 \mathrm{kcal} / \mathrm{mol}$ ). ${ }^{31}$ Numerous sensors have been reported based on the selective cleavage of oxygen-silicon bonds and carbon-silicon bonds by fluoride. ${ }^{45,46}$ These types of sensors usually have an electron acceptor: (a fluorophore or chromophore containing an electron withdrawing group) as well as a fluoride receptor comprised of one or more oxygen-silicon or carbon-silicon moieties. However, unlike the PET process, the receptor and reporter are usually linked through a conjugated linker or directly attached to each other. The sensors by themselves are normally non-fluorescent or weakly fluorescent because of the free bond rotation of the silicon moieties. Upon fluoride reacting with the sensor, the silicon moieties leave and the receptor becomes a strong electron donating group. The charge can be transferred into the fluorophore, greatly enhancing the "pushpull" effect of the fluorophore and lowering the HOMO LUMO energy gap, making the excitation and emission wavelength red-shifted and improving the quantum yield. ${ }^{47}$ This process is known as the ICT process (Figure 1-5). This type of sensor usually undergoes an off-on process upon reacting with fluoride.

The key factors of this type of sensors are the rate of fluoride cleavage of the O-Si or C-Si bond and the quantum yield and molar extinction coefficient of the reporter. These factors determine the sensors' detection limit. Table 1 summarizes the sensors based on this mechanism and their detection limits for fluoride. 
Since these types of sensors are reaction based, their selectivity to fluoride is usually very good. Also, they usually exhibit a turn-on process upon reacting with fluoride increasing the sensitivity compared with other types of sensors. By taking advantage of these two main superiorities, many research groups have designed this type of sensor to detect fluoride in living cells. Furthermore, this type of sensor can also be used to detect the fluoride levels in different organs in living animals like zebrafish ${ }^{48}$ and C. elegans. ${ }^{49,50}$ 


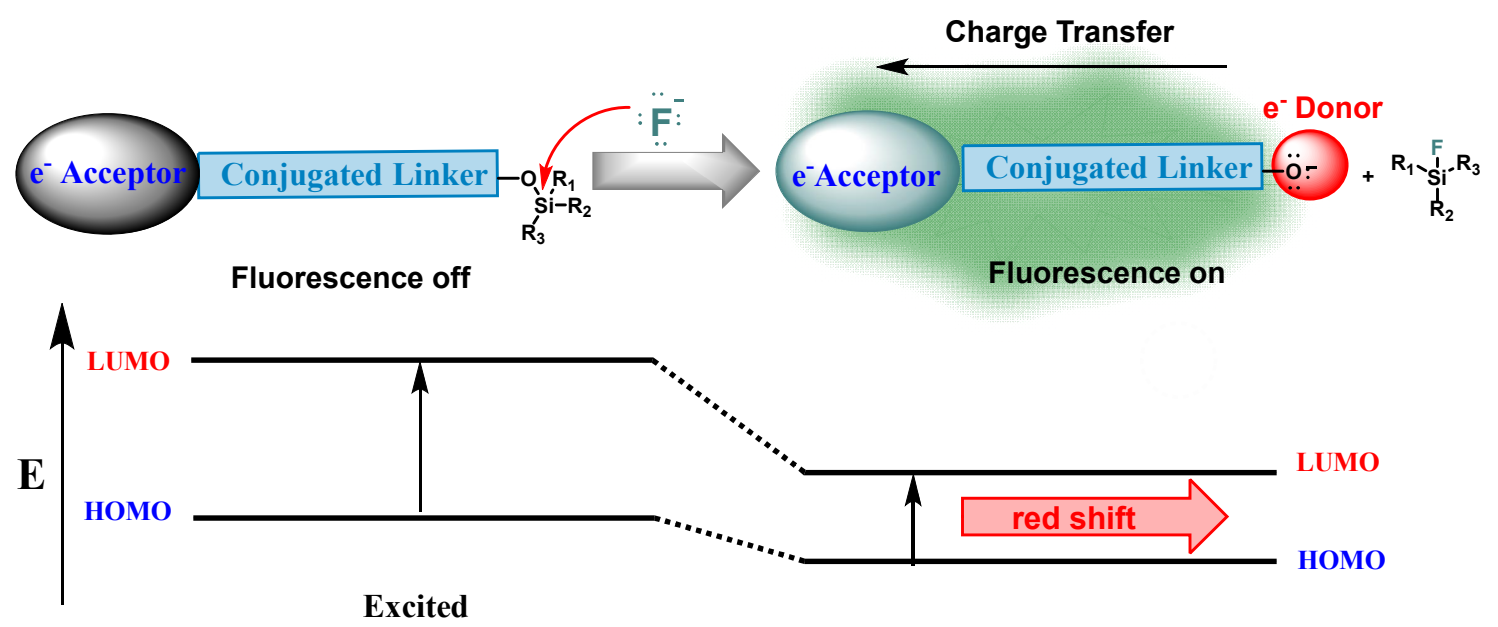

Figure 1-5. Mechanism of fluoride sensors based on the ICT process 
Table 1. Detection limits of representative probes for fluoride in aqueous samples. Reprinted with permission from the American Chemical Society.

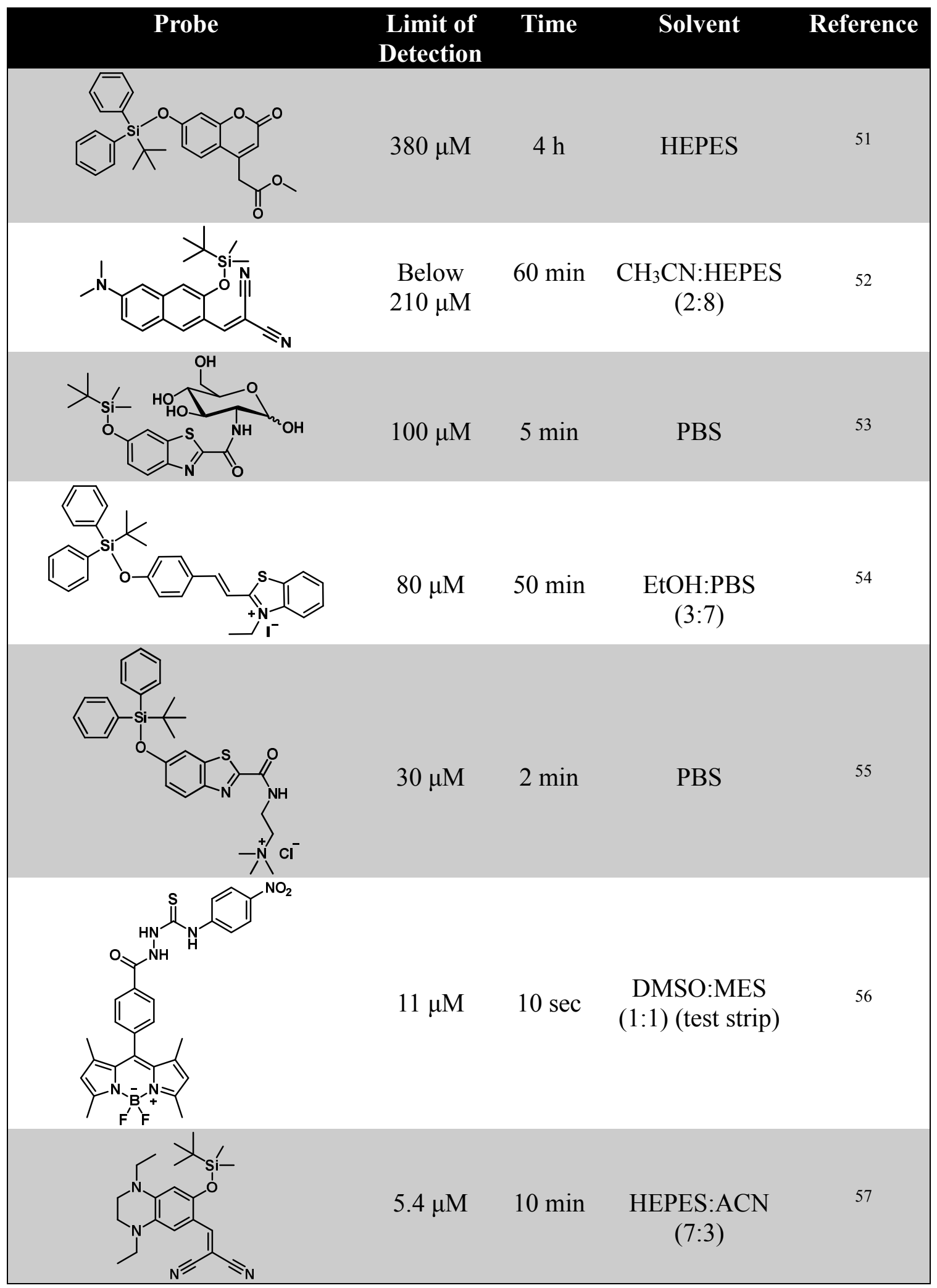


Table 1. Detection limits of representative probes for fluoride in aqueous samples. Reprinted with permission from the American Chemical Society. (Continued)

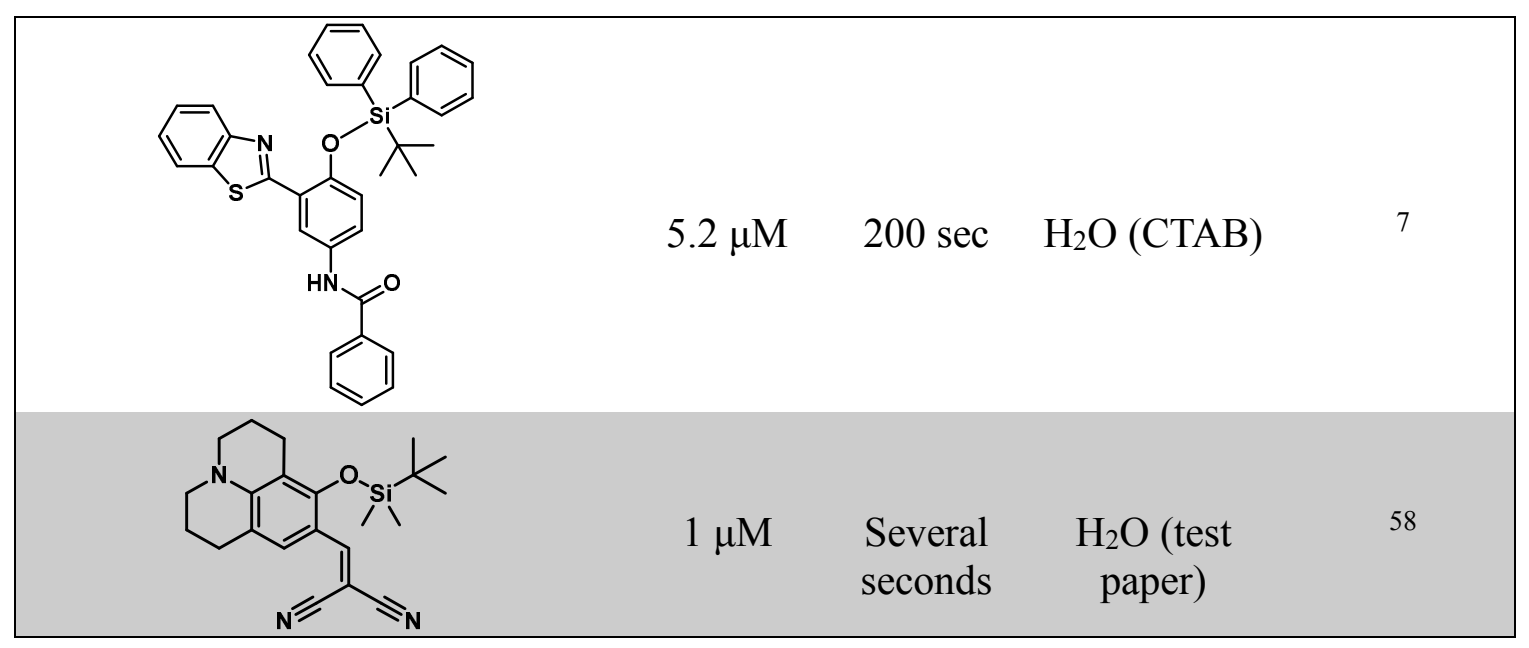




\section{CHAPTER 2 8-Silyloxyquinoline Platform for the Sensitive}

\section{Detection of Aqueous Fluoride}

\subsection{Introduction}

The entirety of this paper entitled "The 8-Silyloxyquinoline Scaffold as a Versatile Platform for the Sensitive Detection of Aqueous Fluoride" is presented in Appendix A. ${ }^{59}$

As detailed in chapter 1, there is a critical need for the development of sensitive assays for fluoride. The goal of this work is to design straightforward, sensitive assay platforms for the detection of the fluoride in the laboratory as well as the field. In the long-term we seek to leverage these probes to investigate the role of fluoride in biological systems. 


\subsection{Results and Discussion}

\subsubsection{Rational Design of an 8-silyloxyquinoline-based Fluoride Sensor}

Among the three sensing mechanisms described in chapter 1, the fluoride induced cleavage of oxygen-silicon bonds stands out as a selective approach for fluoride detection. In order to further improve the sensitivity of this method, a fluorophore with reasonable quantum yield is needed and more importantly, higher affinity for fluoride. Since fluoride has the highest electronegativity of the halogens, we decided to employ the electrondeficient fluorophore. 8-hydroxyquinoline scaffold distinguished itself as an electron deficient conjugated system with reasonable quantum yield. This scaffold has also been used to provide a sensitive fluorescent readout in aqueous samples. ${ }^{60-63}$ Therefore, we chose to investigate the ability of 8-hydroxyquinoline derivatives to function as fluoride sensors.

Based on the ICT mechanism, we envisioned the synthesis of a TBDPS protected 8-hydroxyquinoline (2) (Scheme 1). We hypothesized that cleavage of the TBDPS group in $\mathbf{2}$ by fluoride would result in the rapid formation of a fluorescent species. We reasoned that by introducing an amide functionality at position 2 of intermediate 1, the metal binding ability could be significantly disrupted and also allow for facile modification in order to tune the spectral properties of our fluoride chemodosimeter platform. Lastly, we chose to include a sulfonamide at position 5 in sensor $\mathbf{2}$ as an electron withdrawing moiety in order to promote fluorescence via an ICT mechanism.

We synthesized 2 following Scheme 1 and investigated its response to fluoride by addition of $1 \mathrm{mM}$ TBAF to a dioxane solution of $\mathbf{2}$. We observed a remarkable change in both the absorbance and fluorescence emission spectra of the solutions upon addition of 
TBAF to 2, producing a desilylated fluorescent product 3 (Scheme 1) with molar absorption coefficient $\varepsilon=6600 \mathrm{M}^{-1} \mathrm{~cm}^{-1}$ and quantum yield $\Phi=0.16$ (Figure 2-1). With this satisfactory result, we further used a Job plot to determine the stoichiometry of binding between 2 and fluoride to be 1:1 (Figure 2-2), further demonstrating a detection mechanism in which one fluorine atom reacts with one molecule of $\mathbf{2}$ to produce TBDPSF and a fluorescent species, 3. 

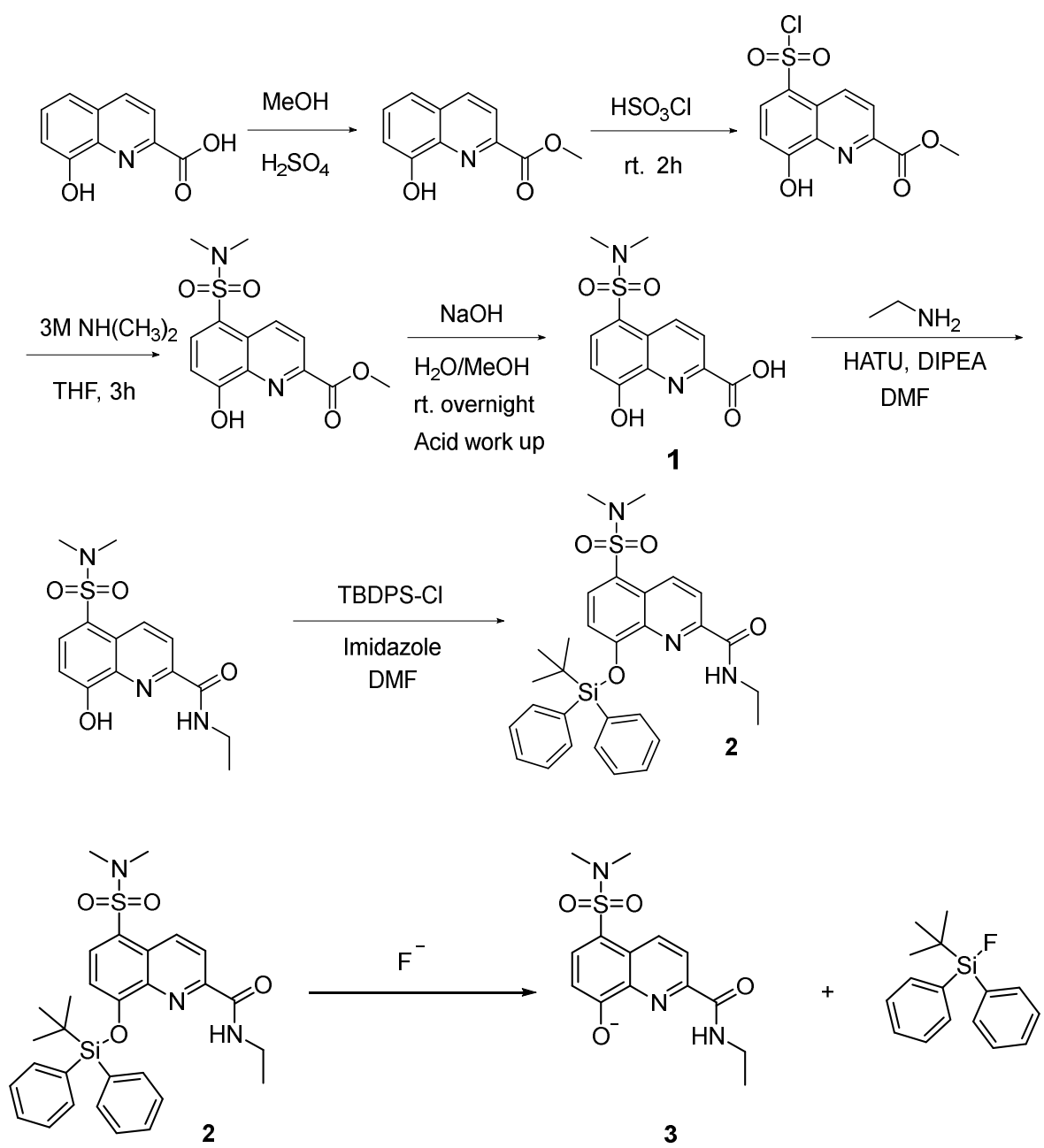

Scheme 1. Synthesis of 8-silyloxyquinoline-based fluoride sensor 2 and reaction of fluoride sensor $\mathbf{2}$ with fluoride anion to produce the desilylated product $\mathbf{3}$. Reprinted with permission from the American Chemical Society. 
(A)

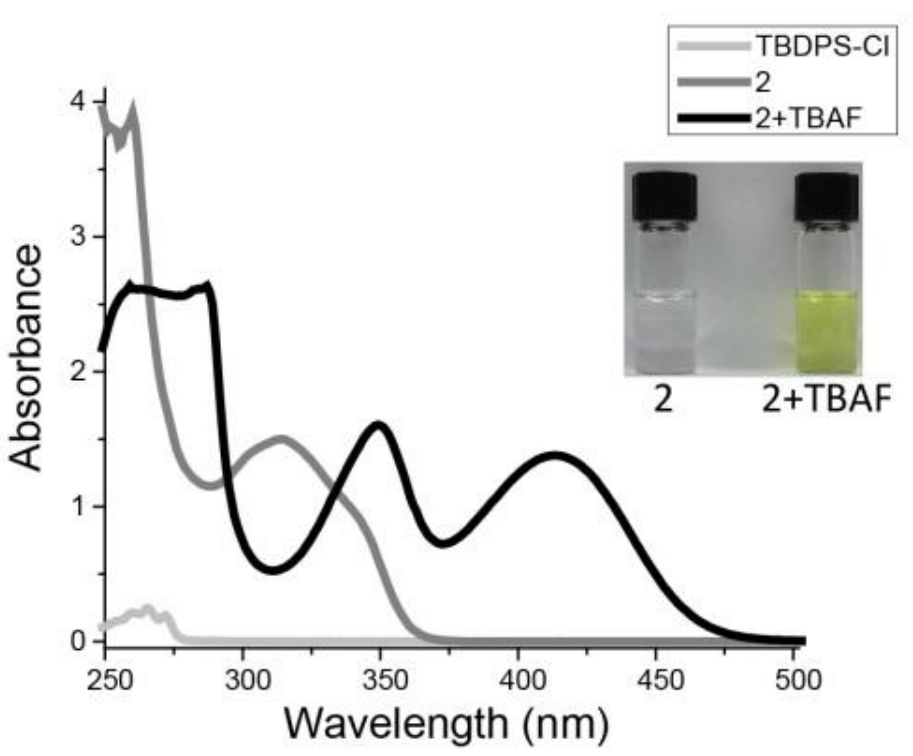

(B)

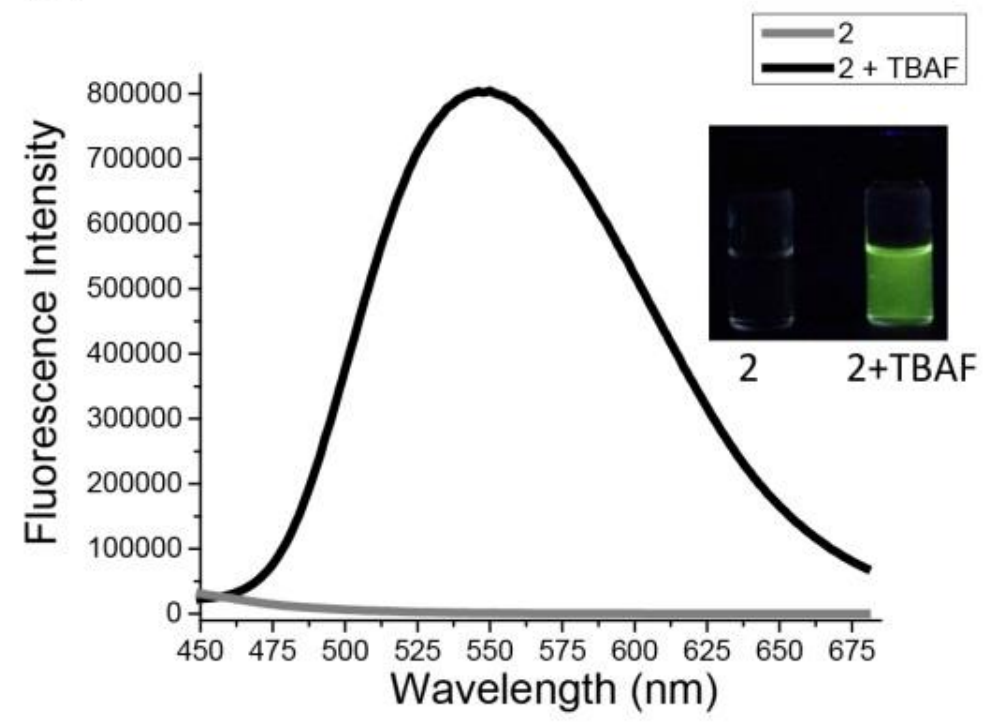

Figure 2-1. The absorbance (A) and fluorescence (B) of $2(200 \mu \mathrm{M})$ in the absence or presence of $1 \mathrm{mM}$ TBAF in dioxane, TBDPS-Cl is shown as a control. Fluorescence spectra were acquired by excitation at $345 \mathrm{~nm}$. Reprinted with permission from the American Chemical Society. 


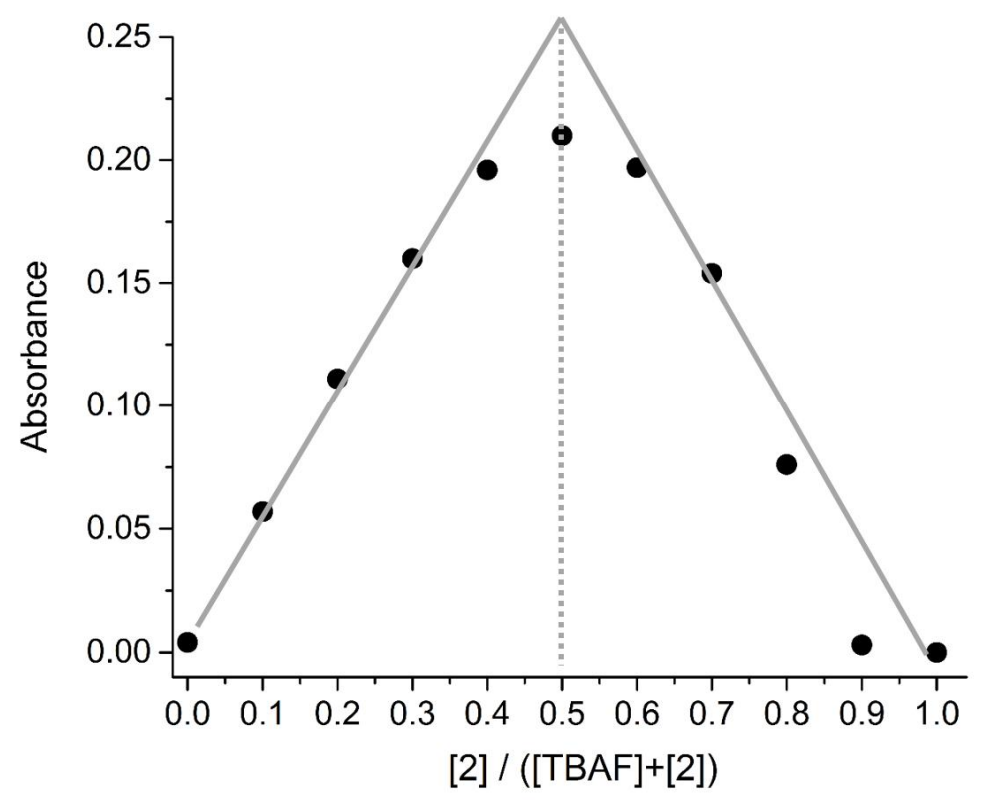

Figure 2-2. A Job plot of 2 with TBAF. [TBAF] $+[2]=200 \mu \mathrm{M}$ in dioxane. The absorbance was recorded $15 \mathrm{~min}$ after $\mathbf{2}$ and TBAF were mixed. Reprinted with permission from the American Chemical Society. 


\subsubsection{Limit of Detection and Selectivity of Fluoride Sensor 2 .}

Confident in the mechanism of fluoride detection by $\mathbf{2}$, we next investigated the limit of detection of $\mathbf{2}$ for TBAF in dioxane (Figure 2-3). These data demonstrated the ability of 2 to resolve concentrations of TBAF as low as $0.56 \mu \mathrm{M}(11 \mathrm{ppb})$. Building upon these promising results we next assessed the response of 2 to $\mathrm{NaF}$ in a 50:50 (v/v) solution of water:dioxane. These data demonstrate that $\mathbf{2}$ is capable of detecting as little as $3.8 \mu \mathrm{M}$ or $72 \mathrm{ppb}$ of $\mathrm{NaF}$ in aqueous solutions, which is well below current guidelines for fluoride in drinking water (Figure 2-4) ${ }^{64}$ Moreover, the limit of detection for $\mathbf{2}$ for inorganic fluoride in aqueous solutions is among the most sensitive of reported silylbased fluoride sensors (Table 1-1).

We also interrogated the response of 2 to environmentally and biologically relevant anions besides fluoride. Impressively, we observed background levels of fluorescence for all anions expect for fluoride. In addition, the response of $\mathbf{2}$ was not appreciably perturbed due to direct competition with any anions (Figure 2-5). To further investigate the selectivity of our sensors, we also tested the ability of $\mathbf{2}$ to report on the presence of $\mathrm{NaF}$ in a synthetic aquifer sample. ${ }^{65}$ These experiments clearly demonstrate that environmentally relevant concentrations of cations and anions found in groundwater do not interfere with our assay (Figure 2-6). Lastly, we assessed the rate of reaction of $\mathbf{2}$ with $\mathrm{NaF}$, yielding a rate constant of $116 \mathrm{M}^{-1} \mathrm{~min}^{-1}$ (Figure 2-7).

These data demonstrate the ability to rapidly detect fluoride in aqueous samples. Overall, the above experiments indicate the potential to utilize 2 for the sensitive laboratory detection of fluoride in water samples. 
(A)
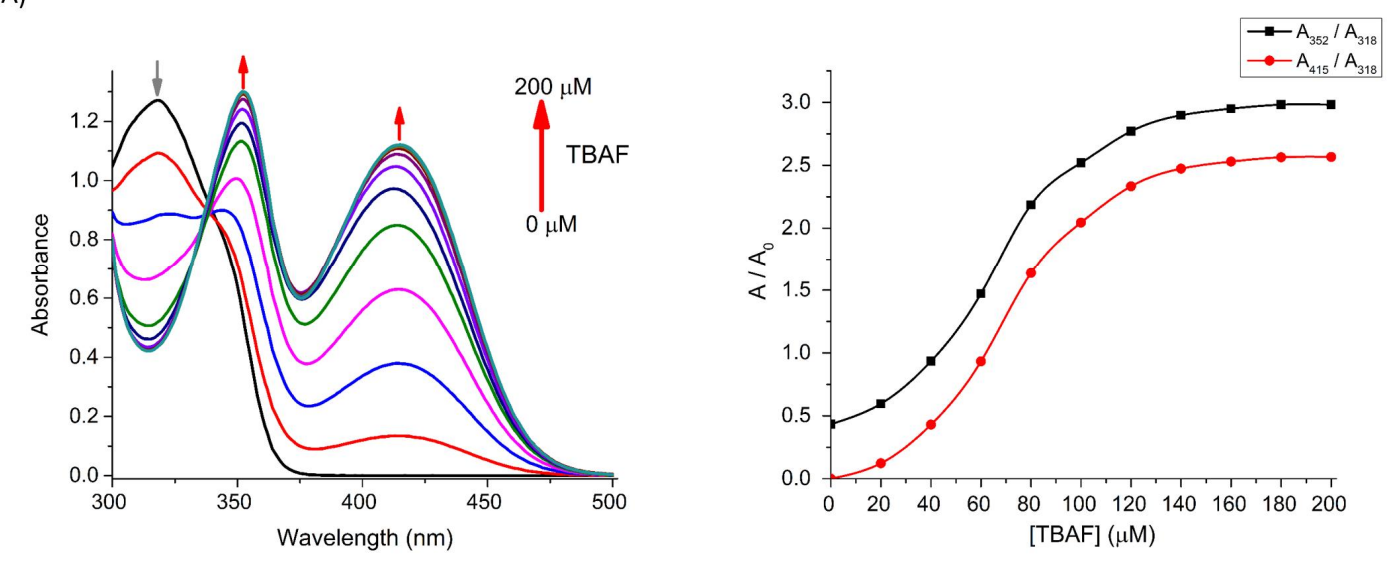

(B)
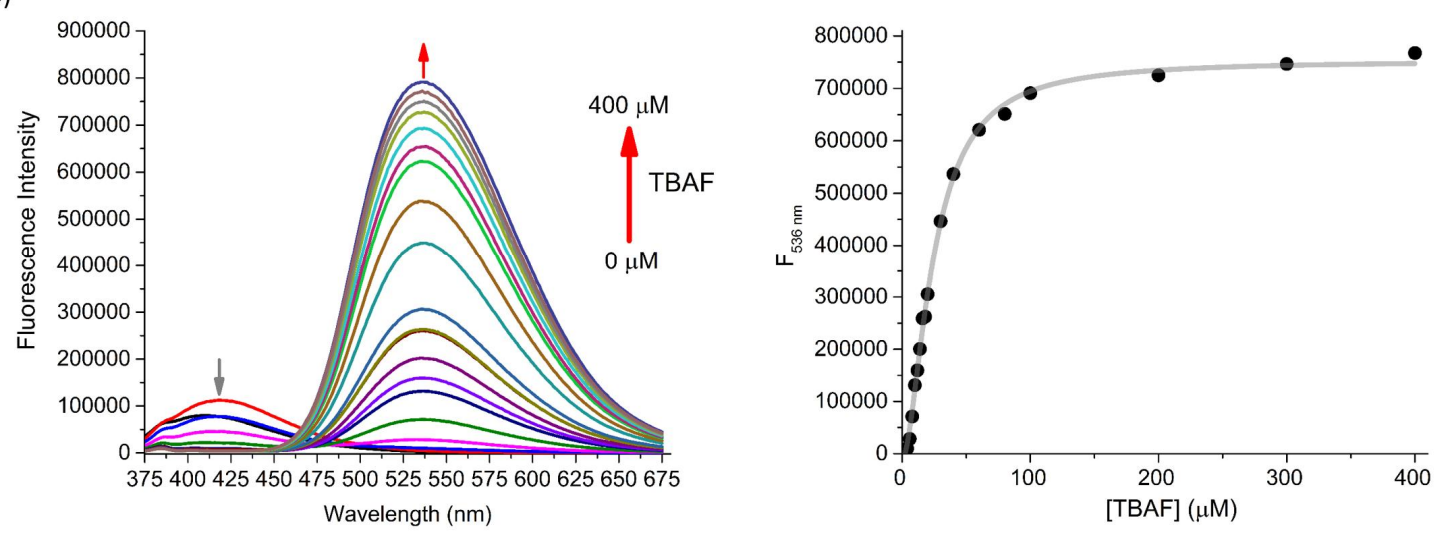

(C)
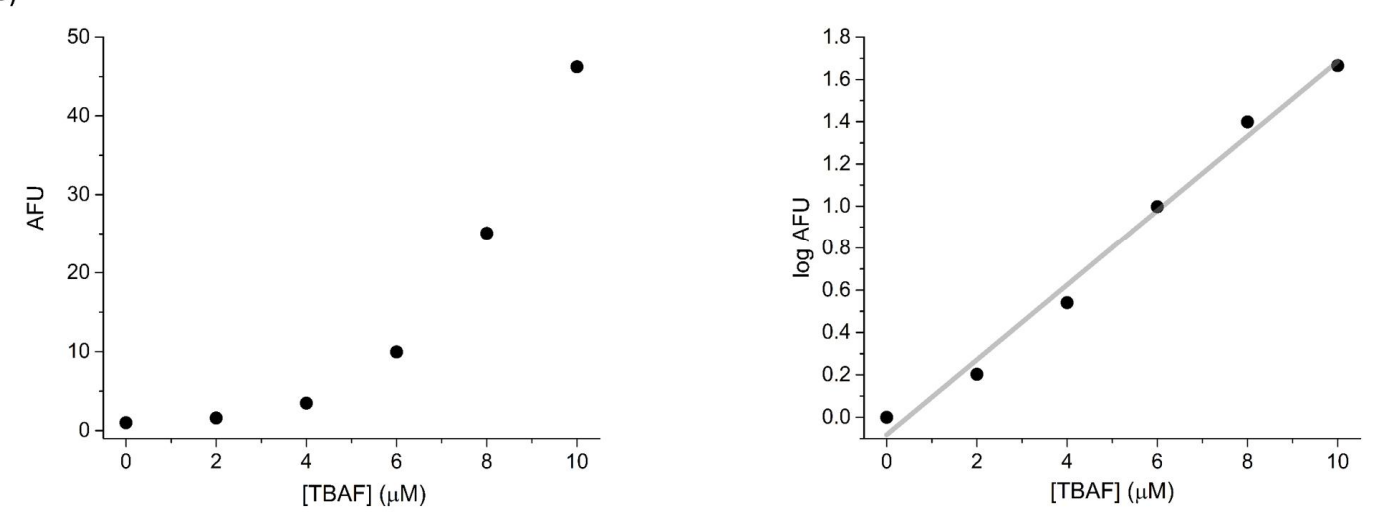

Figure 2-3. The absorbance (A) and fluorescence (B) titration of $2(20 \mu \mathrm{M})$ in dioxane.

(C) The limit of detection of $2(20 \mu \mathrm{M})$ in dioxane. $\left(y=0.17672 x-0.08282, R^{2}=0.987\right)$.

Reprinted with permission from the American Chemical Society. 


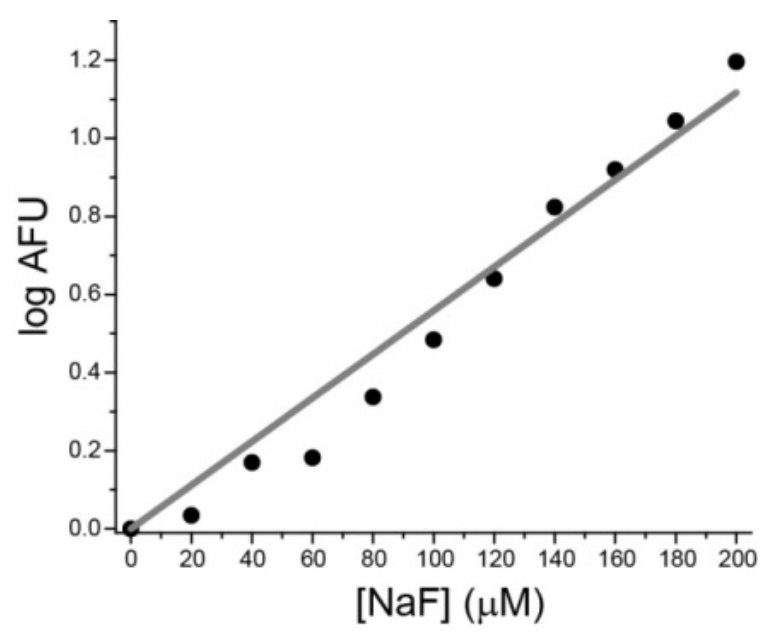

Figure 2-4. The emission of $20 \mu \mathrm{M} 2$ (at $542 \mathrm{~nm}$ ) in 50:50 (v/v) $10 \mathrm{mM}$ HEPES buffer $(\mathrm{pH}=7.4)$ :dioxane solution in the presence of the indicated concentration of $\mathrm{NaF}$. Reprinted with permission from the American Chemical Society. 


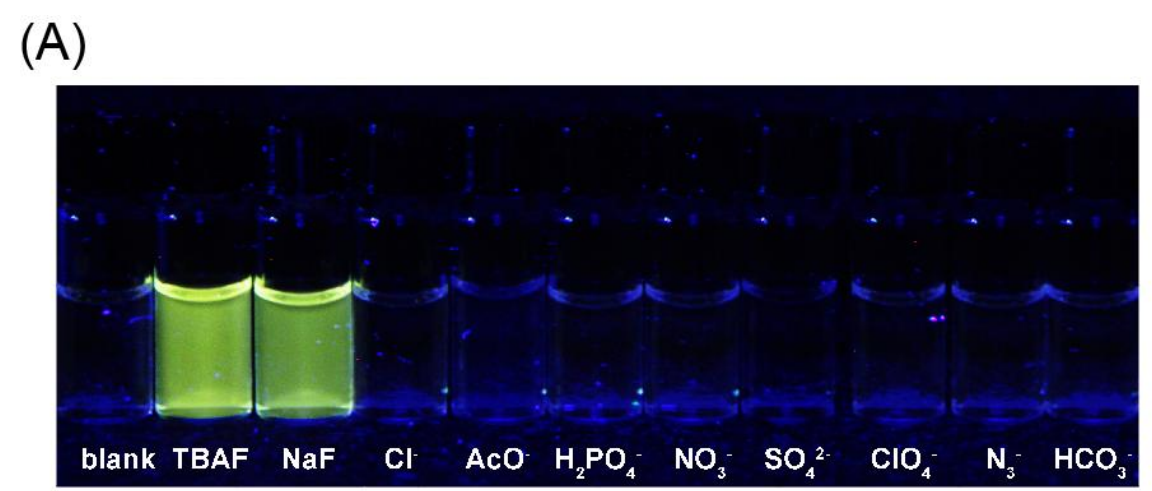

(B)

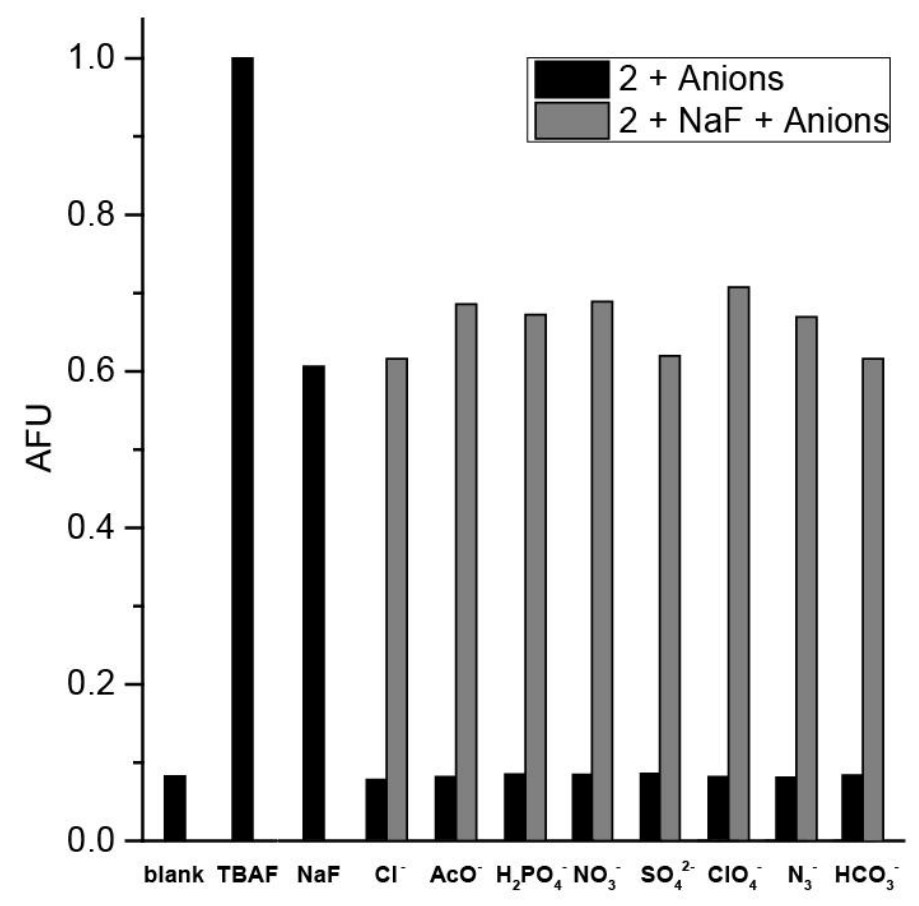

Figure 2-5. The selectivity of $\mathbf{2}(20 \mu \mathrm{M})$ for fluoride. (A) Images of $\mathbf{2}$, under UV light, in the presence of the indicated anion $(200 \mu \mathrm{M})$. (B) Black bars represent the fluorescence of 2 in the presence of the indicated anion $(200 \mu \mathrm{M})$, while grey bars indicate the fluorescence of 2 in the presence of the indicated anion $(200 \mu \mathrm{M})$ as well as $\mathrm{NaF}(200$ $\mu \mathrm{M})$. Assays were conducted in 50:50 (v/v) $10 \mathrm{mM}$ HEPES $(\mathrm{pH}=7.4)$ : dioxane. Reprinted with permission from the American Chemical Society. 


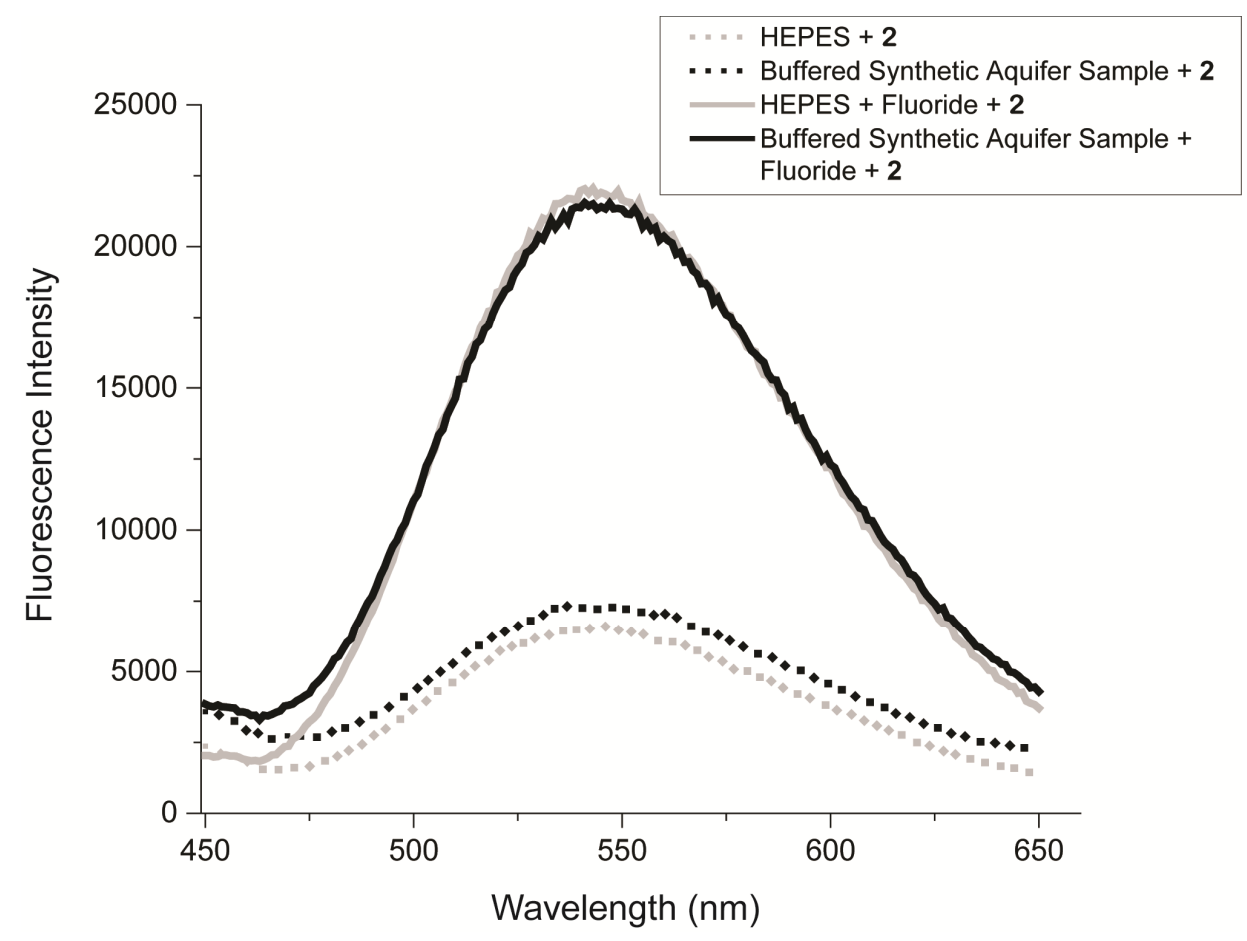

Figure 2-6. The fluorescence emission spectra of fluoride probe $2(20 \mu \mathrm{M})$ in the presence or absence of $100 \mu \mathrm{M} \mathrm{NaF}$. Assays were conducted in 50:50 (v/v) $10 \mathrm{mM}$ HEPES $(\mathrm{pH}=7.4)$ :dioxane or 50:50 $(\mathrm{v} / \mathrm{v})$ buffered synthetic aquifer sample : dioxane. Reprinted with permission from the American Chemical Society. 


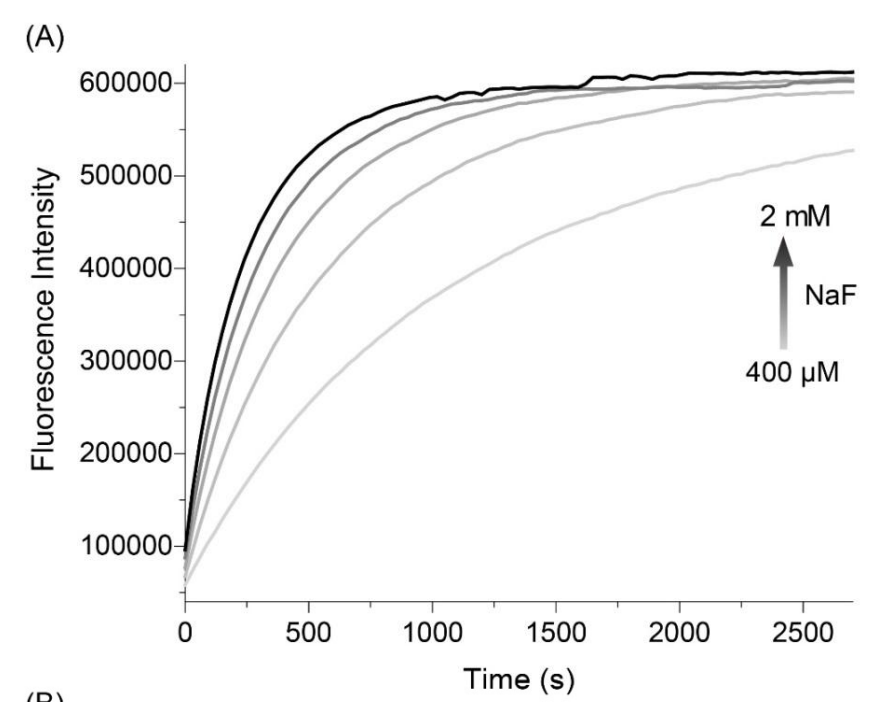

(B)

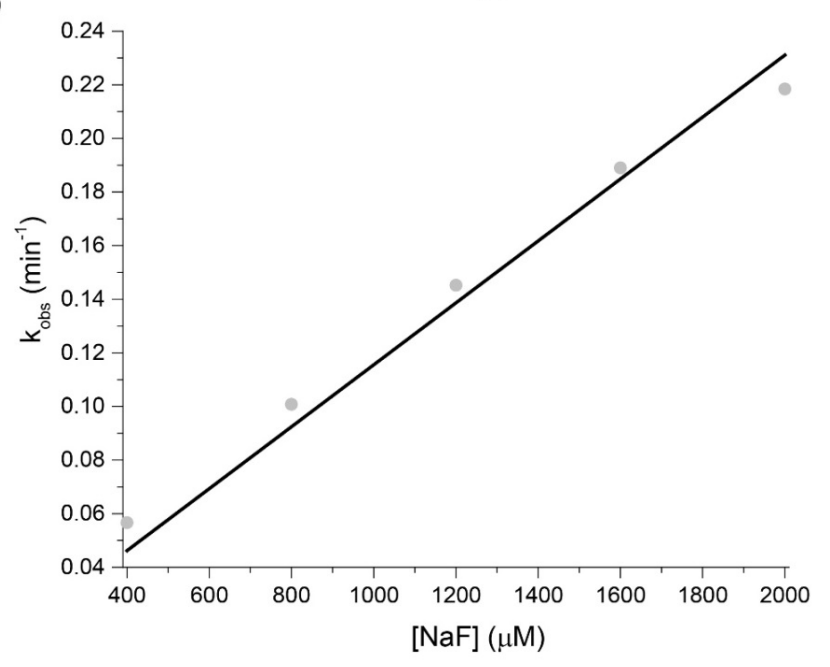

Figure 2-7. (A) The fluorescence increase of $2(20 \mu \mathrm{M})$ in the presence of increasing concentrations of $\mathrm{NaF}(400 \mu \mathrm{M}$ to $2 \mathrm{mM})$ in 50:50 (v/v) solution of HEPES buffer (10 $\mathrm{mM}, \mathrm{pH}=7.4$ ): dioxane. (B) The observed pseudo-first-order rate constant as a function of $\mathrm{NaF}$ concentration. The excitation and emission wavelengths were $393 \mathrm{~nm}$ and $542 \mathrm{~nm}$, respectively. The second order rate constant was calculated to be $1.16 \times 10^{2} \mathrm{M}^{-1} \mathrm{~min}^{-1}$. (Linear fitting: $y=1.16 \times 10^{-4} x, R^{2}=0.996$ ). Reprinted with permission from the American Chemical Society. 


\subsubsection{Test-Strip-Based Sensing of Fluoride in Aqueous Samples.}

Building upon these results, we envisioned a fluoride assay platform in which probe molecules would be adsorbed onto test-strips. We anticipated that these test-strips could then be utilized to measure fluoride concentrations in neat aqueous samples by monitoring the change in fluorescence of our probe. Such an assay format could allow for the point-of-use detection of fluoride. However, such an approach would require a fluoride chemosensor with low water solubility, ensuring that the probe would remain associated with the test-strip during subsequent analysis. We hypothesized that the ability to readily modify substituents on our fluoride sensing scaffold could yield a fluoride sensor with the desired physical properties. Accordingly, we appended an aniline substituent to 1 and protected this new fluoride sensor with TBDPS to afford fluoride sensor 4 (Scheme 2). As expected, addition of TBAF to a dioxane containing solution of 4 resulted in dramatic changes in the absorbance and emission spectra, producing a desilylated product with $\varepsilon=6330 \mathrm{M}^{-1} \mathrm{~cm}^{-1}$ and $\Phi=0.11$ (Figure 2-8). Moreover, we observed a red-shift in the emission maxima of 4 compared to 2 in dioxane (553 versus $536 \mathrm{~nm}$, respectively). In addition to these changes in the spectral properties of 4 compared to $\mathbf{2}$, initial assays indicated that probe $\mathbf{4}$ was highly insoluble in aqueous samples (data not shown). Taking advantage of the insolubility of $\mathbf{4}$ in aqueous solutions, we immersed filter paper strips in a DCM solution of 4 . These test-strips were dried and subsequently dipped into water samples containing increasing concentrations of $\mathrm{NaF}$ for 5 seconds. Test-strips were subsequently dried and imaged; clearly demonstrating the ability to detect fluoride at concentrations as low as $0.95 \mathrm{ppm}(50 \mu \mathrm{M})$ using a straightforward assay format (Figure 2-9). This test-strip-based assay was also capable of 
selectively detecting fluoride in a synthetic aquifer sample ${ }^{65}$ (Figure 2-10). These data also indicate the potential of the 8-silyloxyquinoline scaffold as a versatile architecture for development of tailored fluoride sensing platforms. In the long term, the test-stripbased assay described above could be coupled with hand-held lateral fluorescence readers to enable the rapid detection of fluoride in the field. 

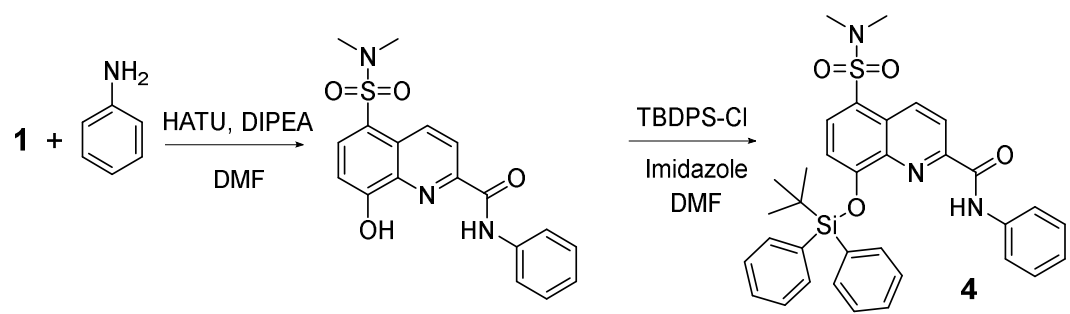

Scheme 2. Synthesis of an aniline derivative 4 of fluoride sensor 2. Reprinted with permission from the American Chemical Society. 
(A)

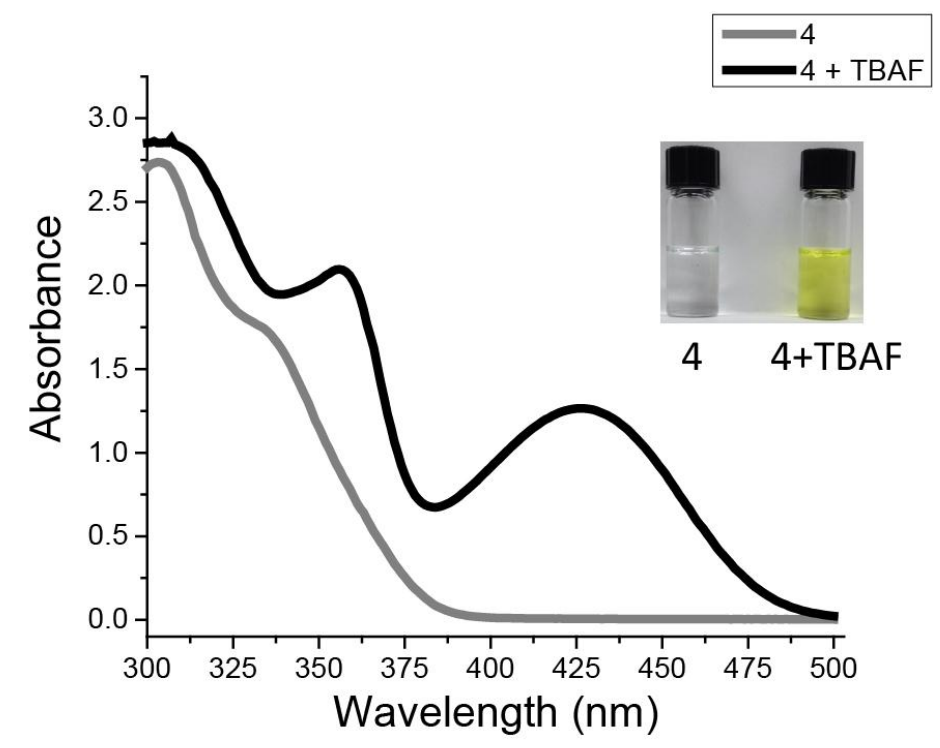

(B)

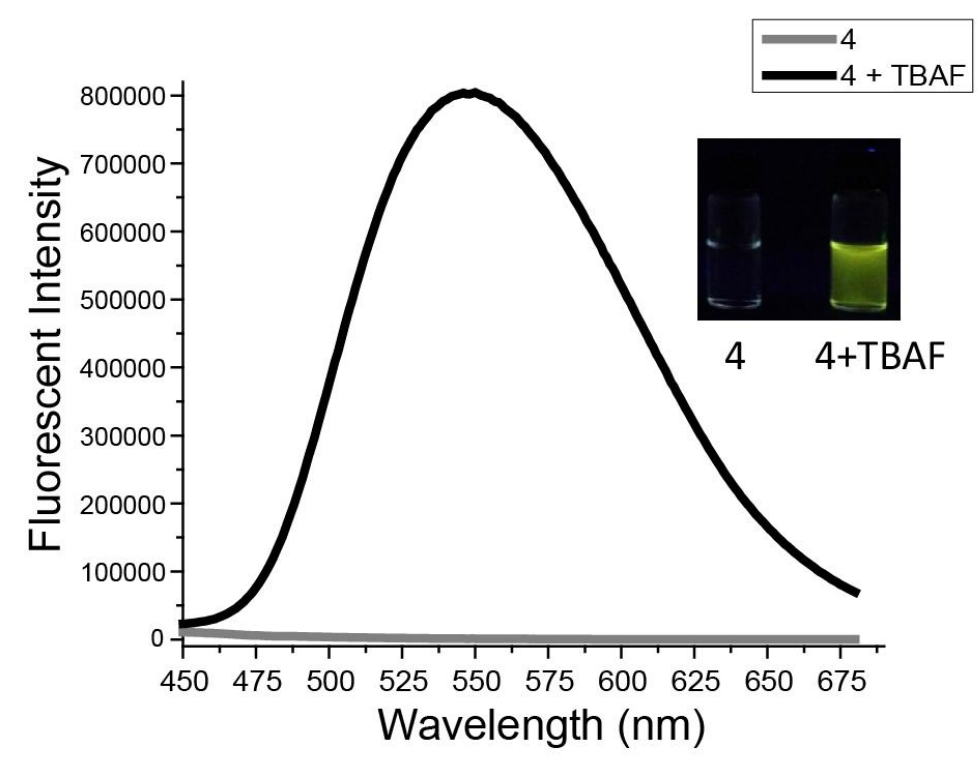

Figure 2-8. Absorbance (A) and emission spectra (B) of $200 \mu \mathrm{M} 4$ in the presence or absence of $1 \mathrm{mM}$ TBAF in dioxane. Reprinted with permission from the American Chemical Society. 


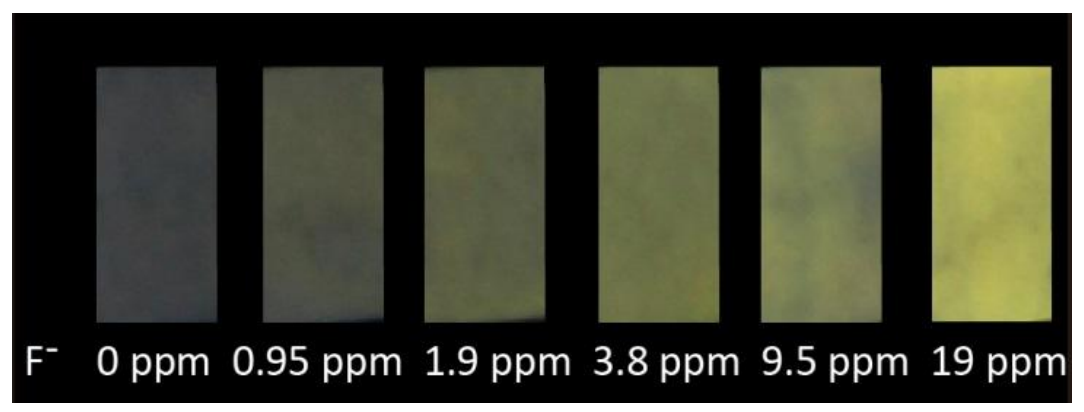

Figure 2-9. The fluorescence of test-trips containing 4 in the presence of the indicated concentration of $\mathrm{NaF}$ in water. Increasing fluorescence is observed with increasing $\mathrm{NaF}$ concentration. Reprinted with permission from the American Chemical Society. 


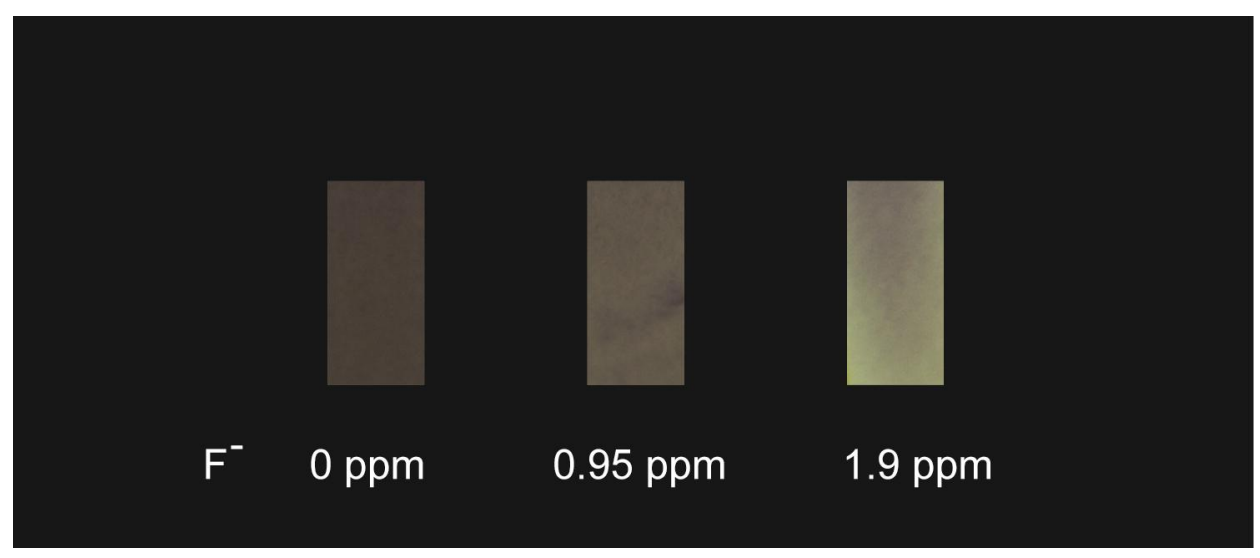

Figure 2-10. Test-strips of probe 4 in the presence of the indicated concentration of $\mathrm{NaF}$ in $10 \mathrm{mM}$ acetate $(\mathrm{pH}=4.8)$ buffered aquifer samples. Reprinted with permission from the American Chemical Society. 


\subsection{Experimental Procedures}

\subsubsection{General Reagents and Instrumentation}

Unless otherwise noted, reactions were performed in oven-dried glassware under an inert atmosphere of $\mathrm{N}_{2}$. All reagents and solvents were used as commercially supplied. Reaction progress was monitored by TLC and products were purified by flash chromatography using Merck silica gel 60 (230-400 mesh). ${ }^{1} \mathrm{H}$ NMR and ${ }^{13} \mathrm{C}$ NMR experiments were conducted in $\mathrm{CDCl}_{3}$ under room temperature and the spectra were recorded on Bruker-DRX-Avance 300 or $400 \mathrm{MHz}$ instruments. Chemical shifts are reported relative to $\mathrm{CDCl}_{3}$ (7.26 ppm for ${ }^{1} \mathrm{H}$ NMR and $77.0 \mathrm{ppm}$ for ${ }^{13} \mathrm{C}$ NMR). Mass spectra were recorded using electrospray ionization mass spectrometry (ESI, Thermo Finnigan LCQ Advantage). Mass data are reported in units of $\mathrm{m} / \mathrm{z}$ for $[\mathrm{M}+\mathrm{H}]^{+}$or $[\mathrm{M}+\mathrm{Na}]^{+}$. Fluorescence spectra were recorded on a FluoroMax-4 Spectrofluorometer (Horiba Scientific) using $5 \mathrm{~nm}$ slit widths. UV-Vis spectra were recorded using a BioMate 3S UV-Visible Spectrophotometer (Thermo Scientific). All absorbance assays were performed in $100 \mu \mathrm{L}$ quartz cuvettes, and the fluorescence assays were performed in either $100 \mu \mathrm{L}$ or $3.5 \mathrm{~mL}$ quartz cuvettes.

\subsubsection{Sensors Synthesis and Characterizations}

5-(N,N-dimethylsulfamoyl)-8-hydroxyquinoline-2-carboxylic acid (1)

The key intermediate (1) was synthesized in four steps according to Scheme 3.

methyl 8-hydroxyquinoline-2-carboxylate:

To a solution of 8-hydroxyquinoline-2-carboxylic acid (5g, $26.43 \mathrm{mmol})$ dissolved in methanol (100 mL), 10 drops of concentrated sulfuric acid (98\%) was added. The reaction was then refluxed overnight. Solvent was removed under vacuum and the 
crude material was extracted using a saturated sodium bicarbonate solution and dichloromethane. The organic layer was dried by sodium sulfate and the solvent was removed by evaporation. The resulting orange solid was used for the next step without any further purification.

\section{methyl 5-(chlorosulfonyl)-8-hydroxyquinoline-2-carboxylate:}

Chlorosulfonic acid $(25 \mathrm{~mL})$ was added to a flask containing the orange solid from above and stirred for 2 hours. The resulting solution was extracted using dichloromethane and ice. The organic layer was collected and dried over potassium carbonate. The solvent was subsequently evaporated and the resulting light yellow powder was used for the next step without further purification.

\section{methyl 5-(N,N-dimethylsulfamoyl)-8-hydroxyquinoline-2-carboxylate:}

Dimethylamine (40 mL, $80 \mathrm{mmol})$ was added to THF (1L). The light yellow powder obtained from above was then slowly added over 3 hours under stirring. After the last portion was added, the reaction was continued for $15 \mathrm{~min}$ and then the THF was removed by evaporation. The resulting yellow solid was washed with dichloromethane $(3 \times 15 \mathrm{~mL})$ to remove extra dimethylamine and used for the next step without further purification.

\section{5-(N,N-dimethylsulfamoyl)-8-hydroxyquinoline-2-carboxylic acid (1):}

The crude yellow solid obtained from the previous step was added to an aqueous solution $(100 \mathrm{~mL})$ of $\mathrm{NaOH}(4.23 \mathrm{~g}, 105.72 \mathrm{mmol})$ in methanol $(200 \mathrm{~mL})$. The reaction mixture was stirred overnight at room temperature. Methanol was removed by evaporation and dichloromethane $(3 \times 300 \mathrm{~mL})$ was used to wash the resulting aqueous 
layer. Concentrated aqueous $\mathrm{HCl}$ was then added to the reaction mixture and the $\mathrm{pH}$ was adjusted to $\sim 4$. The resulting precipitate was filtered, washed with water and cold ethanol, and then dried. $1(1.3 \mathrm{~g}, 4.39 \mathrm{mmol}, 16.6 \%)$ was obtained as a yellow solid.

1: ${ }^{1} \mathrm{H}$ NMR (300 MHz, DMSO) $\delta 11.33(\mathrm{~s}, 1 \mathrm{H}), 9.21(\mathrm{~d}, \mathrm{~J}=9.0 \mathrm{~Hz}, 1 \mathrm{H}), 8.33(\mathrm{~d}, \mathrm{~J}=9.0$ $\mathrm{Hz}, 1 \mathrm{H}), 8.19(\mathrm{~d}, \mathrm{~J}=8.4 \mathrm{~Hz}, 1 \mathrm{H}), 7.34(\mathrm{~d}, \mathrm{~J}=8.4 \mathrm{~Hz}, 1 \mathrm{H}), 2.66(\mathrm{~s}, 6 \mathrm{H}) .{ }^{13} \mathrm{C}$ NMR $(75$ MHz, DMSO) $\delta 165.25,159.20,145.59,137.18,136.35,135.58,127.30,122.51,121.28$, 111.16, 37.59. MS (ESI) $m / z$ calcd for $\mathrm{C}_{12} \mathrm{H}_{12} \mathrm{~N}_{2} \mathrm{O}_{5} \mathrm{~S}[\mathrm{M}+\mathrm{H}]^{+}$297.3, found 297.4. 


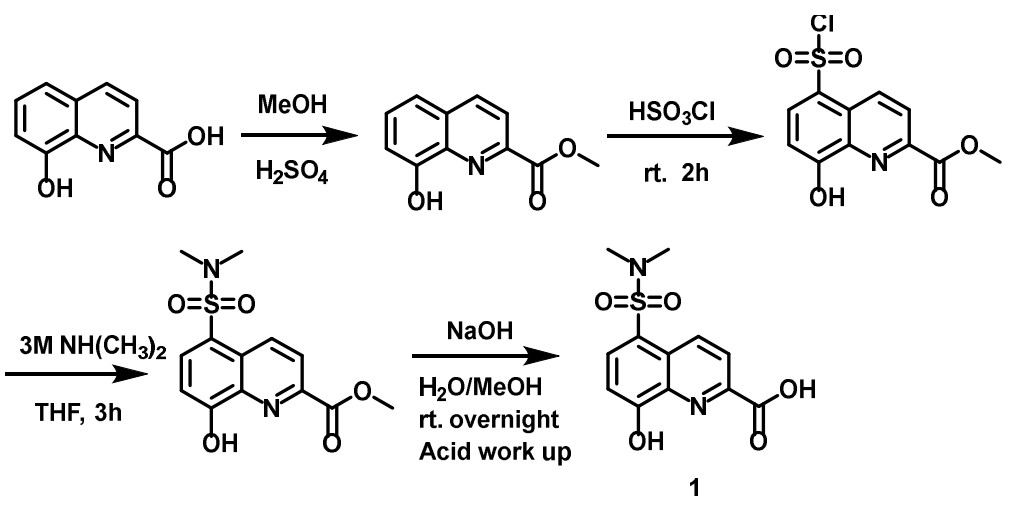

Scheme 3. Synthesis route of the key intermediate 1. Reprinted with permission from the American Chemical Society. 
8-((tert-butyldiphenylsilyl)oxy)-5-(N,N-dimethylsulfamoyl)-N-ethylquinoline-2-

carboxamide (2) and 8-((tert-butyldiphenylsilyl)oxy)-5-(N,N-dimethylsulfamoyl)-N-

phenylquinoline-2-carboxamide (4)

Fluoride probes $\mathbf{2}$ and $\mathbf{4}$ were obtained by coupling $\mathbf{1}$ with the appropriate amine followed by reaction with TBDPSCl (Scheme 4).

\section{Intermediate amides ( $2 a$ and $4 a)$ :}

1 (40 mg, $0.135 \mathrm{mmol})$ and HATU (77mg, $0.203 \mathrm{mmol}$ ) were dissolved in DMF $(1 \mathrm{~mL})$ and to the resulting yellow solution DIPEA $(47 \mu \mathrm{L}, 0.27 \mathrm{mmol})$ was added. The reaction mixture turned orange immediately and was left to stir for 10 min before the appropriate amine $(0.162 \mathrm{mmol})$ was added dropwise. After the reaction reached completion, the mixture was poured into ice-cold water and extracted with ethyl acetate. The organic layer was dried over sodium sulfate, the mixture was filtered, and the solvent was removed. The crude product was then purified by flash chromatography (silica gel, 2:8 hexanes/ethyl acetate). Both $\mathbf{2 a}(35 \mathrm{mg}, 80 \%)$ and $\mathbf{4 a}(38 \mathrm{mg}, 76 \%)$ were obtained as yellow oils.

2a: ${ }^{1} \mathrm{H}$ NMR (400 MHz, Methanol- $\left.d_{4}\right) \delta 9.28(\mathrm{~d}, J=9.2 \mathrm{~Hz}, 1 \mathrm{H}), 8.38(\mathrm{~d}, J=9.0 \mathrm{~Hz}, 1 \mathrm{H})$, $8.25(\mathrm{~d}, J=8.6 \mathrm{~Hz}, 1 \mathrm{H}), 7.30(\mathrm{~d}, J=8.7 \mathrm{~Hz}, 1 \mathrm{H}), 3.55(\mathrm{q}, J=7.3 \mathrm{~Hz}, 2 \mathrm{H}), 2.76(\mathrm{~s}, 6 \mathrm{H})$, $1.33(\mathrm{t}, J=7.4 \mathrm{~Hz}, 3 \mathrm{H}) .{ }^{13} \mathrm{C}$ NMR $\left(101 \mathrm{MHz}\right.$, Methanol- $\left.d_{4}\right) \delta 164.18,158.72,148.18$, $136.99,135.65,134.50,126.77,121.63,120.17,109.76,36.29,34.14,13.49$. MS (ESI) $m / z$ calcd for $\mathrm{C}_{14} \mathrm{H}_{17} \mathrm{~N}_{3} \mathrm{O}_{4} \mathrm{~S}[\mathrm{M}+\mathrm{H}]^{+} 324.4$, found 324.4.

4a: ${ }^{1} \mathrm{H}$ NMR (400 MHz, $\left.\mathrm{CDCl}_{3}\right) \delta 9.97(\mathrm{~s}, 1 \mathrm{H}), 9.22(\mathrm{~d}, J=9.0 \mathrm{~Hz}, 1 \mathrm{H}), 8.50(\mathrm{~d}, J=9.0$ $\mathrm{Hz}, 1 \mathrm{H}), 8.23(\mathrm{~d}, J=8.3 \mathrm{~Hz}, 1 \mathrm{H}), 7.70(\mathrm{~d}, J=8.0 \mathrm{~Hz}, 2 \mathrm{H}), 7.28(\mathrm{~s}, 1 \mathrm{H}), 7.26-7.19(\mathrm{~m}$, 
3H), $7.08(\mathrm{t}, J=7.3 \mathrm{~Hz}, 1 \mathrm{H}), 2.78(\mathrm{~s}, 6 \mathrm{H}) .{ }^{13} \mathrm{C} \mathrm{NMR}\left(101 \mathrm{MHz}, \mathrm{CDCl}_{3}\right) \delta 161.66,156.97$, $148.52,136.97,136.43,136.39,134.61,128.96,126.80,125.09,122.73,121.50,120.80$, 109.91, 37.34. MS (ESI) $m / z$ calcd for $\mathrm{C}_{18} \mathrm{H}_{17} \mathrm{~N}_{3} \mathrm{O}_{4} \mathrm{~S}[\mathrm{M}+\mathrm{H}]^{+}$372.4, found 372.4 .

\section{Fluoride probes 2 and 4:}

2a (30 mg, $0.093 \mathrm{mmol})$ and imidazole (7 $\mathrm{mg}, 0.1 \mathrm{mmol})$ were dissolved in DMF $(0.8 \mathrm{~mL})$. The mixture was cooled down to $0{ }^{\circ} \mathrm{C}$ and TBDPSCl $(26 \mu \mathrm{L}, 0.1 \mathrm{mmol})$ was added dropwise. The reaction was stirred for 15 min at $0{ }^{\circ} \mathrm{C}$ and left overnight under room temperature. The reaction was diluted by water $(20 \mathrm{~mL})$ and extracted by ethyl acetate $(3 \times 20 \mathrm{~mL})$. The organic layer was combined and washed with saturated ammonium chloride $(10 \mathrm{~mL})$, brine $(10 \mathrm{~mL})$, and dried $\left(\mathrm{Na}_{2} \mathrm{SO}_{4}\right)$. The solvent was removed by rotary evaporation and the crude was purified by flash chromatography (silica gel, 8:2 hexanes/ethyl acetate) to yield a white solid 2 (47 mg, 90\%). The silica gel was pretreated with acetone for 15 min to decrease product decomposition. 4 (white solid, $88 \%$ ) was prepared using the same method.

2: ${ }^{1} \mathrm{H}$ NMR $\left(400 \mathrm{MHz}, \mathrm{CDCl}_{3}\right) \delta 9.15(\mathrm{~d}, \mathrm{~J}=9.0 \mathrm{~Hz}, 1 \mathrm{H}), 8.32(\mathrm{~d}, \mathrm{~J}=9.0 \mathrm{~Hz}, 1 \mathrm{H}), 8.09$ $(\mathrm{d}, \mathrm{J}=8.3 \mathrm{~Hz}, 1 \mathrm{H}), 7.76(\mathrm{~d}, \mathrm{~J}=8.0 \mathrm{~Hz}, 4 \mathrm{H}), 7.59(\mathrm{t}, \mathrm{J}=5.8 \mathrm{~Hz}, 1 \mathrm{H}), 7.46-7.40(\mathrm{~m}, 2 \mathrm{H})$, $7.37-7.32(\mathrm{~m}, 4 \mathrm{H}), 7.14(\mathrm{~d}, \mathrm{~J}=8.3 \mathrm{~Hz}, 1 \mathrm{H}), 3.28-3.20(\mathrm{~m}, 2 \mathrm{H}), 2.75(\mathrm{~s}, 6 \mathrm{H}), 1.22(\mathrm{~s}$, 9H), $1.09(\mathrm{t}, \mathrm{J}=7.2 \mathrm{~Hz}, 3 \mathrm{H}) .{ }^{13} \mathrm{C}$ NMR $\left(101 \mathrm{MHz}, \mathrm{CDCl}_{3}\right) \delta$ 163.49, 156.97, 148.91, $139.98,135.20,135.04,133.17,131.78,130.41,128.04,127.53,124.61,120.53,115.97$, 37.33, 34.35, 26.48, 20.25, 14.72. MS (ESI) $\mathrm{m} / z$ calcd for $\mathrm{C}_{30} \mathrm{H}_{35} \mathrm{~N}_{3} \mathrm{O}_{4} \mathrm{SSi}[\mathrm{M}+\mathrm{H}]^{+}$562.8, found 562.9. 
4: ${ }^{1} \mathrm{H}$ NMR (400 MHz, Chloroform- $d$ ) $\delta 9.97$ (s, 1H), $9.28(\mathrm{~d}, J=8.9 \mathrm{~Hz}, 1 \mathrm{H}), 8.53$ (d, $J$ $=9.0 \mathrm{~Hz}, 1 \mathrm{H}), 8.02(\mathrm{~d}, J=8.3 \mathrm{~Hz}, 1 \mathrm{H}), 7.80(\mathrm{~d}, J=6.7 \mathrm{~Hz}, 4 \mathrm{H}), 7.63-7.57(\mathrm{~m}, 2 \mathrm{H})$, $7.51-7.44(\mathrm{~m}, 2 \mathrm{H}), 7.39(\mathrm{t}, J=7.6 \mathrm{~Hz}, 6 \mathrm{H}), 7.22-7.15(\mathrm{~m}, 1 \mathrm{H}), 6.95(\mathrm{~d}, J=8.3 \mathrm{~Hz}$, 1H), $2.78(\mathrm{~s}, 6 \mathrm{H}), 1.31(\mathrm{~s}, 9 \mathrm{H}) .{ }^{13} \mathrm{C}$ NMR $\left(101 \mathrm{MHz}, \mathrm{CDCl}_{3}\right) \delta 161.61,156.73,148.94$, $140.03,137.48,135.76,135.26,133.31,131.36,130.59,129.04,128.21,127.77,124.60$ 124.53, 120.56, 119.94, 115.71, 37.32, 26.68, 20.25. MS (ESI) $m / z$ calcd for $\mathrm{C}_{34} \mathrm{H}_{35} \mathrm{~N}_{3} \mathrm{O}_{4} \mathrm{SSi}[\mathrm{M}+\mathrm{H}]^{+} 609.8$, found 611.0 


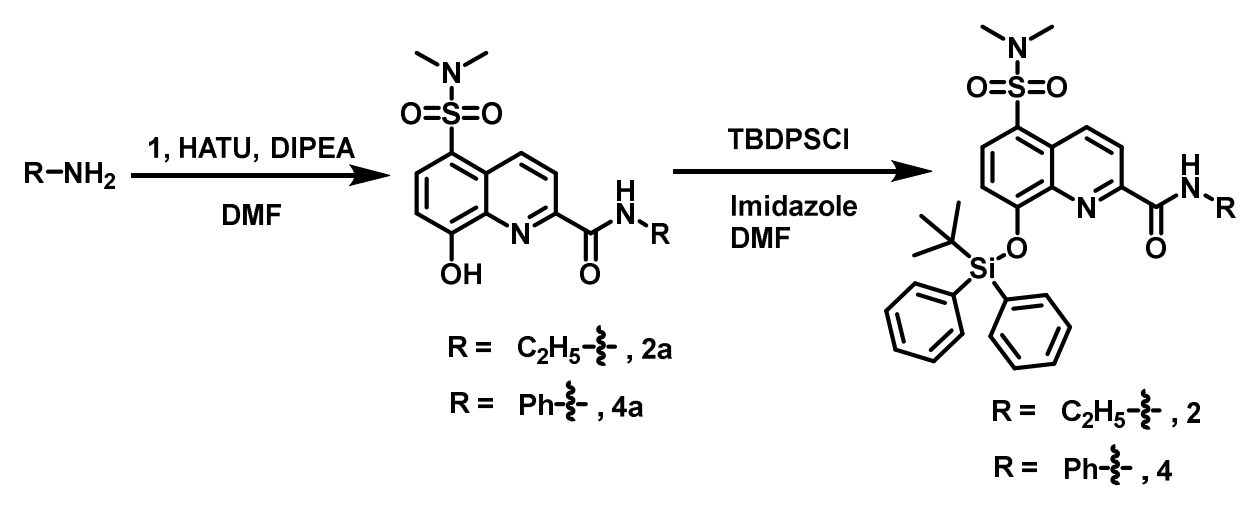

Scheme 4. Synthesis route of fluoride sensor 2 and 4. Reprinted with permission from the American Chemical Society. 


\subsubsection{Determination of Molar Extinction Coefficient}

TBAF $(1 \mathrm{mM})$ was mixed with varying concentrations of the indicated sensor $(0$, $25,50,100$, and $200 \mu \mathrm{M})$ in dioxane. Samples were allowed to react to completion with fluoride and the absorbance of each solution was measured. Molar extinction coefficients were determined from a linear fit of absorbance versus probe concentration.

\subsubsection{Quantum Yield Measurements}

The fluorescence quantum yield of $\mathbf{2}+\mathrm{F}^{-}$and $\mathbf{4}+\mathrm{F}^{-}$were determined using equation (2-1).

$\Phi_{\mathrm{X}}=\left(\Phi_{\mathrm{ST}} \times \mathrm{A}_{\mathrm{ST}} \times \mathrm{F}_{\mathrm{X}} \times \eta_{\mathrm{X}}{ }^{2}\right) /\left(\mathrm{A}_{\mathrm{X}} \times \mathrm{F}_{\mathrm{ST}} \times \eta_{\mathrm{ST}^{2}}\right)^{2}$

$\Phi$ is the quantum yield; $\mathrm{A}$ is the absorbance at the excitation wavelength (A was kept at $\leq 0.05$ during fluorescence measurements in order to avoid self-quenching), $\mathrm{F}$ is the fluorescence intensity at the excitation wavelength; $\eta$ is the refractive index of the solvent. The subscripts ST and X refer to the standard and unknown respectively. Quinine sulfate dihydrate (purchased from AnaSpec) in $0.5 \mathrm{M} \mathrm{H}_{2} \mathrm{SO}_{4}$ was used as the fluorescence reference standard, which has a quantum yield of $0.546(\mathrm{ex} .=310 \mathrm{~nm}$, em, $=455 \mathrm{~nm})$. Quantum yields were measured in dioxane after reactions had progressed to completion in the presence of excess fluoride.

\subsubsection{Absorbance and Fluorescence Assay Conditions}

Sensors were mixed with the indicated concentrations of fluoride ion and were incubated at room temperature for 5 minutes in dioxane or 15 minutes in 50:50 (v/v) 10 $\mathrm{mM}$ HEPES $(\mathrm{pH}=7.4)$ :Dioxane. Fluorescence was measured at the appropriate wavelengths for each probe (Table 2). 
Table 2. Excitation and Emission Wavelengths for Fluoride Sensors in Nanometers. Reprinted with permission from the American Chemical Society.

\begin{tabular}{ccccc} 
& \multicolumn{3}{c}{2} & \multicolumn{2}{c}{4} \\
\cline { 2 - 5 } Solvent & Ex. & Em. & Ex. & Em. \\
Dioxane & 345 & 536 & 346 & 553 \\
$\begin{array}{c}\text { 50:50 (v/v) } 10 \mathrm{mM} \mathrm{HEPES}(\mathrm{pH}= \\
7.4): \text { Dioxane }\end{array}$ & 393 & 542 & N/A & N/A \\
\hline
\end{tabular}




\subsubsection{Selectivity and Competition Assay}

For the selectivity experiments shown in Figure 2-5 anions were prepared in 10 $\mathrm{mM}$ HEPES $(\mathrm{pH}=7.4)$ at $2 \mathrm{x}$ the final concentration in the assay. Sodium salts were used throughout, except for $\mathrm{HSO}_{4}^{-}$and $\mathrm{ClO}_{4}^{-}$were TBA salts were used. Probe 2 was dissolved in dioxane at $40 \mu \mathrm{M}$. Solutions of $10 \mathrm{mM}$ HEPES $(\mathrm{pH}=7.4)$ and dioxane were mixed in 50:50 (v/v) ratio and fluorescence was recorder after 15 minutes.

A synthetic aquifer sample was prepared according known concentrations of cations and anions found in the Minnelusa Aquifer located in South Dakota. ${ }^{65,66}$ Final concentrations of species were: $3.1 \mathrm{mM} \mathrm{CaSO}_{4}, 1.3 \mathrm{mM} \mathrm{MgSO}_{4}, 38 \mu \mathrm{M} \mathrm{K}_{2} \mathrm{SO}_{4}, 4 \mathrm{mM}$ $\mathrm{NaHCO}_{3}, 330 \mu \mathrm{M} \mathrm{NaCl}, 2.6 \mathrm{mM} \mathrm{Na} 2 \mathrm{SO}_{4}$, and $3.75 \mu \mathrm{M} \mathrm{NaBr}$. For probe 2 the fluoride concentration was adjusted to $2 \mathrm{x}$ of the indicated final fluoride concentration using $\mathrm{NaF}$ and the resulting solution was mixed with an equal volume of $10 \mathrm{mM}$ HEPES $(\mathrm{pH}=7.4)$. Finally the buffered synthetic aquifer sample was mixed with dioxane (50:50, v/v) containing $2 \mathrm{x}$ the final concentration of $\mathbf{2}$. Fluorescence was recorded after 15 minutes.

\subsubsection{Rate Constant Determination}

Fluoride sensor $2(20 \mu \mathrm{M})$ in a 50:50 (v/v) solution of HEPES buffer $(10 \mathrm{mM}, \mathrm{pH}=$ 7.4):dioxane was spiked with $400,800,1200,1600,2000 \mu \mathrm{M}$ of $\mathrm{NaF}$. The reaction rate, $\mathrm{k}_{\mathrm{obs}}$, was obtained for each concentration of $\mathrm{NaF}$ by fitting the increase in fluorescence versus time using equation (2-2).

Fluorescence $=1-\exp \left(-\mathrm{k}_{\mathrm{obs}} \mathrm{t}\right)$

where $\mathrm{t}$ is time in minutes. The pseudo-first-order rate constant, $\mathrm{k}_{\mathrm{obs}}$, was then plotted against the concentration of $\mathrm{NaF}$ to yield the second-order rate constant using equation (2-3). 
$\mathrm{k}_{\mathrm{obs}}=\mathrm{k}_{2}[\mathrm{NaF}]$

where $\mathrm{k}_{2}$ is the second-order rate constant.

\subsubsection{Test-Strip Assays}

Filter paper (Whatman, 20 micron) was cut to $0.5 \times 2 \mathrm{~cm}$. Test strips were immersed into a dichloromethane solution containing $4(2 \mathrm{mM})$ and dried in air. To detect fluoride in water, the pre-treated filter paper was immersed into an unbuffered DI water solution (containing $2 \mathrm{mM} \mathrm{CTAB}$ ) for 5 seconds and dried in air for 10 minutes. The fluorescence on the filter paper was observed and recorded under $365 \mathrm{~nm}$ using a hand held UV lamp (UVGL-58 from UVP).

For selectivity assays with probe 4 the synthetic aquifer sample was prepared with $2 \mathrm{x}$ of the final concentration of $\mathrm{NaF}$ in the assay. This sample was then mixed $10 \mathrm{mM}$ acetate $(\mathrm{pH}=4.8)$ containing $2 \mathrm{mM} \mathrm{CTAB}$ at a 50:50 $(\mathrm{v} / \mathrm{v})$ ratio. The resulting solution was measured directly with test-strips of probe $\mathbf{4}$ as described in the preceding paragraph.

\subsection{Conclusions and Future Directions}

In conclusion, we have demonstrated the versatility of the novel 8silyloxyquinoline scaffold for the design of highly sensitive and selective platforms for the quantification of aqueous fluoride. Our initial fluoride sensor $\mathbf{2}$ can be utilized to detect fluoride in water samples, enabling the straightforward analysis of fluoride in the laboratory setting at concentrations well below the recommended levels in drinking water. ${ }^{64}$ The poor water solubility of sensor 4 enabled the development of a test-stripbased assay for fluoride in aqueous samples that could potentially be utilized for the lowcost analysis of fluoride in the field. Taken together this work provides a readily modifiable platform for the analysis of fluoride in water samples. 
For future directions, different analogues based off this 8-hydroxylquinoline template can be designed so that the quantum yield and solubility can be further improved. Also the excitation and emission wavelength can be tuned so that the sensors can be used to detect fluoride in living cell in order to study the influence of fluoride in biological systems.

\section{Appendix A}

The 8-Silyloxyquinoline Scaffold as a Versatile Platform for the Sensitive Detection of Aqueous Fluoride 
Reproduced with permission from:

Zhou, X.; Lai, R.; Li, H. \& Stains, C. I. The 8-Silyloxyquinoline Scaffold as a Versatile Platform for the Sensitive Detection of Aqueous Fluoride. Anal. Chem. ASAP

(doi: 10.1021/acs.analchem.5b00430)

Copyright 2015 American Chemical Society 


\title{
The 8-Silyloxyquinoline Scaffold as a Versatile Platform for the Sensitive Detection of Aqueous Fluoride
}

\author{
Xinqi Zhou, Rui Lai, Hui Li, and Cliff I. Stains* \\ Department of Chemistry, University of Nebraska-Lincoln, Lincoln, Nebraska 68588, United States
}

Supporting Information

ABSTRACT: Utilizing a novel 8-silyloxyquinoline scaffold, we demonstrate the ability to synthesize fluorogenic probes for the sensitive and selective detection of inorganic fluoride $(\mathrm{NaF})$ in aqueous samples. Our initial probe design (2) is capable of detecting inorganic fluoride at levels as low as $3.8 \mu \mathrm{M}(72 \mathrm{ppb})$ in aqueous solutions, well below PHS recommended levels for drinking water $(0.7-1.2 \mathrm{ppm})$, placing this probe among the most sensitive fluoride sensors reported to date. Furthermore, our results highlight the utility of the readily modifiable 8silyloxyquinoline scaffold for the design of tailored fluoride sensing platforms. We demonstrate the ability to rationally tune the fluorescence and physical properties of the 8-silyloxyquinoline scaffold, producing a red-shifted fluoride probe (4) capable of detecting $50 \mu \mathrm{M}(0.95 \mathrm{ppm}) \mathrm{NaF}$ in aqueous samples using a straightforward test-strip-based assay format. Taken together this work provides a template for the design of fluoride sensors capable of reporting on relevant concentrations of fluoride in the laboratory and in the field.

$\mathrm{N}$ umerous studies clearly document the beneficial role of fluoride in maintaining healthy teeth enamel, leading to the common practice of supplementing municipal water supplies and toothpaste with fluoride. ${ }^{1,2}$ However, growing evidence also indicates that chronic overexposure to fluoride can lead to dental or skeletal fluorosis. ${ }^{3,4}$ In particular, regions of endemic fluorosis are now well-described in underdeveloped countries. ${ }^{5-8}$ Fluoride is also a product of the hydrolysis of sarin gas, further motivating the design of fluoride sensors. Current methodologies to quantify fluoride concentration in aqueous solutions, such as the Willard and Wilson method, ${ }^{9}$ ion selective electrodes, ${ }^{10}$ or ion chromatography ${ }^{11}$ rely on timeconsuming manipulations and high cost instrumentation. In contrast, recent advances in small molecule colorimetric-, fluorescent-, luminescent-, and electrochemical-based probes for fluoride could offer significant improvements in assay performance and cost. ${ }^{12-25}$ However, the sensitive detection of fluoride in aqueous samples remains challenging due to the relatively high hydration enthalpy of fluoride in water $(-121$ $\mathrm{kcal} / \mathrm{mol}){ }^{26}$ As a consequence, although numerous fluoride sensing platforms have been described in the literature, these probes generally have detection limits in the mid micromolar range in aqueous samples (Supporting Information, Table S1). Given the current recommendations for fluoride levels in drinking water by the EPA ( 4 ppm or $211 \mu \mathrm{M})$ and PHS $(0.7-$ $1.2 \mathrm{ppm}$ or $37-63 \mu \mathrm{M}),{ }^{1}$ there is a pressing need for the development of chemosensors capable of quantifying fluoride at relevant concentrations in aqueous samples.

Small molecule fluoride sensors have commonly utilized the relatively strong hydrogen bonding potential of fluoride (38.6 $\mathrm{kcal} / \mathrm{mol}$ ) or the selective reaction of fluoride with Lewis acids in order to induce spectroscopic changes in small molecule probes. ${ }^{19,20}$ Although powerful, hydrogen bond-based sensors often suffer from false positive signal generation in the presence of competing anions such as phosphate and acetate. On the other hand, the relatively strong interaction of fluoride with Lewis acids can be utilized to specifically detect fluoride when compared to potential competing anions. Utilizing this approach, Kim and Swager first described the use of silyl groups to selectively detect fluoride in organic solvents. ${ }^{27}$ These probes rely on the dramatic difference in bond dissociation energies between $\mathrm{Si}-\mathrm{O}$ and $\mathrm{Si}-\mathrm{F}$ bonds, 103 versus $141 \mathrm{kcal} /$ mol, respectively. ${ }^{20}$ Indeed, numerous sensors have now been described based on the selective reaction of fluoride with silyl groups. $^{20}$ However, these silicon-based probes are generally limited in their application due to their analytical sensitivity in aqueous samples (Supporting Information, Table S1). Therefore, there is still a need for the fundamental investigation of probe structures employing the silicon-based Lewis acid approach to fluoride detection, with the long-term goal of enabling the sensitive quantification of fluoride in aqueous samples.

\section{EXPERIMENTAL SECTION}

General Reagents and Instrumentation. Unless otherwise noted, reactions were performed in oven-dried glassware under an inert atmosphere of $\mathrm{N}_{2}$. All reagents and solvents were used as commercially supplied. Reaction progress was monitored by thin layer chromatography (TLC), and products

Received: February 1, 2015

Accepted: April 1, 2015 
were purified by flash chromatography using Merck silica gel 60 (230-400 mesh). ${ }^{1} \mathrm{H}$ NMR and ${ }^{13} \mathrm{C}$ NMR experiments were conducted in $\mathrm{CDCl}_{3}$ under room temperature, and the spectra were recorded on Bruker-DRX-Avance 300 or $400 \mathrm{MHz}$ instruments. Chemical shifts are reported relative to $\mathrm{CDCl}_{3}$ (7.26 ppm for ${ }^{1} \mathrm{H}$ NMR and $77.0 \mathrm{ppm}$ for ${ }^{13} \mathrm{C}$ NMR). Mass spectra were recorded using electrospray ionization mass spectrometry (ESI, Thermo Finnigan LCQ Advantage). Mass data are reported in units of $m / z$ for $[\mathrm{M}+\mathrm{H}]^{+}$or $[\mathrm{M}+\mathrm{Na}]^{+}$. Detailed synthetic procedures, characterization data, and computational results can be found in the Supporting Information. Fluorescence spectra were recorded on a FluoroMax-4 spectrofluorometer (Horiba Scientific) using 5 $\mathrm{nm}$ slit widths. UV-vis spectra were recorded using a BioMate 3S UV-visible spectrophotometer (Thermo Scientific). All absorbance assays were performed in $100 \mu \mathrm{L}$ quartz cuvettes, and the fluorescence assays were performed in either $100 \mu \mathrm{L}$ or $3.5 \mathrm{~mL}$ quartz cuvettes.

Determination of Molar Extinction Coefficients. TBAF (1 $\mathrm{mM}$ ) was mixed with varying concentrations of the indicated sensor $(0,25,50,100$, and $200 \mu \mathrm{M})$ in dioxane. Samples were allowed to react to completion with fluoride and the absorbance of each solution was measured. Molar extinction coefficients were determined from a linear fit of absorbance versus probe concentration.

Quantum Yield Measurements. The fluorescence quantum yields of $\mathbf{2}+\mathrm{F}^{-}$and $4+\mathrm{F}^{-}$were determined using eq 1 .

$$
\Phi_{\mathrm{x}}=\left(\Phi_{\mathrm{ST}} \times A_{\mathrm{ST}} \times F_{\mathrm{X}} \times \eta_{\mathrm{X}}^{2}\right) /\left(A_{\mathrm{X}} \times F_{\mathrm{ST}} \times \eta_{\mathrm{ST}}{ }^{2}\right)
$$

where $\Phi$ is the quantum yield, $A$ is the absorbance at the excitation wavelength ( $A$ was kept at $\leq 0.05$ during fluorescence measurements in order to avoid self-quenching), $F$ is the fluorescence intensity at the excitation wavelength, and $\eta$ is the refractive index of the solvent. The subscripts ST and X refer to the standard and unknown, respectively. Quinine sulfate dihydrate (purchased from AnaSpec) in $0.5 \mathrm{M} \mathrm{H}_{2} \mathrm{SO}_{4}$ was used as the fluorescence reference standard, which has a quantum yield of $0.546($ ex. $=310 \mathrm{~nm}$, em. $=455 \mathrm{~nm})$. Quantum yields were measured in dioxane after reactions had progressed to completion in the presence of excess fluoride.

Absorbance and Fluorescence Assay Conditions. Sensors were mixed with the indicated concentrations of fluoride ion and were incubated at room temperature for $5 \mathrm{~min}$ in dioxane or $15 \mathrm{~min}$ in 50:50 (v/v) $10 \mathrm{mM} \operatorname{HEPES}(\mathrm{pH}=$ $7.4)$ :dioxane. Fluorescence was measured at the appropriate wavelengths for each probe (Table 1).

Selectivity of Probe 2. For the selectivity experiments shown in Figure 4, anions were prepared in $10 \mathrm{mM}$ HEPES $(\mathrm{pH}=7.4)$ at twice the final concentration in the assay. Sodium salts were used throughout, except for $\mathrm{ClO}_{4}{ }^{-}$where a TBA salt was used. Probe 2 was dissolved in dioxane at $40 \mu \mathrm{M}$. Anion

Table 1. Excitation and Emission Wavelengths for Fluoride Sensors in Nanometers

\begin{tabular}{|c|c|c|c|c|}
\hline \multirow[b]{2}{*}{ solvent } & \multicolumn{2}{|c|}{2} & \multicolumn{2}{|c|}{4} \\
\hline & ex. & em. & ex. & em. \\
\hline dioxane & 345 & 536 & 346 & 553 \\
\hline $\begin{array}{l}\text { 50:50 (v/v) } 10 \mathrm{mM} \text { HEPES } \\
(\mathrm{pH}=7.4) \cdot \text { dioxane }\end{array}$ & 393 & 542 & $\mathrm{~N} / \mathrm{A}$ & $\mathrm{N} / \mathrm{A}$ \\
\hline
\end{tabular}

solutions were mixed with dioxane in a 50:50 (v/v) ratio, and fluorescence was recorded after $15 \mathrm{~min}$.

A synthetic aquifer sample was prepared according to known concentrations of cations and anions found in the Minnelusa Aquifer located in South Dakota. ${ }^{28,29}$ Final concentrations of species were $3.1 \mathrm{mM} \mathrm{CaSO}_{4}, 1.3 \mathrm{mM} \mathrm{MgSO}_{4}, 38 \mu \mathrm{M} \mathrm{K}_{2} \mathrm{SO}_{4}, 4$ $\mathrm{mM} \mathrm{NaHCO}, 330 \mu \mathrm{M} \mathrm{NaCl}, 2.6 \mathrm{mM} \mathrm{Na}_{2} \mathrm{SO}_{4}$, and $3.75 \mu \mathrm{M}$ $\mathrm{NaBr}$. The fluoride concentration was adjusted to twice the indicated final concentration using $\mathrm{NaF}$, and the resulting solution was mixed with an equal volume of $10 \mathrm{mM}$ HEPES $(\mathrm{pH}=7.4)$. Finally the buffered synthetic aquifer sample was mixed with dioxane $(50: 50, \mathrm{v} / \mathrm{v})$ containg twice the final concentration of 2 . Fluorescence was recorded after $15 \mathrm{~min}$.

Rate Constant Determination. Fluoride sensor 2 (20 $\mu \mathrm{M})$ in a 50:50 (v/v) solution of HEPES buffer $(10 \mathrm{mM}, \mathrm{pH}=$ $7.4)$ :dioxane was spiked with $400,800,1200,1600$, or $2000 \mu \mathrm{M}$ $\mathrm{NaF}$. The reaction rate, $k_{\text {obs }}$, was obtained for each concentration of $\mathrm{NaF}$ by fitting the increase in fluorescence versus time using eq 2 .

$$
\text { fluorescence }=1-\exp \left(-k_{\mathrm{obs}} t\right)
$$

where $t$ is time in minutes. The pseudo-first-order rate constant, $k_{\text {obs }}$, was then plotted against the concentration of $\mathrm{NaF}$ to yield the second-order rate constant using eq 3.

$$
k_{\mathrm{obs}}=k_{2}[\mathrm{NaF}]
$$

where $k_{2}$ is the second-order rate constant.

Test-Strip Assays. Filter paper (Whatman, $20 \mu \mathrm{m}$ ) was cut to $0.5 \mathrm{~cm} \times 2 \mathrm{~cm}$. Test strips were immersed into a dichloromethane (DCM) solution containing $4(2 \mathrm{mM})$ and dried in air. To detect fluoride in water, the pretreated filter paper was immersed into an unbuffered DI water solution (containing $2 \mathrm{mM}$ cetyltrimethylammonium bromide, CTAB) for $5 \mathrm{~s}$ and dried in air for $10 \mathrm{~min}$. The fluorescence on the filter paper was observed and recorded under $365 \mathrm{~nm}$ using a handheld UV lamp (UVGL-58 from UVP).

For selectivity assays with probe 4 , a synthetic aquifer sample was prepared with twice the final concentration of $\mathrm{NaF}$ desired in the assay. This sample was then mixed with $10 \mathrm{mM}$ acetate $(\mathrm{pH}=4.8)$ containing $2 \mathrm{mM} \mathrm{CTAB}$ at a 50:50 (v/v) ratio. The resulting solution was measured directly with test-strips of probe $\mathbf{4}$ as described in the preceding paragraph.

\section{RESULTS AND DISCUSSION}

Rational Design of an 8-Silyloxyquinoline-Based Fluoride Sensor. Given the ability of the 8-hydroxyquinoline scaffold to provide a sensitive fluorescent readout in aqueous samples, ${ }^{30-33}$ we chose to investigate the ability of derivatives of this fluorophore to function as fluoride chemodosimeters. As an initial test of our approach, we envisioned the synthesis of a tert-butyldiphenylsilyl (TBDPS) protected 8-hydroxyquinoline (2) (Scheme 1). We hypothesized that cleavage of the TBDPS group in 2 by fluoride would result in the rapid formation of a fluorescent species. In addition, we reasoned that the carbonyl functionality present at position 2 of intermediate 1 would allow for facile modification in order to tune the spectral properties of our fluoride chemodosimeter platform. Lastly, we chose to include a sulfonamide at position 5 in sensor $\mathbf{2}$ as this functionality has been shown to dramatically increase the fluorescence of 8-hydroxyquinoline derivatives. ${ }^{30}$

We synthesized 2 according to Scheme 1 and investigated its response to fluoride by addition of $1 \mathrm{mM}$ TBAF to a dioxane 
Scheme 1. Synthesis of 8-Silyloxyquinoline-Based Fluoride Sensor 2

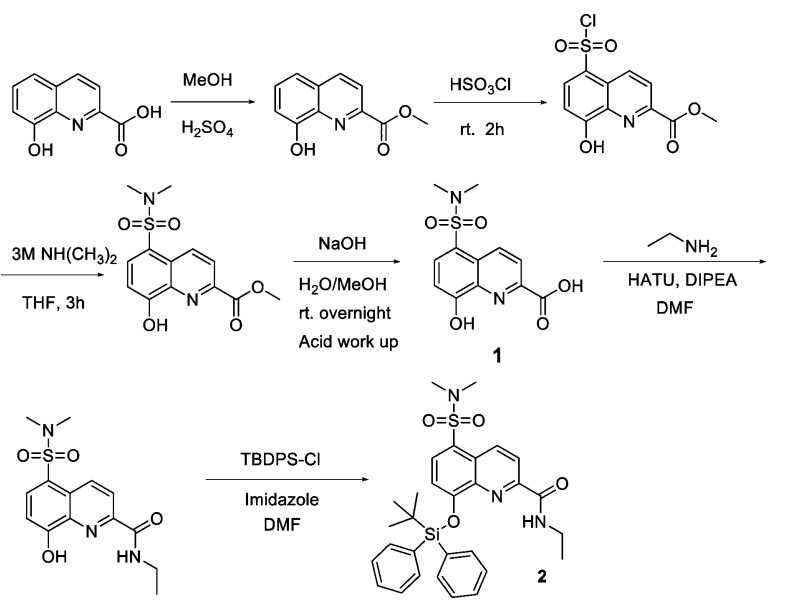

solution of 2. Gratifyingly, we observed a marked change in both the absorbance and fluorescence emission spectra of the solutions upon addition of TBAF, producing a desilylated fluorescent product 3 (Supporting Information, Figure S1) with $\varepsilon=6600 \mathrm{M}^{-1} \mathrm{~cm}^{-1}$ and $\Phi=0.16$ (Figure 1). Using a Job plot

(A)

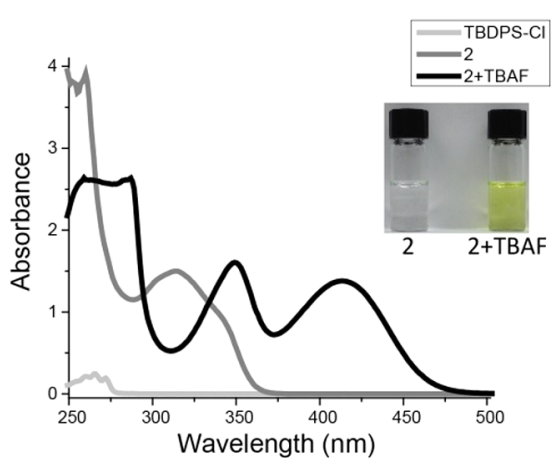

(B)

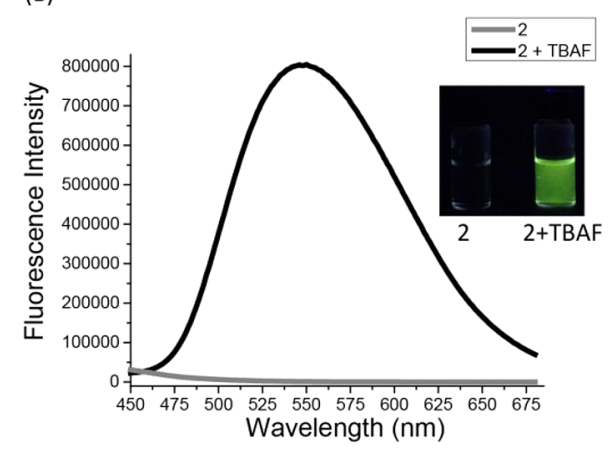

Figure 1. Absorbance (A) and fluorescence (B) of $2(200 \mu \mathrm{M})$ in the absence or presence of $1 \mathrm{mM}$ TBAF in dioxane; TBDPS-Cl is shown as a control. Fluorescence spectra were acquired by excitation at 345 $\mathrm{nm}$.

we determined the stoichiometry of binding between 2 and fluoride to be 1:1 (Supporting Information, Figure S2), providing evidence for a detection mechanism in which one fluorine atom reacts with one molecule of $\mathbf{2}$ to produce TBDPS-F and a fluorescent species, 3.

Computational Evaluation of Fluoride Detection by Probe 2. To better understand the molecular and electronic details of the detection mechanism, we performed density functional theory (DFT) and time-dependent DFT $(\text { TDDFT })^{34,35}$ calculations for 2 and 3 . The 1,4-dioxane solvent was described by using the FixSol $^{36}$ solvation model (dielectric constant 2.25) implemented in the Quantum Chemistry Polarizable force field program (QuanPol) ( $^{37}$ integrated in the General Atomic and Molecular Electronic Structure System (GAMESS) ${ }^{38,39}$ package. The B3LYP ${ }^{40}$ functional and the $6-31++G(d, p)^{41}$ basis set was used in both DFT and TDDFT calculations. The GAMESS TDDFT program implemented by Chiba et al. ${ }^{42,43}$ was used together with the QuanPol FixSol model. We optimized the $S_{0}$ ground state geometries of $\mathbf{2}$ and $\mathbf{3}$ (Figure 2) using B3LYP and

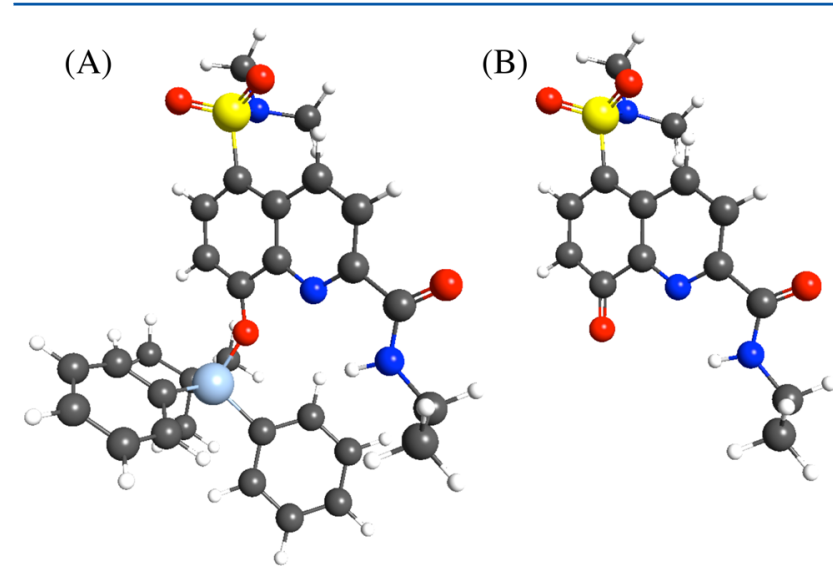

Figure 2. FixSol/B3LYP/6-31++G(d,p) optimized $S_{0}$ ground state geometries of 2 and $3(A, B)$. FixSol/TD-B3LYP/6-31++G(d,p) optimized $S_{1}$ state geometries are similar, but some bond lengths are significantly different due to the electronic structure change.

performed single point energy calculations using TD-B3LYP to obtain the vertical excitation energies $\left(S_{0} \rightarrow S_{n}\right)$. Then we optimized the $S_{1}$ excited state geometries using TD-B3LYP and calculated the $S_{1} \rightarrow S_{0}$ de-excitation energies (fluorescence). It was found that there are two significant absorptions at 340 and $258 \mathrm{~nm}$ ( 3.63 and $4.80 \mathrm{eV}$ ) and no significant fluorescence emission for 2 . There are six significant absorptions for 3 . The first one is at $425 \mathrm{~nm}(2.93 \mathrm{eV})$; the second one is at $350 \mathrm{~nm}$ $(3.61 \mathrm{eV})$; the other four are at 264-273 nm $(4.54,4.56,4.65$, and $4.69 \mathrm{eV})$. The fluorescent emission of 3 is at $514 \mathrm{~nm}(2.41$ $\mathrm{eV})$. The full details of the computational results can be found in the Supporting Information. These calculated absorbance and emission spectra are in excellent agreement with experimental results (Figure 1), confirming the proposed mechanism of fluoride detection.

Limit of Detection and Selectivity of Fluoride Sensor 2. Confident in the mechanism of fluoride detection by 2 , we next investigated the limit of detection of $\mathbf{2}$ for TBAF in dioxane (Supporting Information, Figure S3). These data demonstrated the ability to resolve concentrations of TBAF as low as $0.56 \mu \mathrm{M}(11 \mathrm{ppb})$. Building upon these promising results we next assessed the response of $\mathbf{2}$ to decreasing concentrations $\mathrm{NaF}$ in a 50:50 (v/v) solution of water:dioxane. These experiments revealed that $\mathbf{2}$ is capable of detecting as little as $3.8 \mu \mathrm{M}$ or $72 \mathrm{ppb} \mathrm{NaF}$ in aqueous solutions, which is well below current guidelines for fluoride in drinking water (Figure 3). ${ }^{1}$ Moreover, the limit of detection of $\mathbf{2}$ for inorganic fluoride in aqueous solutions is among the most sensitive of reported silyl-based fluoride sensors (Supporting Information, Table S1). We also interrogated the response of $\mathbf{2}$ to 


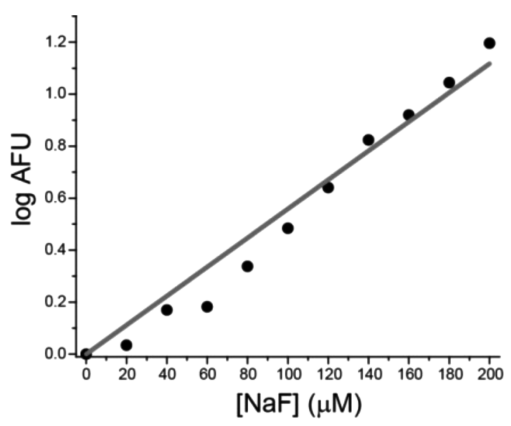

Figure 3. Emission of $20 \mu \mathrm{M} 2$ (at $542 \mathrm{~nm}$ ) in a 50:50 (v/v) $10 \mathrm{mM}$ HEPES $(\mathrm{pH}=7.4)$ :dioxane solution in the presence of the indicated concentration of $\mathrm{NaF}$.

environmentally and biologically relevant anions. Impressively, we observed background levels of fluorescence for all anions in our panel except for fluoride. In addition, the response of $\mathbf{2}$ was not appreciably perturbed due to direct competition with any anion in our panel (Figure 4). We also interrogated the ability

\section{(A)}

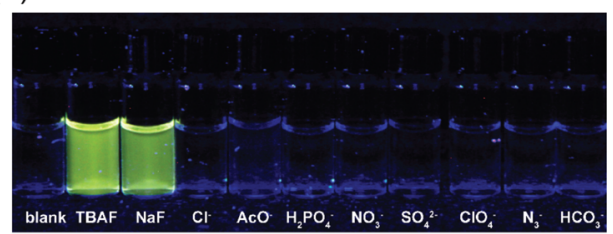

(B)

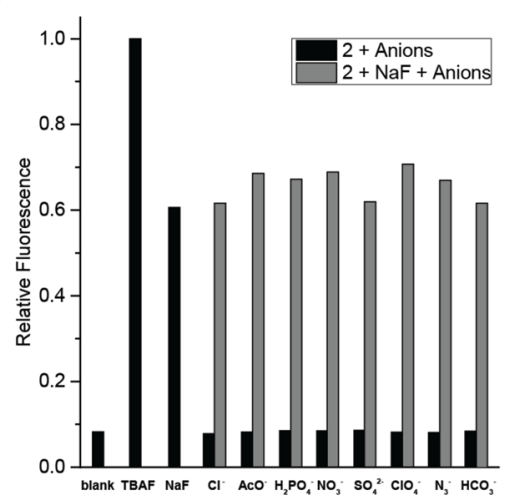

Figure 4. Selectivity of $\mathbf{2}(20 \mu \mathrm{M})$ for fluoride. (A) Images of $\mathbf{2}$, under UV light, in the presence of the indicated anion $(200 \mu \mathrm{M})$. (B) Black bars represent the fluorescence of 2 in the presence of the indicated anion $(200 \mu \mathrm{M})$, while gray bars indicate the fluorescence of $\mathbf{2}$ in the presence of the indicated anion $(200 \mu \mathrm{M})$ as well as $\mathrm{NaF}(200 \mu \mathrm{M})$. Assays were conducted in 50:50 (v/v) $10 \mathrm{mM} \operatorname{HEPES}(\mathrm{pH}=$ 7.4):dioxane.

of 2 to report on the presence of $\mathrm{NaF}$ in a synthetic aquifer sample. ${ }^{29}$ These experiments clearly demonstrate that environmentally relevant concentrations of cations and anions found in groundwater do not interfere with our assay (Supporting Information, Figure S4). Lastly, we assessed the rate of reaction of 2 with $\mathrm{NaF}$, yielding a rate constant of $116 \mathrm{M}^{-1} \mathrm{~min}^{-1}$ (Supporting Information, Figure S5). These data demonstrate the ability to rapidly detect fluoride in aqueous samples. Overall, the above experiments indicate the potential to utilize 2 for the sensitive laboratory detection of fluoride in water samples.

Test-Strip-Based Sensing of Fluoride in Aqueous Samples. Building upon these results, we envisioned a fluoride assay platform in which probe molecules would be adsorbed onto test-strips. We anticipated that these test-strips could then be utilized to measure fluoride concentrations in neat aqueous samples by monitoring the change in fluorescence of our probe. Such an assay format could allow for the point-of-use detection of fluoride. However, such an approach would require a fluoride chemosensor with low water solubility, ensuring that the probe would remain associated with the test-strip during subsequent analysis. We hypothesized that the ability to readily modify substituents on our fluoride sensing scaffold could yield a fluoride sensor with the desired physical properties. Accordingly, we appended an aniline substituent to 1 and protected this new fluoride sensor with TBDPS to afford fluoride sensor 4 (Scheme 2). As expected, addition of TBAF to a dioxane

Scheme 2. Synthesis of an Aniline Derivative of Fluoride Sensor 2
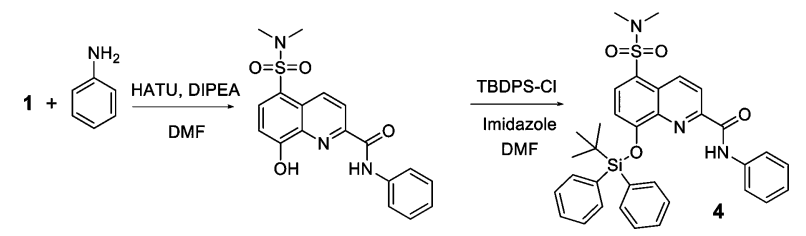

containing solution of 4 resulted in dramatic changes in the absorbance and emission spectra, producing a desilylated product with $\varepsilon=6330 \mathrm{M}^{-1} \mathrm{~cm}^{-1}$ and $\Phi=0.11$ (Figure 5). Moreover, we observed a red-shift in the emission maxima of 4 compared to 2 in dioxane ( 553 versus $536 \mathrm{~nm}$, respectively). In addition to these changes in the spectral properties of 4 compared to 2 , initial assays indicated that probe $\mathbf{4}$ was highly

(A)

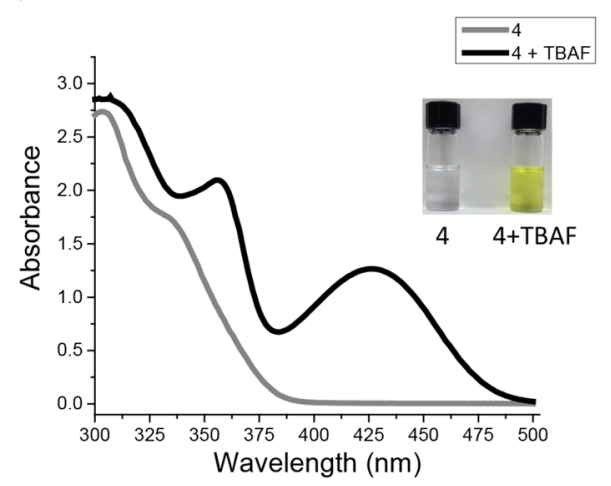

(B)

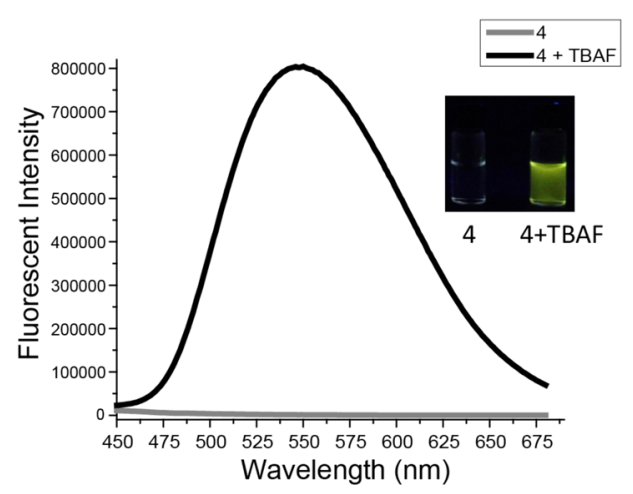

Figure 5. Absorbance (A) and emission spectra (B) of $200 \mu \mathrm{M} 4$ in the absence or presence of $1 \mathrm{mM}$ TBAF in dioxane. 
insoluble in aqueous samples (data not shown). Taking advantage of the insolubility of $\mathbf{4}$ in aqueous solutions, we immersed filter paper strips in a DCM solution of 4 . These teststrips were dried and subsequently dipped into water samples containing increasing concentrations of $\mathrm{NaF}$ for $5 \mathrm{~s}$. Test-strips were subsequently dried and imaged; clearly demonstrating the ability to detect fluoride at concentrations as low as $0.95 \mathrm{ppm}$ $(50 \mu \mathrm{M})$ using a straightforward assay format (Figure 6). This

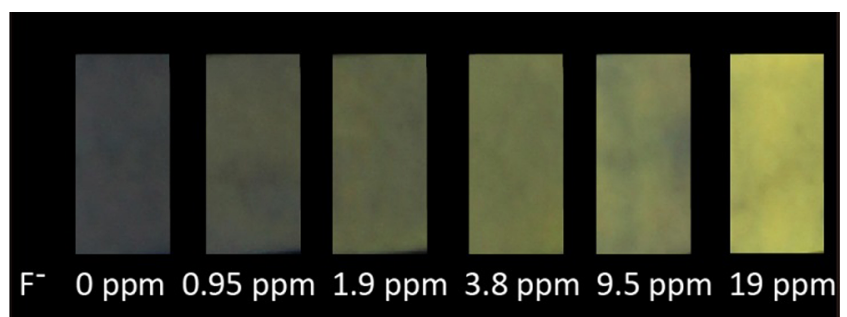

Figure 6. Fluorescence of test-trips containing 4 in the presence of the indicated concentration of $\mathrm{NaF}$ in water. Increasing fluorescence is observed with increasing $\mathrm{NaF}$ concentration.

test-strip-based assay was also capable of selectively detecting fluoride in a synthetic aquifer sample ${ }^{29}$ (Supporting Information, Figure S6). These data indicate the potential of the 8silyloxyquinoline scaffold as a versatile architecture for development of tailored fluoride sensing platforms. In the long term, the test-strip-based assay described above could be coupled with hand-held lateral fluorescence readers to enable the rapid detection of fluoride in the field.

\section{CONCLUSIONS}

In conclusion, we have demonstrated the versatility of the novel 8-silyloxyquinoline scaffold for the design of highly sensitive and selective platforms for the quantification of aqueous fluoride. Our initial fluoride sensor $\mathbf{2}$ can be utilized to detect fluoride in water samples, enabling the straightforward analysis of fluoride in the laboratory setting at concentrations well below the recommended levels in drinking water. ${ }^{1}$ The poor water solubility of sensor 4 enabled the development of a teststrip-based assay for fluoride in aqueous samples that could potentially be utilized for the low-cost analysis of fluoride in the field. Taken together this work provides a readily modifiable, low-cost platform for the analysis of fluoride in water samples.

\section{ASSOCIATED CONTENT}

\section{S Supporting Information}

Synthetic procedures, computational results, full characterization data for new compounds, and supporting data. This material is available free of charge via the Internet at http:// pubs.acs.org.

\section{AUTHOR INFORMATION}

\section{Corresponding Author}

*E-mail: cstains2@unl.edu. Phone: 1-402-472-2617. Fax: 1402-472-9402.

\section{Notes}

The authors declare no competing financial interest.

\section{ACKNOWLEDGMENTS}

We gratefully acknowledge the Department of Chemistry at the University of Nebraska-Lincoln for funding and the Research Instrumentation/NMR as well as Nebraska Center for Mass
Spectrometry facilities for assistance in characterization of the new compounds. We also acknowledge helpful discussion with Prof. Rebecca Lai concerning synthetic aquifer samples.

\section{REFERENCES}

(1) Centers for Disease Control and Prevention. Morbid. Mortal. Wkly. Rep. 2001, 50, 1-42.

(2) Arnold, F. A., Jr.; Dean, H. T.; Jay, P.; Knutson, J. W. Public Health Rep. 1956, 71, 652-658.

(3) Krishnamachari, K. A. Prog. Food Nutr. Sci. 1986, 10, 279-314.

(4) Aoba, T.; Fejerskov, O. Crit. Rev. Oral Biol. Med. 2002, 13, 155170.

(5) Irigoyen, M. E.; Molina, N.; Luengas, I. Community Dent. Oral 1995, 23, 243-245.

(6) Kloos, H.; Haimanot, R. T. Trop. Med. Int. Health 1999, 4, 355364.

(7) Kodali, Y. R. R.; Krishnamachari, K. A. V. R.; Gowrinathsastry, J. Trop. Doct. 1994, 24, 136-137.

(8) Rawlani, S. Indian J. Community Med. 2010, 35, 298-301.

(9) Willard, H. H.; Winter, O. B. Ind. Eng. Chem. Anal. Ed. 1933, 5, 7-10.

(10) De Marco, R.; Clarke, G.; Pejcic, B. Electroanalysis 2007, 19, 1987-2001.

(11) van den Hoop, M. A. G. T.; Cleven, R. F. M. J.; van Staden, J. J.; Neele, J. J. Chromatogr. A 1996, 739, 241-248.

(12) Ashokkumar, P.; Weisshoff, H.; Kraus, W.; Rurack, K. Angew. Chem., Int. Ed. 2014, 53, 2225-2229.

(13) Cametti, M.; Rissanen, K. Chem. Commun. 2009, 2809-2829.

(14) Guo, Z. Q.; Shin, I.; Yoon, J. Chem. Commun. 2012, 48, 59565967.

(15) Hirai, M.; Gabbai, F. P. Angew. Chem., Int. Ed. 2015, 54, 12051209.

(16) Hudnall, T. W.; Chiu, C. W.; Gabbai, F. P. Acc. Chem. Res. 2009, 42, 388-397.

(17) Ke, B.; Chen, W.; Ni, N.; Cheng, Y.; Dai, C.; Dinh, H.; Wang, B. Chem. Commun. 2013, 49, 2494-2496.

(18) Turan, I. S.; Akkaya, E. U. Org. Lett. 2014, 16, 1680-1683.

(19) Wade, C. R.; Broomsgrove, A. E.; Aldridge, S.; Gabbai, F. P. Chem. Rev. 2010, 110, 3958-3984.

(20) Zhou, Y.; Zhang, J. F.; Yoon, J. Chem. Rev. 2014, 114, 55115571.

(21) Li, L.; Ji, Y.; Tang, X. Anal. Chem. 2014, 86, 10006-10009.

(22) Swamy, P. C.; Mukherjee, S.; Thilagar, P. Anal. Chem. 2014, 86, $3616-3624$.

(23) Aboubakr, H.; Brisset, H.; Siri, O.; Raimundo, J. M. Anal. Chem. 2013, 85, 9968-9974.

(24) Li, Y.; Duan, Y.; Zheng, J.; Li, J.; Zhao, W.; Yang, S.; Yang, R. Anal. Chem. 2013, 85, 11456-11463.

(25) Bozdemir, O. A.; Sozmen, F.; Buyukcakir, O.; Guliyev, R.; Cakmak, Y.; Akkaya, E. U. Org. Lett. 2010, 12, 1400-1403.

(26) Smith, D. W. J. Chem. Educ. 1977, 54, 540-542.

(27) Kim, T. H.; Swager, T. M. Angew. Chem., Int. Ed. 2003, 42, $4803-4806$

(28) Korshoj, L. E.; Zaitouna, A. J.; Lai, R. Y. Anal. Chem. 2015, 87, $2560-2564$

(29) Williamson, J. E.; Carter, J. M. Water-Quality Characteristics in the Black Hills Area, South Dakota, Water-Resources Investigations Report 01-4194; U.S. Geological Survey, Rapid City, SD, 2001.

(30) Pearce, D. A.; Jotterand, N.; Carrico, I. S.; Imperiali, B. J. Am. Chem. Soc. 2001, 123, 5160-5161.

(31) Shults, M. D.; Pearce, D. A.; Imperiali, B. J. Am. Chem. Soc. 2003, 125, 10591-10597.

(32) Beck, J. R.; Peterson, L. B.; Imperiali, B.; Stains, C. I. Curr. Protoc. Chem. Biol. 2014, 6, 135-156.

(33) Szalewski, D. A.; Beck, J. R.; Stains, C. I. Bioorg. Med. Chem. Lett. 2014, 24, 5648-5651.

(34) Casida, M. E. In Recent Advances in Density Functional Methods; Chong, D. P., Ed.; World Scientific: Singapore, 1995; p 155. 
(35) Casida, M. E.; Jamorski, C.; Casida, K. C.; Salahub, D. R. J. Chem. Phys. 1998, 108, 4439-4449.

(36) Thellamurege, N. M.; Li, H. J. Chem. Phys. 2012, 137, 246101.

(37) Thellamurege, N. M.; Si, D.; Cui, F.; Zhu, H.; Lai, R.; Li, H. J. Comput. Chem. 2013, 34, 2816-2833.

(38) Schmidt, M. W.; Baldridge, K. K.; Boatz, J. A.; Elbert, S. T.; Gordon, M. S.; Jensen, J. H.; Koseki, S.; Matsunaga, N.; Nguyen, K. A.; Su, S. J. Comput. Chem. 1993, 14, 1347-1363.

(39) Gordon, M. S.; Schmidt, M. W. In Theory and Applications of Computational Chemistry: The First Forty Years; Elsevier: Amsterdam, The Netherlands, 2005; pp 1167-1189.

(40) Becke, A. D. J. Chem. Phys. 1993, 98, 5648-5652.

(41) Francl, M. M.; Pietro, W. J.; Hehre, W. J.; Binkley, J. S.; Gordon, M. S.; DeFrees, D. J.; Pople, J. A. J. Chem. Phys. 1982, 77, 3654-3665. (42) Chiba, M.; Tsuneda, T.; Hirao, K. J. Chem. Phys. 2006, 124, 144106-144111.

(43) Chiba, M.; Tsuneda, T.; Hirao, K. Chem. Phys. Lett. 2006, 420, 391-396. 


\section{Supporting Information}

The 8-Silyloxyquinoline Scaffold as a Versatile Platform for the Sensitive Detection of Aqueous Fluoride

Xinqi Zhou, Rui Lai, Hui Li, and Cliff I. Stains*

Department of Chemistry, University of Nebraska - Lincoln, Lincoln, Nebraska 68588, United States

Phone: 1-402-472-2617; Fax: 1-402-472-9402; E-mail: cstains2@unl.edu

\section{Table of Contents}

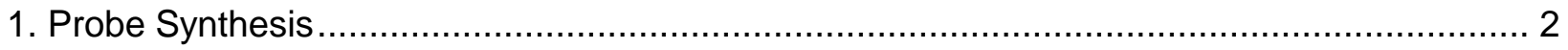

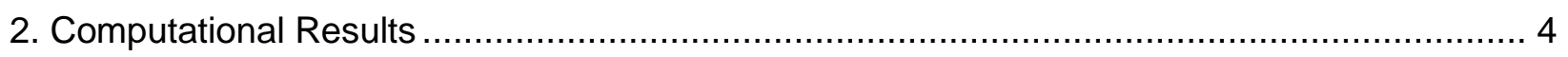

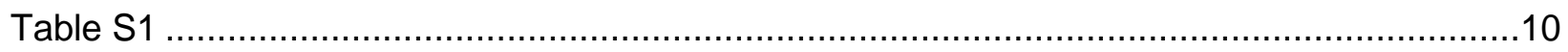

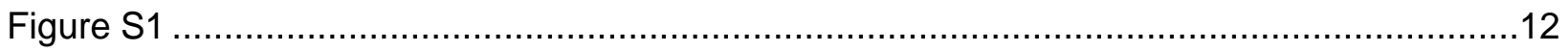

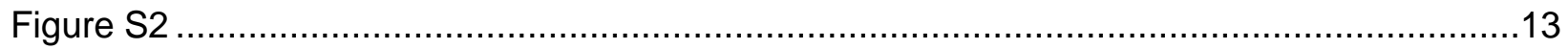

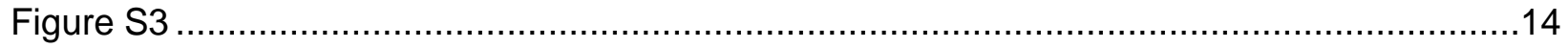

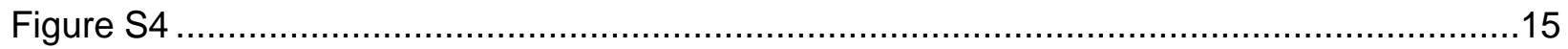

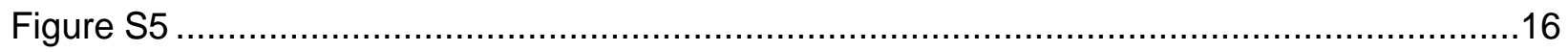

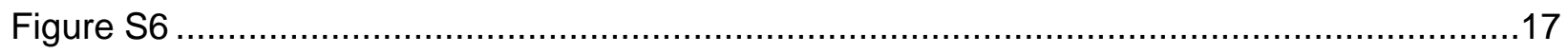

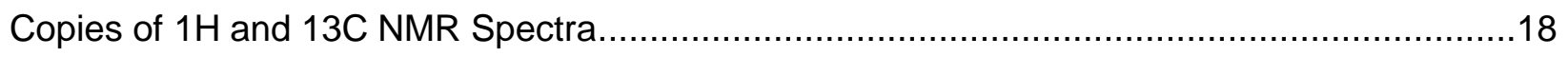

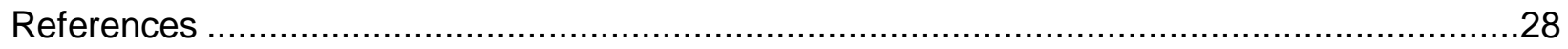




\section{Probe Synthesis}

5-(N,N-dimethylsulfamoyl)-8-hydroxyquinoline-2-carboxylic acid (1)

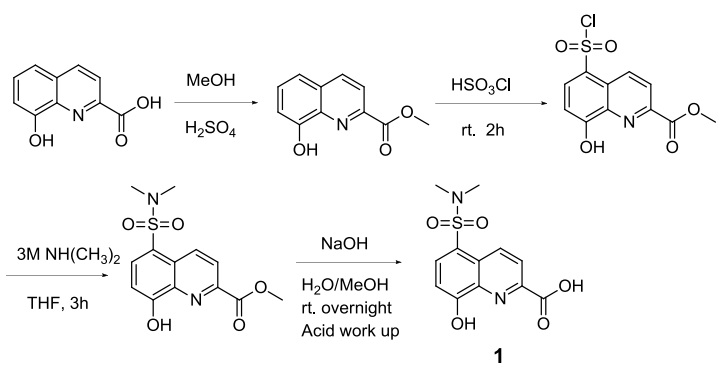

The key intermediate (1) was synthesized in four steps as follows.

methyl 8-hydroxyquinoline-2-carboxylate: To a solution of 8-hydroxyquinoline-2-carboxylic acid $(5 \mathrm{~g}, 26.43 \mathrm{mmol})$ dissolved in methanol $(100 \mathrm{~mL}), 10$ drops of concentrated sulfuric acid $(98 \%)$ was added. The reaction was then refluxed overnight. Solvent was removed under vacuum and the crude material was extracted using a saturated sodium bicarbonate solution and dichloromethane. The organic layer was dried by sodium sulfate and the solvent was removed by evaporation. The resulting orange solid was used for the next step without any further purification.

methyl 5-(chlorosulfonyl)-8-hydroxyquinoline-2-carboxylate: Chlorosulfonic acid (25 mL) was added to a flask containing the orange solid from above and stirred for 2 hours. The resulting solution was extracted using dichloromethane and ice. The organic layer was collected and dried over potassium carbonate. The solvent was subsequently evaporated and the resulting light yellow powder was used for the next step without further purification.

methyl 5-(N,N-dimethylsulfamoyl)-8-hydroxyquinoline-2-carboxylate: Dimethylamine (40 $\mathrm{mL}, 80 \mathrm{mmol}$ ) was added to THF (1L). The light yellow powder obtained from above was then slowly added over 3 hours under stirring. After the last portion was added, the reaction was continued for $15 \mathrm{~min}$ and then the THF was removed by evaporation. The resulting yellow solid was washed with dichloromethane $(3 \times 15 \mathrm{~mL})$ to remove extra dimethylamine and used for the next step without further purification.

5-(N,N-dimethylsulfamoyl)-8-hydroxyquinoline-2-carboxylic acid (1): The crude yellow solid obtained from the previous step was added to an aqueous solution $(100 \mathrm{~mL})$ of $\mathrm{NaOH}(4.23 \mathrm{~g}$, $105.72 \mathrm{mmol})$ in methanol $(200 \mathrm{~mL})$. The reaction mixture was stirred overnight at room temperature. Methanol was removed by evaporation and dichloromethane $(3 \times 300 \mathrm{~mL})$ was used to wash the resulting aqueous layer. Concentrated aqueous $\mathrm{HCl}$ was then added to the reaction mixture and the $\mathrm{pH}$ was adjusted to $\sim 4$. The resulting precipitate was filtered, washed with water and cold ethanol, and then dried. $1(1.3 \mathrm{~g}, 4.39 \mathrm{mmol}, 16.6 \%)$ was obtained as a yellow solid.

1: ${ }^{1} \mathrm{H}$ NMR (300 MHz, DMSO) $\delta 11.33(\mathrm{~s}, 1 \mathrm{H}), 9.21(\mathrm{~d}, \mathrm{~J}=9.0 \mathrm{~Hz}, 1 \mathrm{H}), 8.33(\mathrm{~d}, \mathrm{~J}=9.0 \mathrm{~Hz}, 1 \mathrm{H})$, $8.19(\mathrm{~d}, \mathrm{~J}=8.4 \mathrm{~Hz}, 1 \mathrm{H}), 7.34(\mathrm{~d}, \mathrm{~J}=8.4 \mathrm{~Hz}, 1 \mathrm{H}), 2.66(\mathrm{~s}, 6 \mathrm{H}) .{ }^{13} \mathrm{C}$ NMR $(75 \mathrm{MHz}$, DMSO) $\delta$ 165.25, 159.20, 145.59, 137.18, 136.35, 135.58, 127.30, 122.51, 121.28, 111.16, 37.59. MS (ESI) $\mathrm{m} / \mathrm{z}$ calcd for $\mathrm{C}_{12} \mathrm{H}_{12} \mathrm{~N}_{2} \mathrm{O}_{5} \mathrm{~S}[\mathrm{M}+\mathrm{H}]^{+} 297.3$, found 297.4. 
8-((tert-butyldiphenylsilyl)oxy)-5-(N,N-dimethylsulfamoyl)- $N$-ethylquinoline-2-carboxamide (2) and 8-((tert-butyldiphenylsilyl)oxy)-5-(N,N-dimethylsulfamoyl)- $\mathrm{N}$-phenylquinoline-2-carboxamide (4)

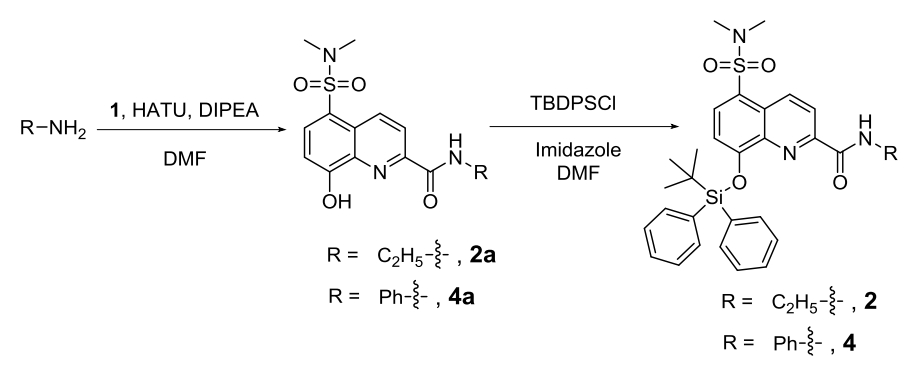

Fluoride probes 2 and $\mathbf{4}$ were obtained by coupling $\mathbf{1}$ with the appropriate amine followed by reaction with TBDPSCI.

Intermediate amides (2a and 4a): 1 (40 mg, $0.135 \mathrm{mmol}$ ) and HATU (77mg, $0.203 \mathrm{mmol}$ ) were dissolved in DMF ( $1 \mathrm{~mL}$ ) and to the resulting yellow solution DIPEA ( $47 \mu \mathrm{L}, 0.27 \mathrm{mmol})$ was added. The reaction mixture turned orange immediately and was left to stir for $10 \mathrm{~min}$ before the appropriate amine $(0.162 \mathrm{mmol})$ was added dropwise. After the reaction reached completion, the mixture was poured into ice-cold water and extracted with ethyl acetate. The organic layer was dried over sodium sulfate, the mixture was filtered, and the solvent was removed. The crude product was then purified by flash chromatography (silica gel, 2:8 hexanes/ethyl acetate). Both $\mathbf{2 a}(35 \mathrm{mg}, 80 \%)$ and $\mathbf{4 a}$ ( $38 \mathrm{mg}, 76 \%)$ were obtained as yellow oils.

2a: ${ }^{1} \mathrm{H}$ NMR $\left(400 \mathrm{MHz}\right.$, Methanol- $\left.d_{4}\right) \delta 9.28(\mathrm{~d}, J=9.2 \mathrm{~Hz}, 1 \mathrm{H}), 8.38(\mathrm{~d}, J=9.0 \mathrm{~Hz}, 1 \mathrm{H}), 8.25(\mathrm{~d}$, $J=8.6 \mathrm{~Hz}, 1 \mathrm{H}), 7.30(\mathrm{~d}, J=8.7 \mathrm{~Hz}, 1 \mathrm{H}), 3.55(\mathrm{q}, J=7.3 \mathrm{~Hz}, 2 \mathrm{H}), 2.76(\mathrm{~s}, 6 \mathrm{H}), 1.33(\mathrm{t}, J=7.4$ $\mathrm{Hz}, 3 \mathrm{H}) .{ }^{13} \mathrm{C}$ NMR $\left(101 \mathrm{MHz}\right.$, Methanol- $\left.d_{4}\right) \delta 164.18,158.72,148.18,136.99,135.65,134.50$, $126.77,121.63,120.17,109.76,36.29,34.14,13.49$. MS (ESI) $m / z$ calcd for $\mathrm{C}_{14} \mathrm{H}_{17} \mathrm{~N}_{3} \mathrm{O}_{4} \mathrm{~S}$ $[\mathrm{M}+\mathrm{H}]^{+}$324.4, found 324.4 .

4a: ${ }^{1} \mathrm{H} \mathrm{NMR}\left(400 \mathrm{MHz}, \mathrm{CDCl}_{3}\right) \delta 9.97(\mathrm{~s}, 1 \mathrm{H}), 9.22(\mathrm{~d}, J=9.0 \mathrm{~Hz}, 1 \mathrm{H}), 8.50(\mathrm{~d}, J=9.0 \mathrm{~Hz}, 1 \mathrm{H})$, $8.23(\mathrm{~d}, J=8.3 \mathrm{~Hz}, 1 \mathrm{H}), 7.70(\mathrm{~d}, J=8.0 \mathrm{~Hz}, 2 \mathrm{H}), 7.28(\mathrm{~s}, 1 \mathrm{H}), 7.26-7.19(\mathrm{~m}, 3 \mathrm{H}), 7.08(\mathrm{t}, J=$ $7.3 \mathrm{~Hz}, 1 \mathrm{H}), 2.78(\mathrm{~s}, 6 \mathrm{H}) .{ }^{13} \mathrm{C} \mathrm{NMR}\left(101 \mathrm{MHz}, \mathrm{CDCl}_{3}\right) \delta 161.66,156.97,148.52,136.97,136.43$, 136.39, 134.61, 128.96, 126.80, 125.09, 122.73, 121.50, 120.80, 109.91, 37.34. MS (ESI) m/z calcd for $\mathrm{C}_{18} \mathrm{H}_{17} \mathrm{~N}_{3} \mathrm{O}_{4} \mathrm{~S}[\mathrm{M}+\mathrm{H}]^{+}$372.4, found 372.4.

Fluoride probes 2 and 4: $2 \mathrm{a}(30 \mathrm{mg}, 0.093 \mathrm{mmol})$ and imidazole $(7 \mathrm{mg}, 0.1 \mathrm{mmol})$ were dissolved in DMF $(0.8 \mathrm{~mL})$. The mixture was cooled down to $0{ }^{\circ} \mathrm{C}$ and tertbutylchlorodiphenylsilane $(26 \mu \mathrm{L}, 0.1 \mathrm{mmol})$ was added dropwise. The reaction was stirred for $15 \mathrm{~min}$ at $0^{\circ} \mathrm{C}$ and left overnight under room temperature. The reaction was diluted by water (20 $\mathrm{mL}$ ) and extracted by ethyl acetate $(3 \times 20 \mathrm{~mL})$. The organic layer was combined and washed with saturated ammonium chloride $(10 \mathrm{~mL})$, brine $(10 \mathrm{~mL})$, and dried $\left(\mathrm{Na}_{2} \mathrm{SO}_{4}\right)$. The solvent was removed by rotary evaporation and the crude was purified by flash chromatography (silica gel, 8:2 hexanes/ethyl acetate) to yield a white solid $2(47 \mathrm{mg}, 90 \%)$. The silica gel was pretreated with acetone for 15 min to decrease product decomposition. 4 (white solid, 88\%) was prepared using the same method.

2: ${ }^{1} \mathrm{H}$ NMR $\left(400 \mathrm{MHz}, \mathrm{CDCl}_{3}\right) \delta 9.15(\mathrm{~d}, \mathrm{~J}=9.0 \mathrm{~Hz}, 1 \mathrm{H}), 8.32(\mathrm{~d}, \mathrm{~J}=9.0 \mathrm{~Hz}, 1 \mathrm{H}), 8.09(\mathrm{~d}, \mathrm{~J}=$ $8.3 \mathrm{~Hz}, 1 \mathrm{H}), 7.76(\mathrm{~d}, \mathrm{~J}=8.0 \mathrm{~Hz}, 4 \mathrm{H}), 7.59(\mathrm{t}, \mathrm{J}=5.8 \mathrm{~Hz}, 1 \mathrm{H}), 7.46-7.40(\mathrm{~m}, 2 \mathrm{H}), 7.37-7.32$ 
$(\mathrm{m}, 4 \mathrm{H}), 7.14(\mathrm{~d}, \mathrm{~J}=8.3 \mathrm{~Hz}, 1 \mathrm{H}), 3.28-3.20(\mathrm{~m}, 2 \mathrm{H}), 2.75(\mathrm{~s}, 6 \mathrm{H}), 1.22(\mathrm{~s}, 9 \mathrm{H}), 1.09(\mathrm{t}, \mathrm{J}=7.2$ $\mathrm{Hz}, 3 \mathrm{H}) .{ }^{13} \mathrm{C}$ NMR $\left(101 \mathrm{MHz}, \mathrm{CDCl}_{3}\right) \delta 163.49,156.97,148.91,139.98,135.20,135.04,133.17$, 131.78, 130.41, 128.04, 127.53, 124.61, 120.53, 115.97, 37.33, 34.35, 26.48, 20.25, 14.72. MS (ESI) $\mathrm{m} / \mathrm{z}$ calcd for $\mathrm{C}_{30} \mathrm{H}_{35} \mathrm{~N}_{3} \mathrm{O}_{4} \mathrm{SSi}[\mathrm{M}+\mathrm{H}]^{+} 562.8$, found 562.9 .

4: ${ }^{1} \mathrm{H}$ NMR (400 MHz, Chloroform- $\left.d\right) \delta 9.97(\mathrm{~s}, 1 \mathrm{H}), 9.28(\mathrm{~d}, J=8.9 \mathrm{~Hz}, 1 \mathrm{H}), 8.53(\mathrm{~d}, J=9.0 \mathrm{~Hz}$, $1 \mathrm{H}), 8.02(\mathrm{~d}, J=8.3 \mathrm{~Hz}, 1 \mathrm{H}), 7.80(\mathrm{~d}, J=6.7 \mathrm{~Hz}, 4 \mathrm{H}), 7.63-7.57(\mathrm{~m}, 2 \mathrm{H}), 7.51-7.44(\mathrm{~m}, 2 \mathrm{H})$, $7.39(\mathrm{t}, J=7.6 \mathrm{~Hz}, 6 \mathrm{H}), 7.22-7.15(\mathrm{~m}, 1 \mathrm{H}), 6.95(\mathrm{~d}, J=8.3 \mathrm{~Hz}, 1 \mathrm{H}), 2.78(\mathrm{~s}, 6 \mathrm{H}), 1.31(\mathrm{~s}, 9 \mathrm{H})$. ${ }^{13} \mathrm{C}$ NMR $\left(101 \mathrm{MHz}, \mathrm{CDCl}_{3}\right) \delta 161.61,156.73,148.94,140.03,137.48,135.76,135.26,133.31$, 131.36, 130.59, 129.04, 128.21, 127.77, 124.60, 124.53, 120.56, 119.94, 115.71, 37.32, 26.68, 20.25. MS (ESI) $\mathrm{m} / z$ calcd for $\mathrm{C}_{34} \mathrm{H}_{35} \mathrm{~N}_{3} \mathrm{O}_{4} \mathrm{SSi}[\mathrm{M}+\mathrm{H}]^{+} 609.8$, found 611.0.

\section{Computational Results}

The FixSol/B3LYP/6-31++G(d,p) optimized $S_{0}$ ground state geometry of $\mathbf{2}$ is:

\begin{tabular}{|c|c|c|c|c|}
\hline $\mathrm{C}$ & 6.0 & 0.5834144950047 & -0.3629622735684 & -0.2692633620346 \\
\hline $\mathrm{C}$ & 6.0 & 0.0800959435072 & 0.9073589457767 & 0.1986521847636 \\
\hline $\mathrm{C}$ & 6.0 & -1.2849538354660 & 1.0250556926587 & 0.6422724845581 \\
\hline $\mathrm{C}$ & 6.0 & -2.1029229746956 & -0.1507409435284 & 0.6173746543746 \\
\hline $\mathrm{C}$ & 6.0 & -1.5747473344856 & -1.3615825122418 & 0.2080056381702 \\
\hline $\mathrm{C}$ & 6.0 & -0.2447047125838 & -1.4730409278710 & -0.2293207447063 \\
\hline 0 & 8.0 & 1.8237451245672 & -0.3915719940406 & -0.7662131902253 \\
\hline $\mathrm{H}$ & 1.0 & -1.0969598312593 & 4.3606293913735 & 1.3895935864086 \\
\hline $\mathrm{H}$ & 1.0 & -2.7090940778307 & 2.4624459030133 & 1.4368752458510 \\
\hline $\mathrm{H}$ & 1.0 & -2.2034644217384 & -2.2483965847865 & 0.2121393462494 \\
\hline $\mathrm{H}$ & 1.0 & 0.1211890392355 & -2.4355975029594 & -0.5655150891647 \\
\hline $\mathrm{S}$ & 16.0 & -3.8547978798546 & -0.2095384026094 & 1.0415929897506 \\
\hline 0 & 8.0 & -4.2321598446761 & 0.9903532802333 & 1.8172855329952 \\
\hline O & 8.0 & -4.1481199015483 & -1.5304087070799 & 1.6236921221626 \\
\hline $\mathrm{N}$ & 7.0 & -4.5892133461105 & -0.2133395692503 & -0.5007193706365 \\
\hline $\mathrm{H}$ & 1.0 & -6.0162804048940 & -1.6728599439101 & 0.0469315663060 \\
\hline $\mathrm{H}$ & 1.0 & -3.4072931736935 & 1.3607912808533 & -1.2821077692291 \\
\hline $\mathrm{C}$ & 6.0 & -1.6976598033797 & 2.3172673638090 & 1.0773421610962 \\
\hline $\mathrm{C}$ & 6.0 & -0.8108182753915 & 3.3681225628827 & 1.0574983564641 \\
\hline $\mathrm{C}$ & 6.0 & 0.5112017331798 & 3.1407767826219 & 0.6100857952262 \\
\hline $\mathrm{N}$ & 7.0 & 0.9369960519877 & 1.9593499233683 & 0.1980323070080 \\
\hline $\mathrm{C}$ & 6.0 & 1.4935386558901 & 4.2956311574733 & 0.6082110604989 \\
\hline $\mathrm{N}$ & 7.0 & 2.7596122910557 & 3.9715907306142 & 0.2695626668689 \\
\hline C & 6.0 & 3.8539031503410 & 4.9377237888054 & 0.2429540855704 \\
\hline $\mathrm{C}$ & 6.0 & 4.6184959931681 & 5.0164173798062 & 1.5697963210463 \\
\hline 0 & 8.0 & 1.1199257869944 & 5.4405195924738 & 0.8973936222662 \\
\hline $\mathrm{H}$ & 1.0 & 2.9457557654574 & 2.9897003351427 & 0.0920568338621 \\
\hline $\mathrm{H}$ & 1.0 & 3.4238298256985 & 5.9135297988895 & -0.0045513161887 \\
\hline $\mathrm{H}$ & 1.0 & 4.5291832089947 & 4.6477121017287 & -0.5697059833277 \\
\hline $\mathrm{H}$ & 1.0 & 5.4279073509146 & 5.7536747339960 & 1.4933269854056 \\
\hline $\mathrm{H}$ & 1.0 & 3.9507038771742 & 5.3225956698416 & 2.3833640093220 \\
\hline $\mathrm{H}$ & 1.0 & 5.0611245147396 & 4.0464922348420 & 1.8278336791678 \\
\hline C & 6.0 & -5.9779841069070 & -0.7180498067650 & -0.4813562677534 \\
\hline $\mathrm{C}$ & 6.0 & -4.4577200472444 & 1.0626200430726 & -1.2243605223528 \\
\hline $\mathrm{H}$ & 1.0 & -6.2748547638541 & -0.8760117847905 & -1.5235986429642 \\
\hline $\mathrm{H}$ & 1.0 & -4.8180779784203 & 0.8984444159692 & -2.2452780190421 \\
\hline $\mathrm{H}$ & 1.0 & -6.6770787402863 & -0.0075154096570 & -0.0145987985020 \\
\hline $\mathrm{H}$ & 1.0 & -5.0419876632434 & 1.8717304861291 & -0.7611250019731 \\
\hline SI & 14.0 & 3.2273972400535 & -1.3710846548780 & -0.8326382182884 \\
\hline $\mathrm{C}$ & 6.0 & 3.0124887315584 & -2.8074105573559 & -2.1089208739447 \\
\hline $\mathrm{C}$ & 6.0 & 3.6407381661918 & -1.8890987386619 & 0.9407693848101 \\
\hline $\mathrm{C}$ & 6.0 & 4.4743067961380 & -0.1116129444601 & -1.5023524491792 \\
\hline $\mathrm{C}$ & 6.0 & 5.8644789890894 & -0.3463264165651 & -1.4882561506377 \\
\hline $\mathrm{C}$ & 6.0 & 4.0243541717299 & 1.0892329362670 & -2.0867020283549 \\
\hline C & 6.0 & 6.7661939163215 & 0.5739655265311 & -2.0320951305540 \\
\hline $\mathrm{C}$ & 6.0 & 4.9211076660840 & 2.0103102893934 & -2.6400050913980 \\
\hline $\mathrm{C}$ & 6.0 & 6.2955559245764 & 1.7559767981357 & -2.6133323460058 \\
\hline $\mathrm{C}$ & 6.0 & 2.2763408877219 & -4.0554529242957 & -1.5725954336723 \\
\hline $\mathrm{C}$ & 6.0 & 4.4159322077360 & -3.2702192499630 & -2.5752894204715 \\
\hline
\end{tabular}




$\begin{array}{ll}6.0 & 2.2443359261189 \\ 6.0 & 4.6575129785779 \\ 6.0 & 2.9135393294075 \\ 6.0 & 4.9486214075158 \\ 6.0 & 3.1968201918665 \\ 6.0 & 4.2200502409112 \\ 1.0 & 4.5432758389127 \\ 1.0 & 2.9600331344682 \\ 1.0 & 6.2600993780107 \\ 1.0 & 7.8343601882401 \\ 1.0 & 6.9935984361362 \\ 1.0 & 5.2323280715626 \\ 1.0 & 5.7410371914327 \\ 1.0 & 4.4426491619327 \\ 1.0 & 2.6178735113242 \\ 1.0 & 2.1062667983608 \\ 1.0 & 4.3019608528698 \\ 1.0 & 5.0250762138250 \\ 1.0 & 4.9734970666359 \\ 1.0 & 2.1674852028351 \\ 1.0 & 1.2258667906665 \\ 1.0 & 2.8367033677859 \\ 1.0 & 2.1681763198297 \\ 1.0 & 2.7578467510396 \\ 1.0 & 1.2680194122566\end{array}$
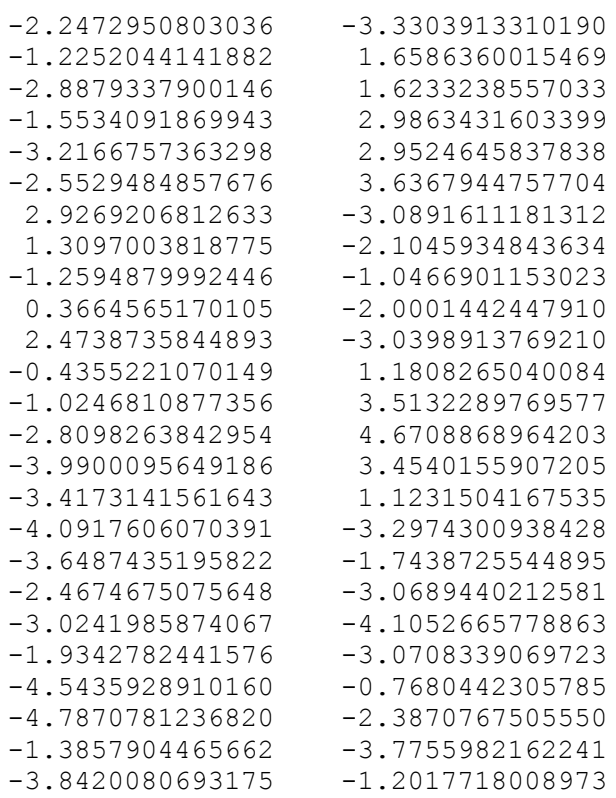

The FixSol/TD-B3LYP/6-31++G(d,p) excitation energies for 2 at $\mathrm{S}_{0}$ ground state geometry. There are two transitions, $S_{0^{-}}>S_{1}$ at $3.63 \mathrm{eV}$ with an oscillator strength 0.154 and $S_{0^{-}}>S_{13}$ at $4.80 \mathrm{eV}$ with an oscillator strength 0.814 :

\begin{tabular}{|c|c|c|c|c|c|c|c|}
\hline \multicolumn{2}{|c|}{ STATE } & $\begin{array}{l}\text { ENERGY } \\
\text { HARTREE }\end{array}$ & $\begin{array}{c}\text { EXCITATION } \\
\text { EV }\end{array}$ & $\begin{array}{c}\text { TRANS ITION } \\
\mathrm{X}\end{array}$ & $\begin{array}{c}N \text { DIPOLE } \\
Y\end{array}$ & $\begin{array}{c}A \cdot U . \\
Z\end{array}$ & $\begin{array}{r}\text { OSCILLATOR } \\
\text { STRENGTH }\end{array}$ \\
\hline 0 & A & -2316.1513835956 & 0.000 & & & & \\
\hline 1 & A & -2316.0178875095 & 3.633 & 1.0864 & -0.6711 & -0.3179 & 0.154 \\
\hline 2 & A & -2316.0130603540 & 3.764 & -0.0935 & 0.1085 & -0.0479 & 0.002 \\
\hline 3 & A & -2315.9998637266 & 4.123 & 0.1797 & 0.1035 & 0.0002 & 0.004 \\
\hline 4 & A & -2315.9984187165 & 4.162 & 0.2791 & -0.0113 & -0.0487 & 0.008 \\
\hline 5 & A & -2315.9943314870 & 4.274 & $0.0211-$ & -0.1249 & 0.0091 & 0.002 \\
\hline 6 & A & -2315.9937831718 & 4.289 & $0.6980-$ & -0.2549 & -0.0303 & 0.058 \\
\hline 7 & A & -2315.9926330280 & 4.320 & $0.1835-$ & -0.0149 & -0.0825 & 0.004 \\
\hline 8 & A & -2315.9906819450 & 4.373 & 0.1263 & 0.1467 & -0.0191 & 0.004 \\
\hline 9 & A & -2315.9890951945 & 4.416 & 0.2145 & 0.0654 & -0.2140 & 0.010 \\
\hline 10 & A & -2315.9858883025 & 4.503 & -0.0533 & 0.0164 & 0.0632 & 0.001 \\
\hline 11 & A & -2315.9785534960 & 4.703 & 0.1663 & 0.1413 & 0.0534 & 0.006 \\
\hline 12 & A & -2315.9749131885 & 4.802 & $-0.1831-$ & -0.3586 & 0.0154 & 0.019 \\
\hline 13 & A & -2315.9748358888 & 4.804 & 1.7454 & 1.9548 & 0.2282 & 0.814 \\
\hline 1 & A & -2315.9717627884 & 4.888 & $0.2371-$ & -0.7321 & 0.0457 & 0.071 \\
\hline 3 & A & -2315.9647791866 & 5.078 & 0.3187 & 0.2283 & 0.0124 & 0.019 \\
\hline
\end{tabular}

The $\mathrm{S}_{0^{-}}>\mathrm{S}_{1}$ transition is mainly between MO149 (HOMO) and MO150 (LUMO):

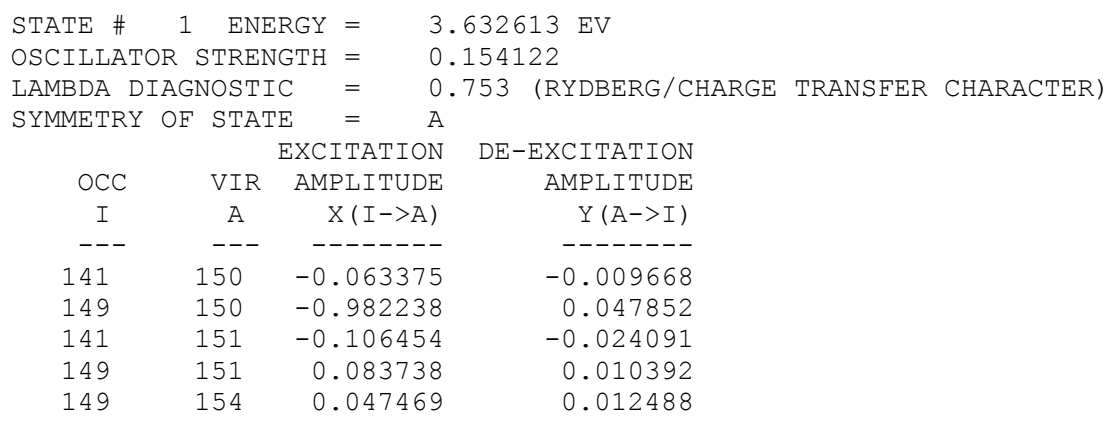


The FixSol/TD-B3LYP/6-31++G(d,p) optimized (only for 16 steps) $S_{1}$ state geometry of 2 is:

\begin{tabular}{|c|c|c|}
\hline $\mathrm{C}$ & 6.0 & 0.5604862738972 \\
\hline $\mathrm{C}$ & 6.0 & 0.0888001867051 \\
\hline $\mathrm{C}$ & 6.0 & -1.2611155701553 \\
\hline C & 6.0 & -2.0645042695759 \\
\hline $\mathrm{C}$ & 6.0 & -1.5641666678896 \\
\hline $\mathrm{C}$ & 6.0 & -0.2779742255020 \\
\hline 0 & 8.0 & 1.7951966720710 \\
\hline $\mathrm{H}$ & 1.0 & -1.0588537324763 \\
\hline $\mathrm{H}$ & 1.0 & -2.6510035168098 \\
\hline $\mathrm{H}$ & 1.0 & -2.1811985926395 \\
\hline $\mathrm{H}$ & 1.0 & 0.0845140604553 \\
\hline $\mathrm{S}$ & 16.0 & -3.7106349456233 \\
\hline 0 & 8.0 & -4.2729198197444 \\
\hline 0 & 8.0 & -4.1602059600985 \\
\hline $\mathrm{N}$ & 7.0 & -4.636951847952 \\
\hline $\mathrm{H}$ & 1.0 & -5.4540432253329 \\
\hline $\mathrm{H}$ & 1.0 & -3.6961398221131 \\
\hline $\mathrm{C}$ & 6.0 & -1.6580201856052 \\
\hline $\mathrm{C}$ & 6.0 & -0.7705912239972 \\
\hline $\mathrm{C}$ & 6.0 & 0.515872504608 \\
\hline $\mathrm{N}$ & 7.0 & 0.9424819308547 \\
\hline $\mathrm{C}$ & 6.0 & 1.5047816640269 \\
\hline $\mathrm{N}$ & 7.0 & 2.7510571896407 \\
\hline $\mathrm{C}$ & 6.0 & 3.8787580865392 \\
\hline $\mathrm{C}$ & 6.0 & 4.6386014862972 \\
\hline 0 & 8.0 & 1.1801750541486 \\
\hline $\mathrm{H}$ & 1.0 & 2.8961450666597 \\
\hline $\mathrm{H}$ & 1.0 & 3.4919381964984 \\
\hline $\mathrm{H}$ & 1.0 & 4.5433884603263 \\
\hline $\mathrm{H}$ & 1.0 & 5.4808472242996 \\
\hline $\mathrm{H}$ & 1.0 & 3.9795262892731 \\
\hline $\mathrm{H}$ & 1.0 & 5.0350783103944 \\
\hline $\mathrm{C}$ & 6.0 & -5.633130935701 \\
\hline $\mathrm{C}$ & 6.0 & -4.623597140605 \\
\hline $\mathrm{H}$ & 1.0 & -5.5720371017528 \\
\hline $\mathrm{H}$ & 1.0 & -4.7318335923197 \\
\hline $\mathrm{H}$ & 1.0 & -6.653071276819 \\
\hline $\mathrm{H}$ & 1.0 & -5.4702711081640 \\
\hline SI & 14.0 & 3.1845166314268 \\
\hline $\mathrm{C}$ & 6.0 & 2.9578780309747 \\
\hline $\mathrm{C}$ & 6.0 & 3.6105299849031 \\
\hline $\mathrm{C}$ & 6.0 & 4.4564306120109 \\
\hline $\mathrm{C}$ & 6.0 & 5.8448661153992 \\
\hline C & 6.0 & 4.0126734838360 \\
\hline $\mathrm{C}$ & 6.0 & 6.7484280791713 \\
\hline $\mathrm{C}$ & 6.0 & 4.910108545367 \\
\hline $\mathrm{C}$ & 6.0 & 6.2851972786571 \\
\hline $\mathrm{C}$ & 6.0 & 2.2111920288760 \\
\hline $\mathrm{C}$ & 6.0 & 4.3521734394104 \\
\hline $\mathrm{C}$ & 6.0 & 2.1866341417264 \\
\hline $\mathrm{C}$ & 6.0 & 4.647118193259 \\
\hline $\mathrm{C}$ & 6.0 & 2.877339300706 \\
\hline $\mathrm{C}$ & 6.0 & 4.9419970350083 \\
\hline $\mathrm{C}$ & 6.0 & 3.1674554229808 \\
\hline $\mathrm{C}$ & 6.0 & 4.201789103384 \\
\hline $\mathrm{H}$ & 1.0 & 4.5357980147782 \\
\hline $\mathrm{H}$ & 1.0 & 2.949605072078 \\
\hline $\mathrm{H}$ & 1.0 & 6.241121719583 \\
\hline $\mathrm{H}$ & 1.0 & 7.8161432443032 \\
\hline $\mathrm{H}$ & 1.0 & 6.987457344095 \\
\hline $\mathrm{H}$ & 1.0 & 5.228350302339 \\
\hline $\mathrm{H}$ & 1.0 & 5.743250219941 \\
\hline $\mathrm{H}$ & 1.0 & 4.424199924708 \\
\hline $\mathrm{H}$ & 1.0 & 2.5801849013509 \\
\hline $\mathrm{H}$ & 1.0 & 2.059104124511 \\
\hline & 1.0 & 4.22057571891 \\
\hline
\end{tabular}

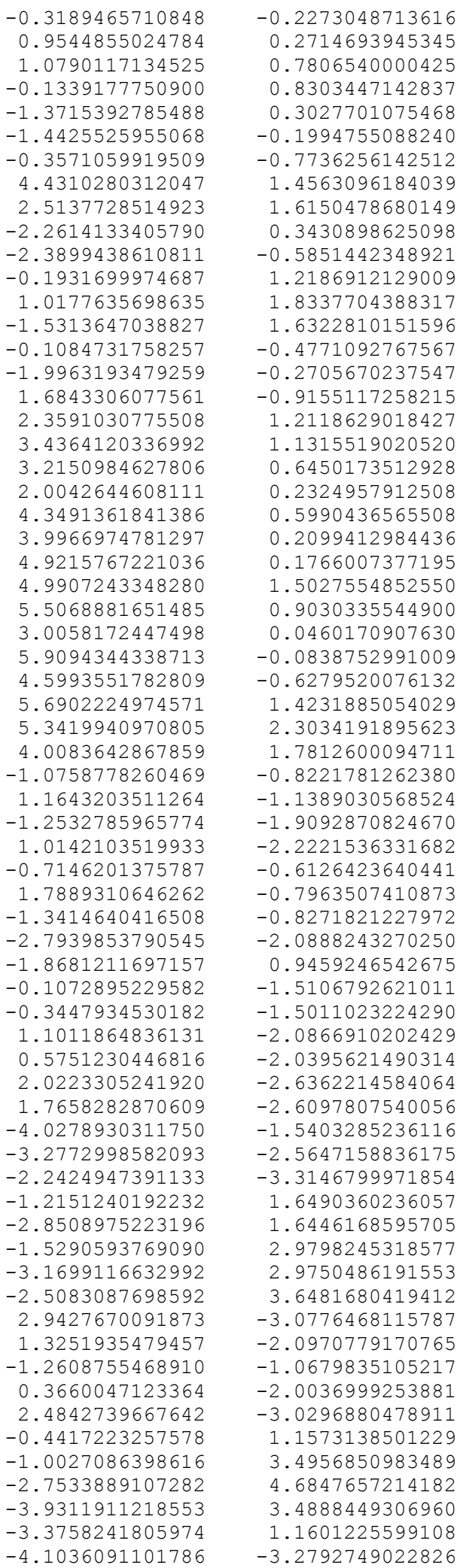

$-0.2273048713616$

0.2714693945345

0.7806540000425

0.8303447142837

0.3027701075468

$-0.1994755088240$

$-0.7736256142512$

1.4563096184039

1.6150478680149

0.3430898625098

$-0.5851442348921$

1.2186912129009

1.8337704388317

1.6322810151596

$-0.4771092767567$

$-0.2705670237547$

$-0.9155117258215$

1.2118629018427

1.1315519020520

0.6450173512928

0.2324957912508

0.5990436565508

0.2099412984436

0.1766007377195

1.5027554852550

0.9030335544900

0.0460170907630

$-0.0838752991009$

$-0.6279520076132$

1.4231885054029

2.3034191895623

1.7812600094711

$-0.8221781262380$

$-1.1389030568524$

$-1.9092870824670$

$-2.2221536331682$

$-0.6126423640441$

$-0.7963507410873$

$-0.8271821227972$

$-2.0888243270250$

0.9459246542675

$-1.5106792621011$

$-1.5011023224290$

$-2.0866910202429$

$-2.0395621490314$

$-2.6362214584064$

$-2.6097807540056$

$-1.5403285236116$

$-2.5647158836175$

$-3.3146799971854$

1.6490360236057

1.6446168595705

2. 9798245318577

2. 9750486191553

3. 6481680419412

$-3.0776468115787$

$-2.0970779170765$

$-1.0679835105217$

$-2.0036999253881$

$-3.0296880478911$

1.1573138501229

3.4956850983489

4.6847657214182

3.4888449306960

1.1601225599108

$-3.2792749022826$ 


$\begin{array}{lllll}\mathrm{H} & 1.0 & 4.9651420918418 & -3.6559452105760 & -1.7352870418477 \\ \mathrm{H} & 1.0 & 4.9140943250484 & -2.4857876696538 & -3.0728284224711 \\ \mathrm{H} & 1.0 & 2.1102580936225 & -3.0273178995127 & -4.0814772475496 \\ \mathrm{H} & 1.0 & 1.1703199002770 & -1.9251581654817 & -3.0567182252706 \\ \mathrm{H} & 1.0 & 2.7592966963872 & -4.5019944602838 & -0.7207688709152 \\ \mathrm{H} & 1.0 & 2.1065988645499 & -4.7730699064957 & -2.3422177083198 \\ \mathrm{H} & 1.0 & 2.7006150060799 & -1.3862964669151 & -3.7685878711347 \\ \mathrm{H} & 1.0 & 1.2017121076402 & -3.7966824618284 & -1.1819258945004\end{array}$

\section{The FixSol/TD-B3LYP/6-31++G(d,p) de-excitation $\left(S_{1->} S_{0}\right)$ energy for 2 after 16 steps of optimization:}

\begin{tabular}{|c|c|c|c|c|c|c|c|}
\hline$T$ & & $\begin{array}{l}\text { ENERGY } \\
\text { HARTREE }\end{array}$ & $\begin{array}{c}\text { EXCITATION } \\
\text { EV }\end{array}$ & $\begin{array}{c}\text { TRANSITION } \\
\mathrm{X}\end{array}$ & $\begin{array}{c}N \text { DIPOLE, } \\
Y\end{array}$ & $\begin{array}{c}\text { A. U. } \\
\text { Z }\end{array}$ & $\begin{array}{r}\text { OSCILLATOR } \\
\text { STRENGTH }\end{array}$ \\
\hline 0 & A & -2316.0972572290 & 0.000 & & & & \\
\hline 1 & A & -2316.0401920534 & 1.553 & $0.4516-$ & $-0.0562-$ & -0.0777 & 0.008 \\
\hline 2 & A & -2315.9955997331 & 2.766 & 0.2635 & 0.1775 & -0.0108 & 0.007 \\
\hline 3 & A & -2315.9809616855 & 3.165 & $-0.1987-$ & $-0.1586-$ & -0.1447 & 0.007 \\
\hline 4 & A & -2315.9728294554 & 3.386 & -1.1355 & 0.1546 & 0.1710 & 0.111 \\
\hline & A & -2315.9699111304 & 3.465 & 1.2890 & $2813-$ & -0.1532 & 0.150 \\
\hline
\end{tabular}

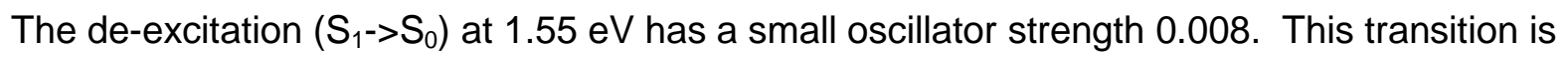
mainly between MO149 (HOMO) and MO150 (LUMO):

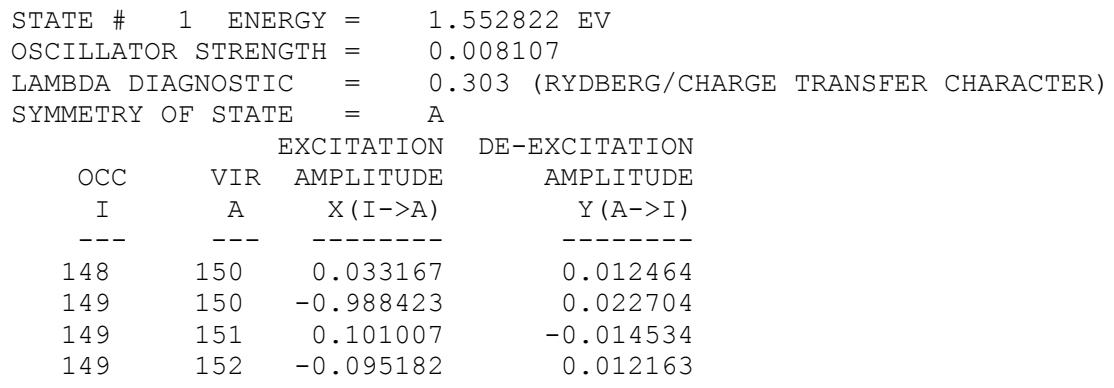

\section{The FixSol/B3LYP/6-31++G(d,p) optimized $S_{0}$ ground state geometry of 3 is:}

$\begin{array}{lrr}\mathrm{C} & 6.0 & 0.8875628470290 \\ \mathrm{C} & 6.0 & 0.0739299525622 \\ \mathrm{C} & 6.0 & -1.3289374725761 \\ \mathrm{C} & 6.0 & -1.9446305690987 \\ \mathrm{C} & 6.0 & -1.1764789162455 \\ \mathrm{C} & 6.0 & 0.1682879755685 \\ \mathrm{O} & 8.0 & 2.1129141843506 \\ \mathrm{H} & 1.0 & -1.7632024029603 \\ \mathrm{H} & 1.0 & -3.0251499632477 \\ \mathrm{H} & 1.0 & -1.6674631292923 \\ \mathrm{H} & 1.0 & 0.7258089025729 \\ \mathrm{~S} & 16.0 & -3.6480107066781 \\ \mathrm{O} & 8.0 & -4.2680010443568 \\ \mathrm{O} & 8.0 & -3.8174526221607 \\ \mathrm{~N} & 7.0 & -4.3646591671135 \\ \mathrm{H} & 1.0 & -5.7652391511379 \\ \mathrm{H} & 1.0 & -3.2263171444427 \\ \mathrm{C} & 6.0 & -1.9779106551687 \\ \mathrm{C} & 6.0 & -1.2814253567373 \\ \mathrm{C} & 6.0 & 0.0860115934470 \\ \mathrm{~N} & 7.0 & 0.7254476757039 \\ \mathrm{C} & 6.0 & 0.8821071879385 \\ \mathrm{~N} & 7.0 & 2.1877084711891 \\ \mathrm{C} & 6.0 & 3.1418296246019 \\ \mathrm{C} & 6.0 & 3.9400339441061 \\ \mathrm{O} & 8.0 & 0.3592794348076\end{array}$

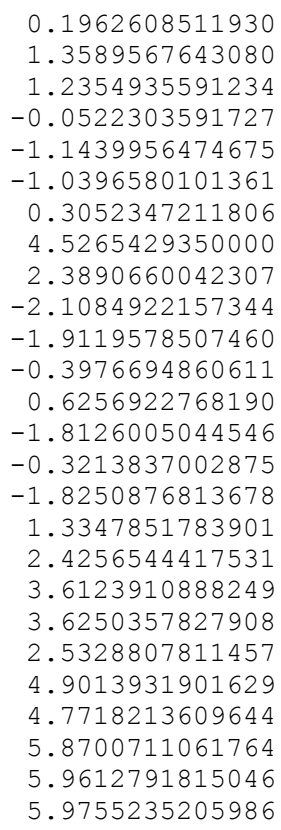

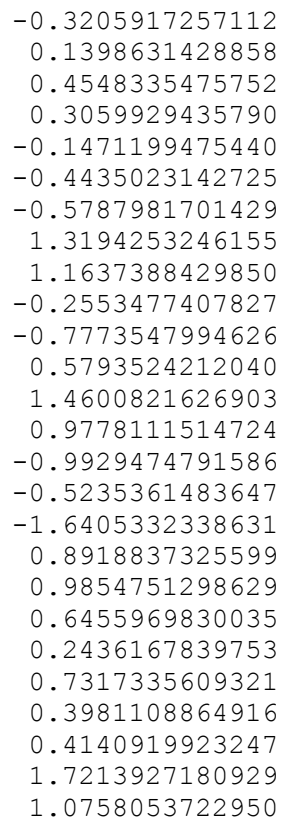




$\begin{array}{rrrrr}\mathrm{H} & 1.0 & 2.4900810692149 & 3.8304880244967 & 0.1565005335610 \\ \mathrm{H} & 1.0 & 2.5813578603980 & 6.7968190936456 & 0.2505230595071 \\ \mathrm{H} & 1.0 & 3.8244529362972 & 5.7343992345868 & -0.4340348192706 \\ \mathrm{H} & 1.0 & 4.6535019934689 & 6.7945342088693 & 1.6704226595375 \\ \mathrm{H} & 1.0 & 3.2697484441426 & 6.1317939419589 & 2.5712923181433 \\ \mathrm{H} & 1.0 & 4.5024249490109 & 5.0369999883685 & 1.9036282699699 \\ \mathrm{C} & 6.0 & -5.7417634849633 & -0.8453008661464 & -1.0058107462832 \\ \mathrm{C} & 6.0 & -4.2679339560855 & 1.0038363690727 & -1.6208649746589 \\ \mathrm{H} & 1.0 & -6.0415865225045 & -0.9580504044995 & -2.0543290704308 \\ \mathrm{H} & 1.0 & -4.6146373019598 & 0.9062476595865 & -2.6559015120118 \\ \mathrm{H} & 1.0 & -6.4541234193260 & -0.1707121955720 & -0.5034720486199 \\ \mathrm{H} & 1.0 & -4.8815386285101 & 1.7630877559345 & -1.1092406796239\end{array}$

The FixSol/TD-B3LYP/6-31++G(d,p) excitation energies for 3 . There are six transitions $\left(S_{1}, S_{3}\right.$, $\mathrm{S}_{8}, \mathrm{~S}_{9}, \mathrm{~S}_{10}, \mathrm{~S}_{11}$ ) with significant oscillator strengths:

\begin{tabular}{|c|c|c|c|c|c|c|c|}
\hline \multicolumn{2}{|c|}{ STATE } & $\begin{array}{l}\text { ENERGY } \\
\text { HARTREE }\end{array}$ & $\begin{array}{c}\text { EXCITATION } \\
\text { EV }\end{array}$ & $\begin{array}{c}\text { TRANSITIO } \\
\mathrm{X}\end{array}$ & $\begin{array}{c}\mathrm{N} \text { DIPOLE } \\
\mathrm{Y}\end{array}$ & A.U. & $\begin{array}{r}\text { OSCILLATOR } \\
\text { STRENGTH }\end{array}$ \\
\hline 0 & A & -1405.9854977807 & 0.000 & & & & \\
\hline 1 & A & -1405.8777931217 & 2.931 & 0.5328 & -1.0693 & -0.3722 & 0.112 \\
\hline 2 & A & -1405.8589972197 & 3.442 & 0.0084 & 0.0101 & 0.0271 & 0.000 \\
\hline 3 & A & -1405.8529190414 & 3.608 & -1.1417 & -1.2468 & -0.1257 & 0.254 \\
\hline 4 & A & -1405.8346220901 & 4.106 & -0.0828 & 0.0231 & -0.1128 & 0.002 \\
\hline 5 & A & -1405.8344136743 & 4.111 & -0.6426 & 0.0449 & -0.0691 & 0.042 \\
\hline 6 & A & -1405.8285525510 & 4.271 & -0.0009 & -0.0095 & -0.0130 & 0.000 \\
\hline 7 & A & -1405.8280816590 & 4.284 & -0.2185 & -0.0295 & -0.0088 & 0.005 \\
\hline 8 & A & -1405.8188541805 & 4.535 & -0.9995 & -0.2417 & 0.2304 & 0.123 \\
\hline 9 & A & -1405.8179628404 & 4.559 & 0.8549 & 0.1608 & -0.0936 & 0.085 \\
\hline 10 & A & -1405.8146893608 & 4.648 & -0.5259 & -1.5237 & -0.3058 & 0.307 \\
\hline 11 & A & -1405.8129994288 & 4.694 & -1.1005 & -0.5991 & 0.0472 & 0.181 \\
\hline 12 & A & -1405.8112995093 & 4.740 & 0.0221 & -0.2563 & -0.1141 & 0.009 \\
\hline 13 & A & -1405.8101177264 & 4.772 & -0.3227 & -0.3041 & -0.0299 & 0.023 \\
\hline 1 & A & -1405.8096805490 & 4.784 & 0.1415 & -0.1316 & 0.0006 & 0.004 \\
\hline 15 & A & -1405.8070830999 & 4.855 & -0.0860 & -0.1038 & 0.1038 & 0.003 \\
\hline
\end{tabular}

\section{The FixSol/TD-B3LYP/6-31++G(d,p) optimized $\mathrm{S}_{1}$ state geometry of $\mathbf{3}$ is:}

$\begin{array}{lrr}\mathrm{C} & 6.0 & 0.8590342506798 \\ \mathrm{C} & 6.0 & 0.0993847053895 \\ \mathrm{C} & 6.0 & -1.2728446324540 \\ \mathrm{C} & 6.0 & -1.9260996835629 \\ \mathrm{C} & 6.0 & -1.2221947322017 \\ \mathrm{C} & 6.0 & 0.1417571552564 \\ \mathrm{O} & 8.0 & 2.0893147825080 \\ \mathrm{H} & 1.0 & -1.7054090471208 \\ \mathrm{H} & 1.0 & -2.9927353511257 \\ \mathrm{H} & 1.0 & -1.7343456555846 \\ \mathrm{H} & 1.0 & 0.7143943773348 \\ \mathrm{~S} & 16.0 & -3.6900559641948 \\ \mathrm{O} & 8.0 & -4.2523063925851 \\ \mathrm{O} & 8.0 & -3.8743466134677 \\ \mathrm{~N} & 7.0 & -4.3457851149298 \\ \mathrm{H} & 1.0 & -5.5271012004922 \\ \mathrm{H} & 1.0 & -3.3989135631755 \\ \mathrm{C} & 6.0 & -1.9557860677282 \\ \mathrm{C} & 6.0 & -1.2312691962167 \\ \mathrm{C} & 6.0 & 0.1251176207016 \\ \mathrm{~N} & 7.0 & 0.8141993351106 \\ \mathrm{C} & 6.0 & 0.8911685541124 \\ \mathrm{~N} & 7.0 & 2.2192771176936 \\ \mathrm{C} & 6.0 & 3.1827199643003 \\ \mathrm{C} & 6.0 & 3.8556999908295 \\ \mathrm{O} & 8.0 & 0.3851351419336 \\ \mathrm{H} & 1.0 & 2.5191753275352 \\ \mathrm{H} & 1.0 & 2.6599644507533 \\ \mathrm{H} & 1.0 & 3.9460499640438\end{array}$

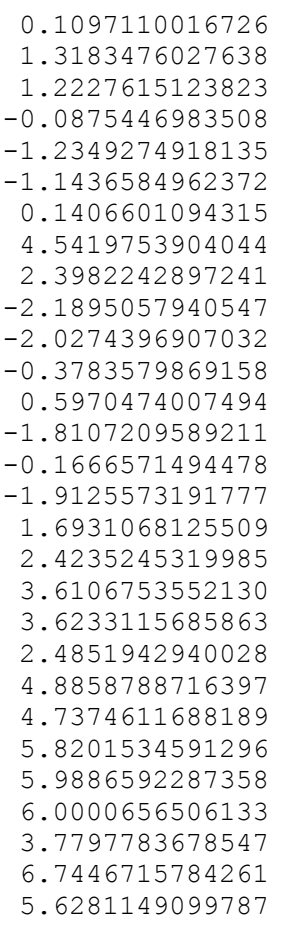

$-0.2362107594148$

0.1402001956382

0.4439160272556

0.3382804355918

$-0.0100577016258$

$-0.2851401405416$

$-0.5019322828116$

1.1784860576925

1.1442514278402

$-0.0724132459776$

$-0.5570398525801$

0.5975042117191

1.5546278833217

0.9038915306732

$-0.9679988704594$

$-0.8476989580656$

$-1.3466779673470$

0.8432959818169

0.8793942429666

0.5462592749745

0.1845734834317

0.6024764340735

0.3072651455054

0.3538685036776

1.7253840898254

0.8877166137156

0.1406399982856

0.0835563417775

$-0.4118978464419$ 


$\begin{array}{rr}1.0 & 4.5842042628022 \\ 1.0 & 3.1077753414033 \\ 1.0 & 4.3828316077832 \\ 6.0 & -5.6264155232130 \\ 6.0 & -4.3841868834827 \\ 1.0 & -5.8489062818146 \\ 1.0 & -4.6590308932409 \\ 1.0 & -6.4559212297470 \\ 1.0 & -5.1175322533500\end{array}$

6.8108478425694

6.2182390306708

5.0717803973890

$-0.8722757074583$

1.2298436783943

$-0.8437799473772$

1.2098693485524

$-0.3993862171545$

1.8360967438842

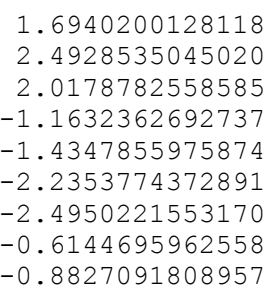

1.6940200128118

178782545020

$-1.4347855975874$

$-2.2353774372891$

$-0.6144695962558$

$-0.8827091808957$

The FixSol/TD-B3LYP/6-31++G(d,p) fluorescent de-excitation energy $\left(\mathrm{S}_{1}->\mathrm{S}_{0}\right)$ for 3 at the optimized $\mathrm{S}_{1}$ state geometry is $2.41 \mathrm{eV}$ with an oscillator strength 0.074 :

\begin{tabular}{|c|c|c|c|c|c|c|c|}
\hline $\mathrm{ST}$ & & $\begin{array}{l}\text { ENERGY } \\
\text { HARTREF }\end{array}$ & $\begin{array}{c}\text { EXCITATION } \\
\text { EV }\end{array}$ & $\begin{array}{c}\text { TRANS ITION } \\
X\end{array}$ & $\begin{array}{c}N \text { DIPOLE, } \\
\text { Y }\end{array}$ & $\therefore, A \cdot U$. & $\begin{array}{r}\text { OSCILLATOR } \\
\text { STRENGTH }\end{array}$ \\
\hline 0 & A & -1405.9753918641 & 0.000 & & & & \\
\hline 1 & A & -1405.8867560907 & 2.412 & $0.4453-$ & $-0.9883-$ & -0.2863 & 0.074 \\
\hline 2 & A & -1405.8613557896 & 3.103 & $-0.0005-$ & $-0.0230-$ & -0.0253 & 0.000 \\
\hline 3 & A & -1405.8499430267 & 3.414 & -0.9958 & $-1.3485-$ & -0.1233 & 0.236 \\
\hline 4 & A & -1405.8324395052 & 3.890 & $0.6421-$ & -0.0951 & 0.0894 & 0.041 \\
\hline 5 & A & -1405.8263515177 & 4.056 & 0.0974 & 0.0181 & 0.1058 & 0.002 \\
\hline
\end{tabular}


Table S1. Detection limits of representative probes for fluoride in aqueous samples.

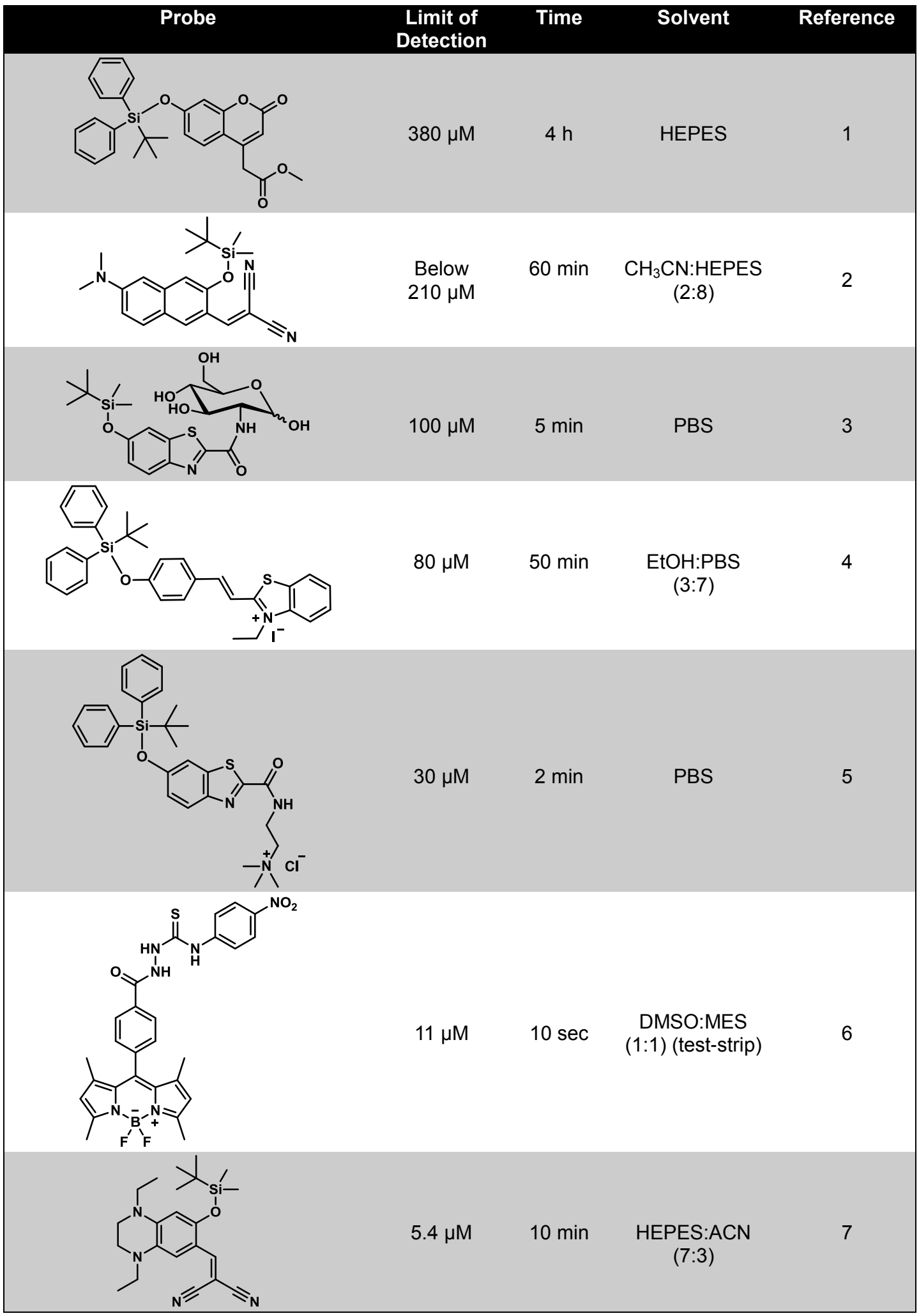




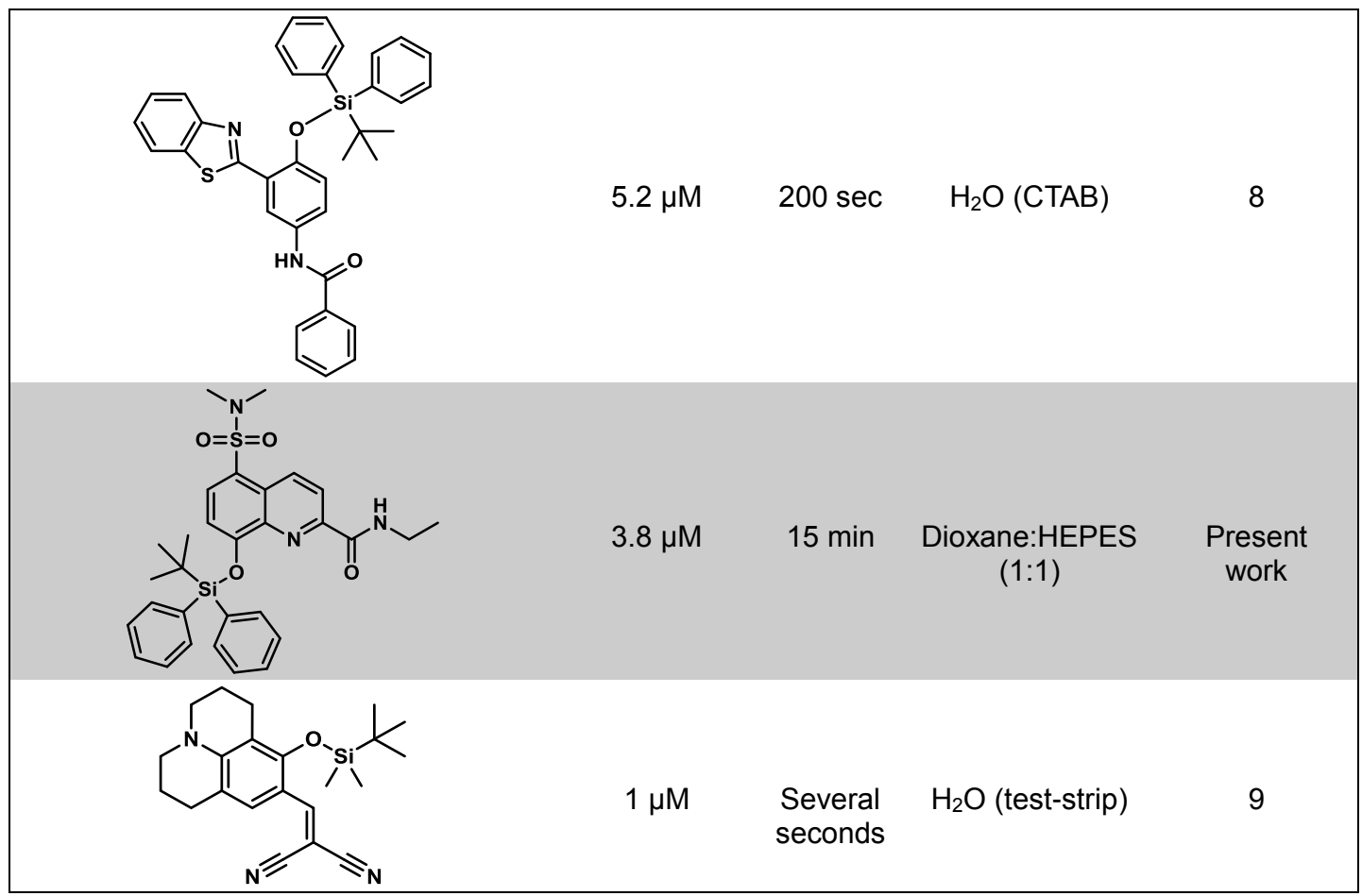


Figure $\mathbf{~} 1$

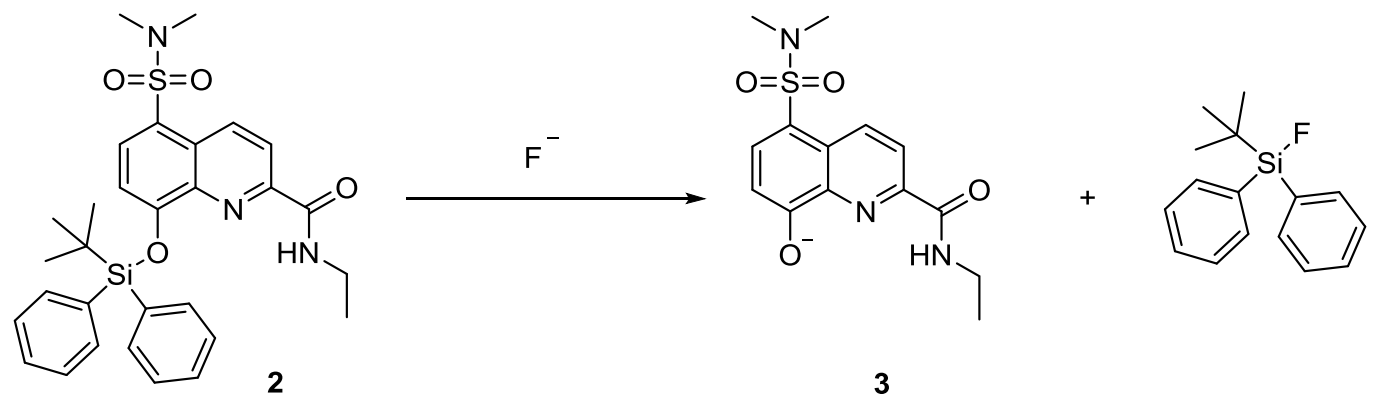

Reaction of fluoride sensor $\mathbf{2}$ with fluoride anion to produce the desilylated product 3. 


\section{Figure S2}

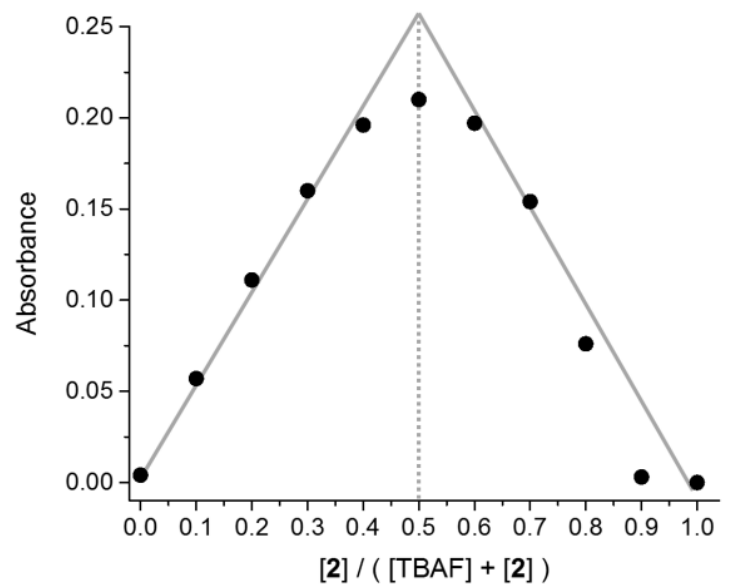

A Job plot of 2 with TBAF. [TBAF] + [2] = $200 \mu \mathrm{M}$ in dioxane. The absorbance was recorded 15 min after 2 and TBAF were mixed. 


\section{Figure S3}

(A)
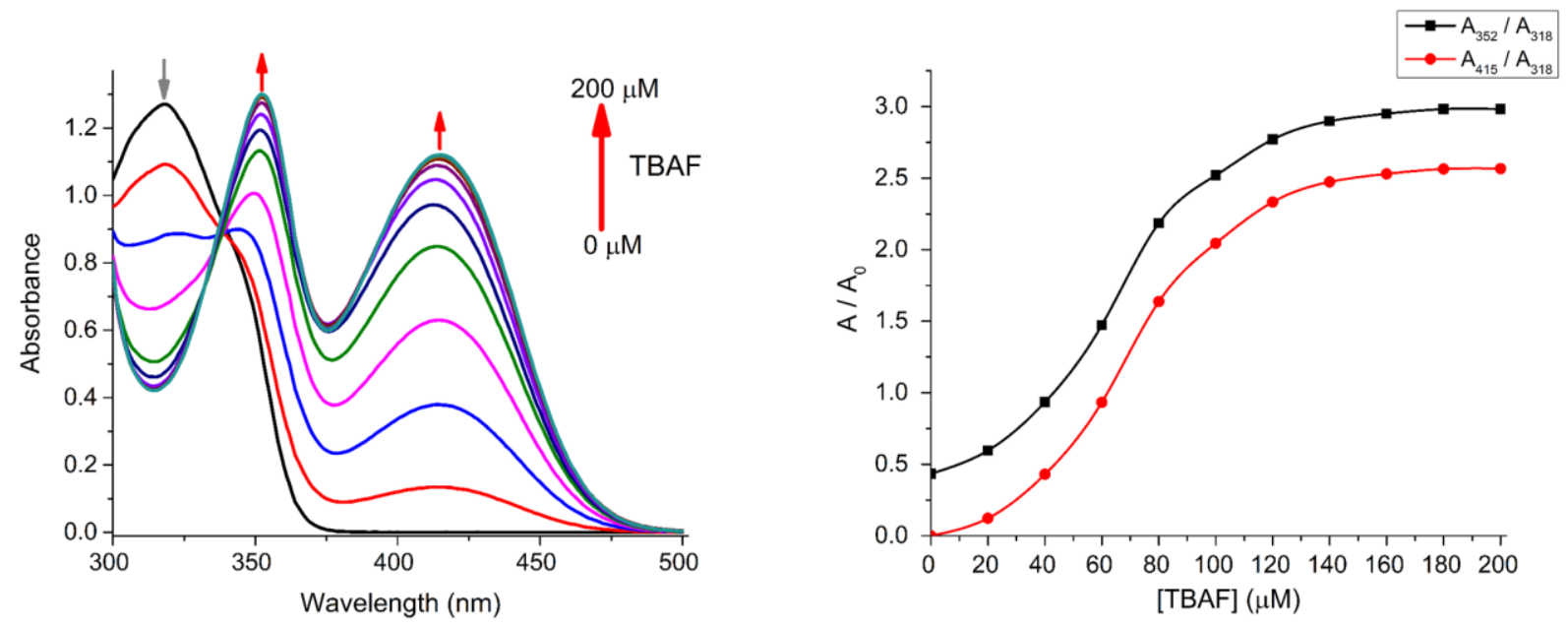

(B)
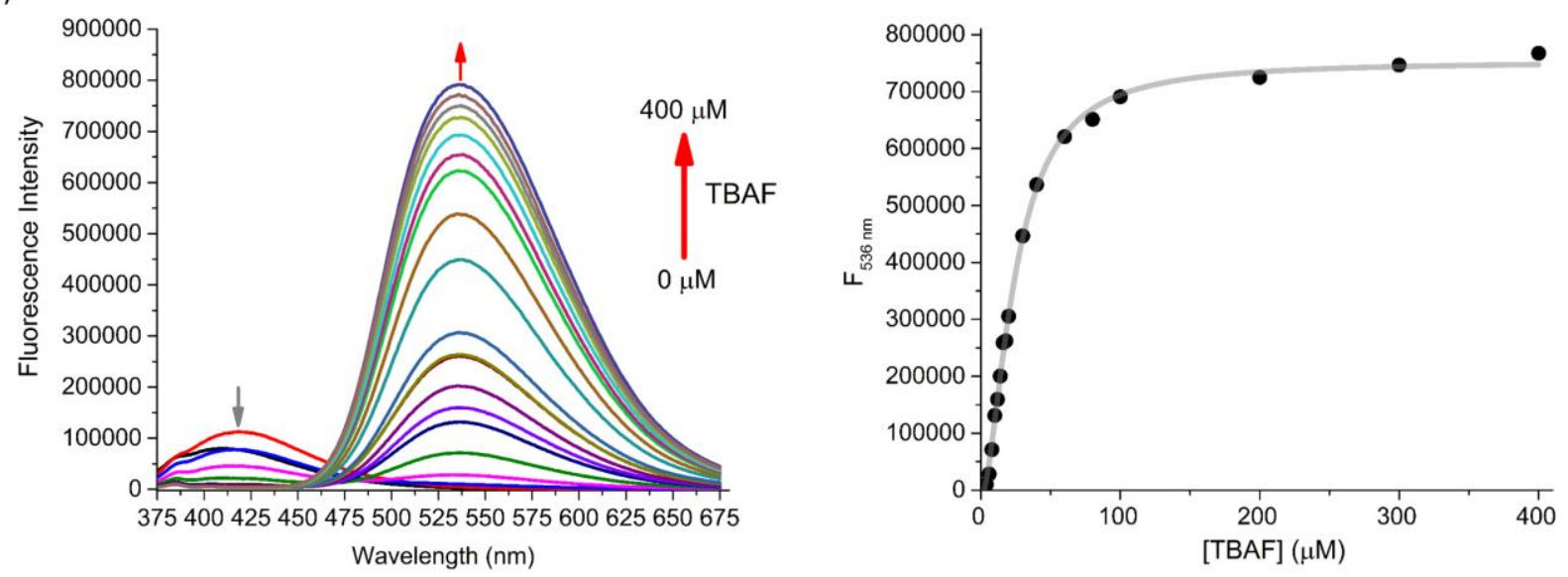

(C)
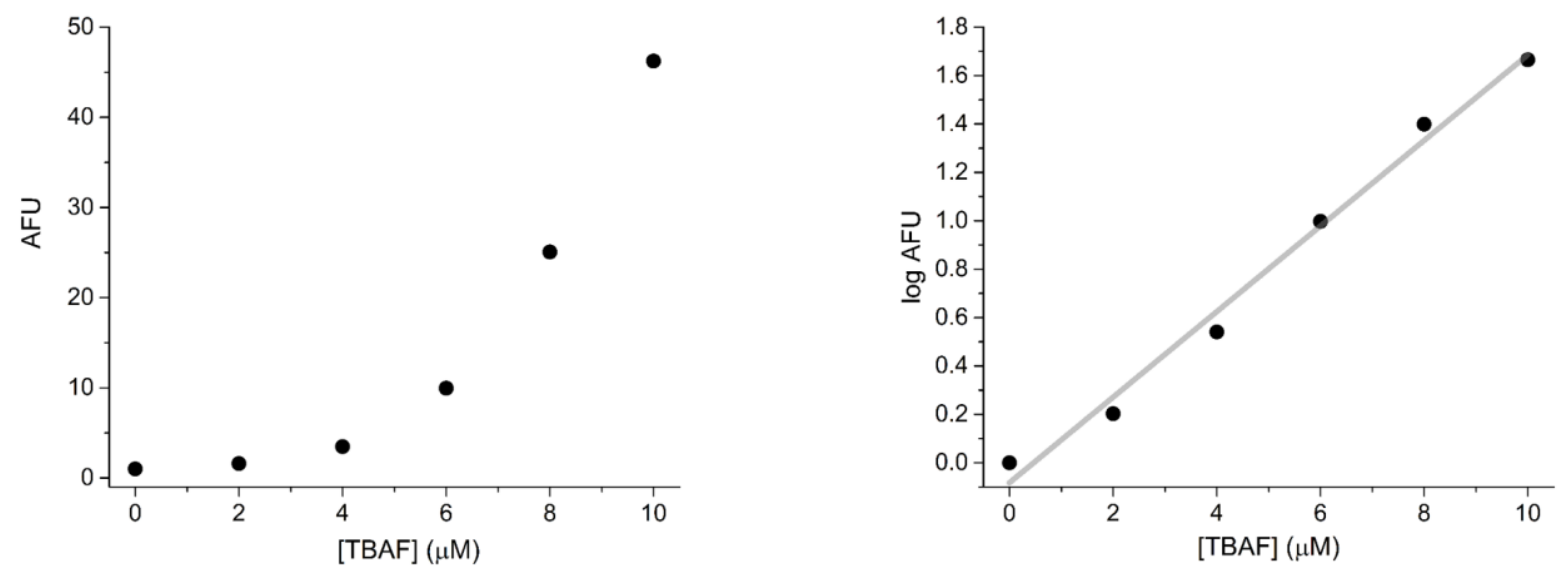

The absorbance (A) and fluorescence (B) titration of $2(20 \mu \mathrm{M})$ in dioxane. (C) The limit of detection of $2(20 \mu \mathrm{M})$ in dioxane. $\left(y=0.17672 x-0.08282, R^{2}=0.987\right)$ 
Figure S4

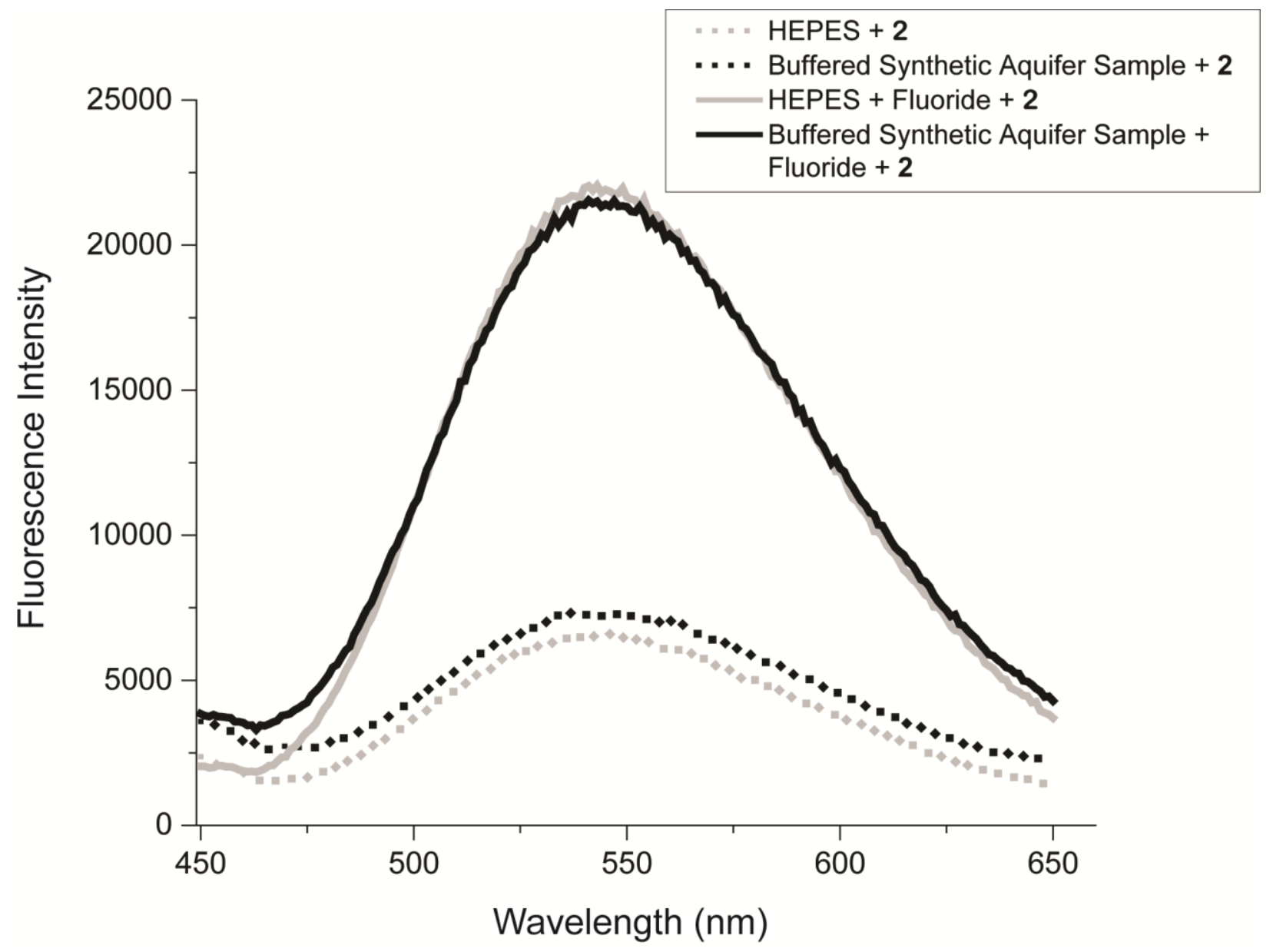

The fluorescence emission spectra of fluoride probe $2(20 \mu \mathrm{M})$ in the absence or presence of $100 \mu \mathrm{M} \mathrm{NaF}$. Assays were conducted in 50:50 (v/v) $10 \mathrm{mM} \mathrm{HEPES}(\mathrm{pH}=7.4)$ :dioxane or 50:50 $(\mathrm{v} / \mathrm{v})$ buffered synthetic aquifer sample:dioxane. 
Figure S5

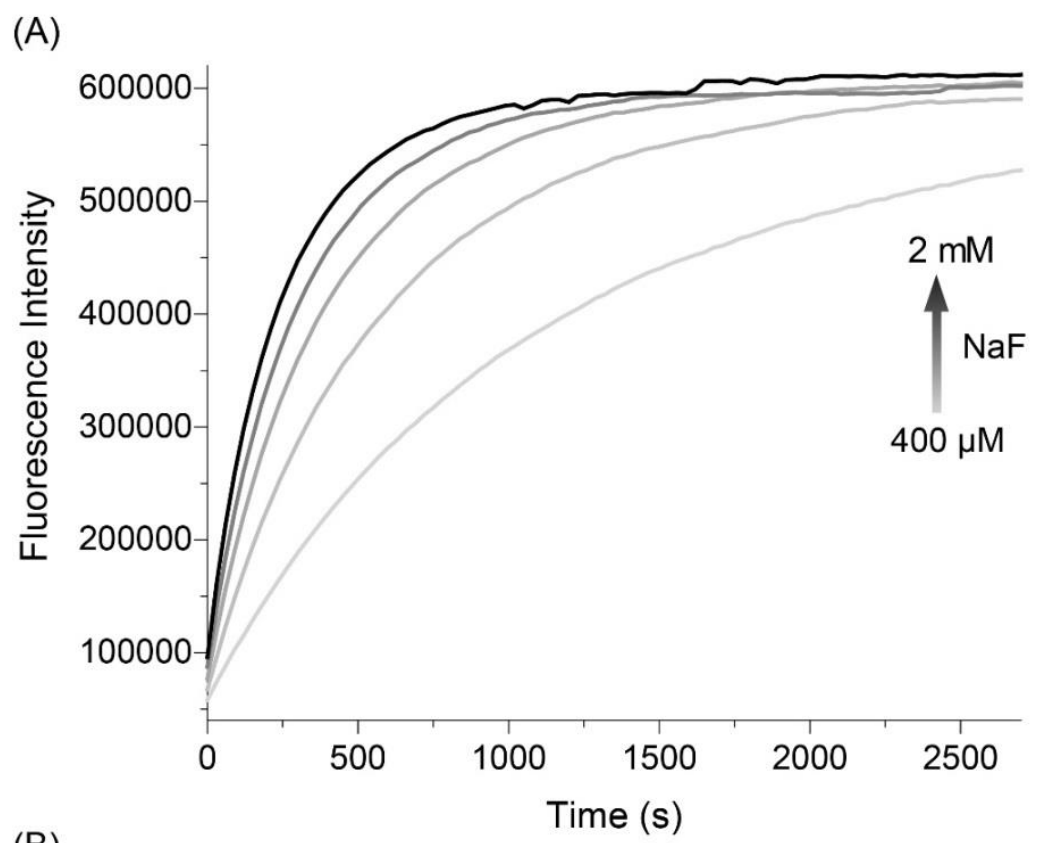

(B)

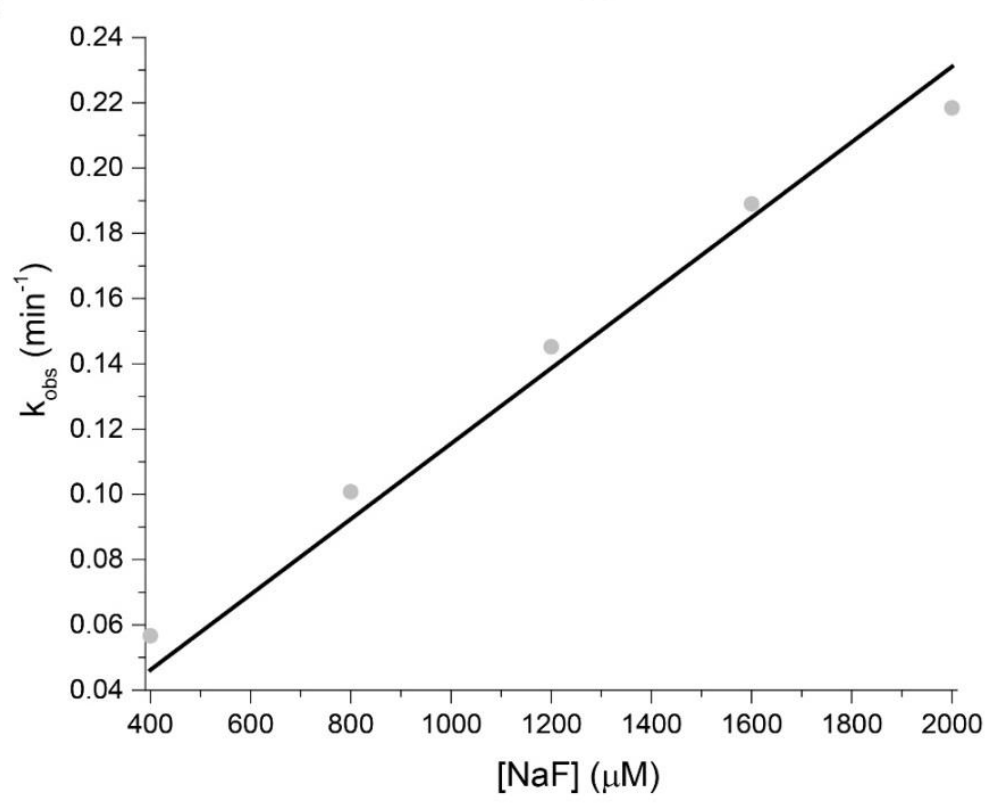

(A) The fluorescence increase of $2(20 \mu \mathrm{M})$ in the presence of increasing concentrations of $\mathrm{NaF}$ $(400 \mu \mathrm{M}$ to $2 \mathrm{mM})$ in a 50:50 (v/v) solution of HEPES buffer $(10 \mathrm{mM}, \mathrm{pH}=7.4)$ :dioxane. (B) The observed pseudo-first-order rate constant as a function of $\mathrm{NaF}$ concentration. The excitation and emission wavelengths were $393 \mathrm{~nm}$ and $542 \mathrm{~nm}$, respectively. The second order rate constant was calculated to be $1.16 \times 10^{2} \mathrm{M}^{-1} \mathrm{~min}^{-1}$. (Linear fit: $\mathrm{y}=1.16 \times 10^{-4} \mathrm{x}, \mathrm{R}^{2}=0.996$ ). 


\section{Figure S6}

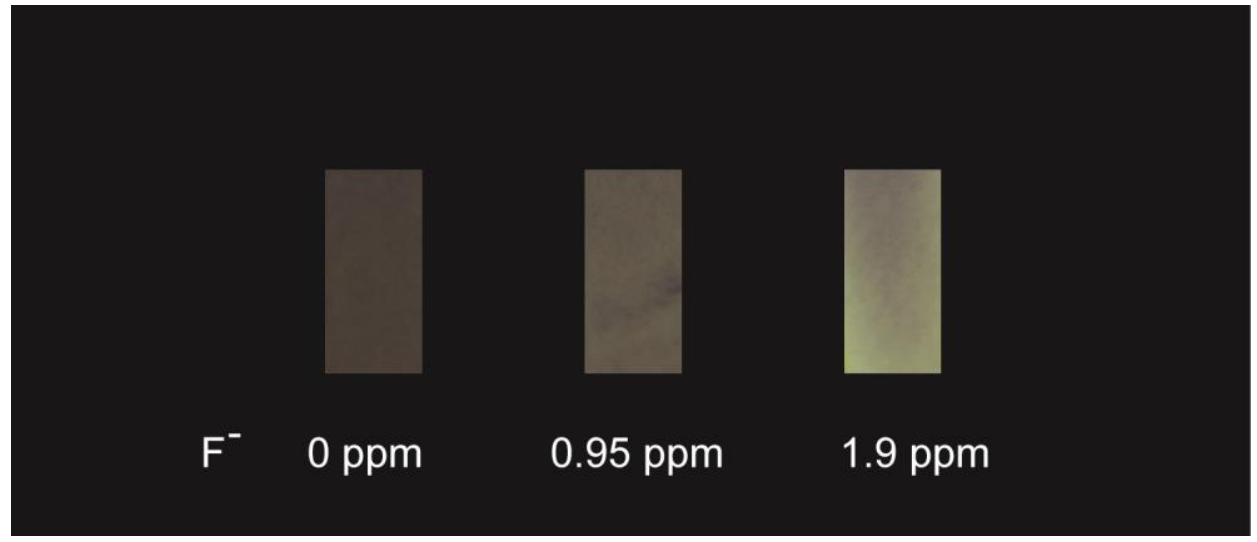

Test-strips of probe 4 in the presence of the indicated concentration of $\mathrm{NaF}$ in $5 \mathrm{mM}$ acetate $(\mathrm{pH}$ $=4.8$ ) buffered synthetic aquifer samples. 


\section{Copies of 1H and 13C NMR Spectra}

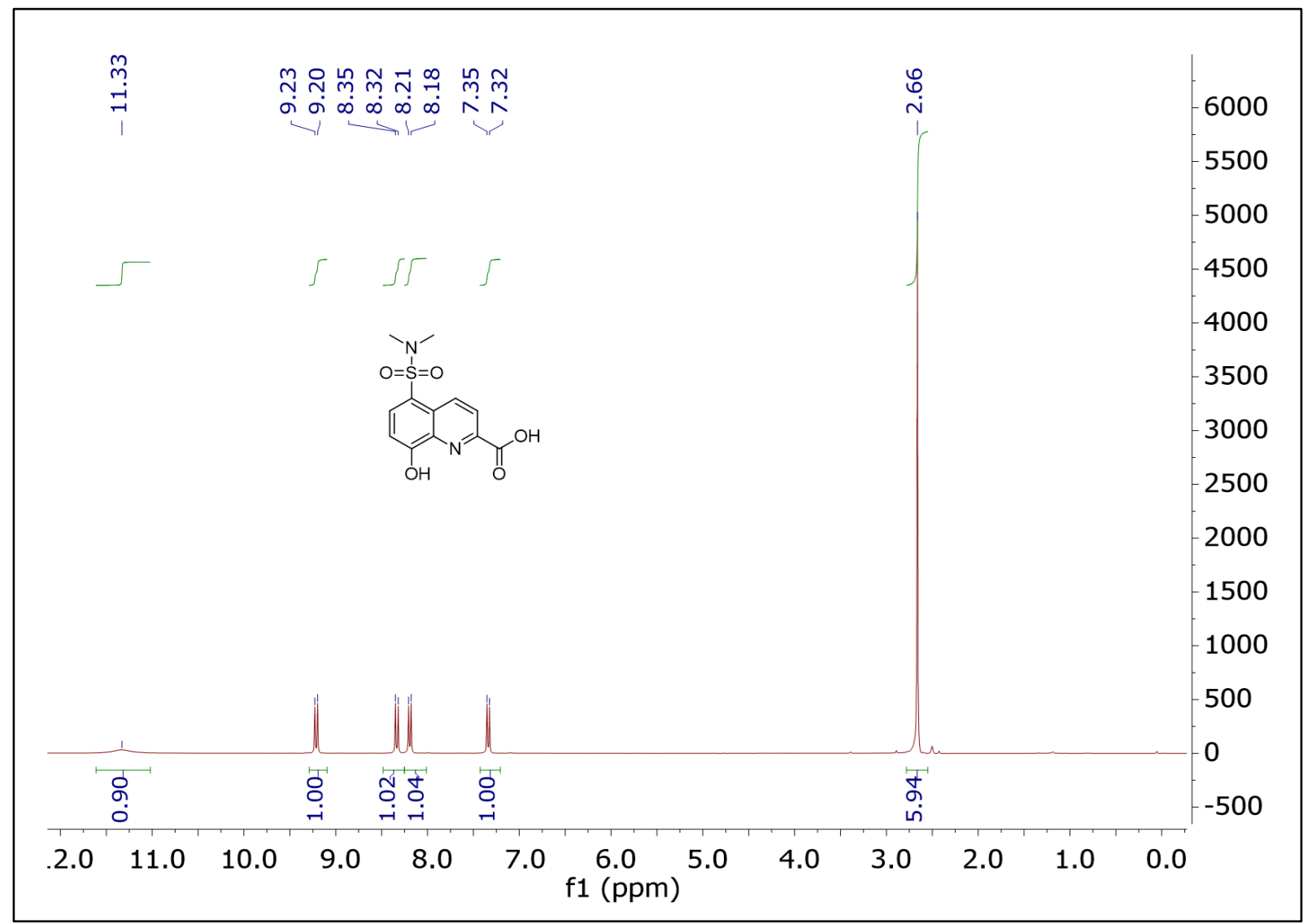

${ }^{1} \mathrm{H}$ NMR chart of 1 in DMSO- $\mathrm{d}_{6}(300 \mathrm{MHz})$ 


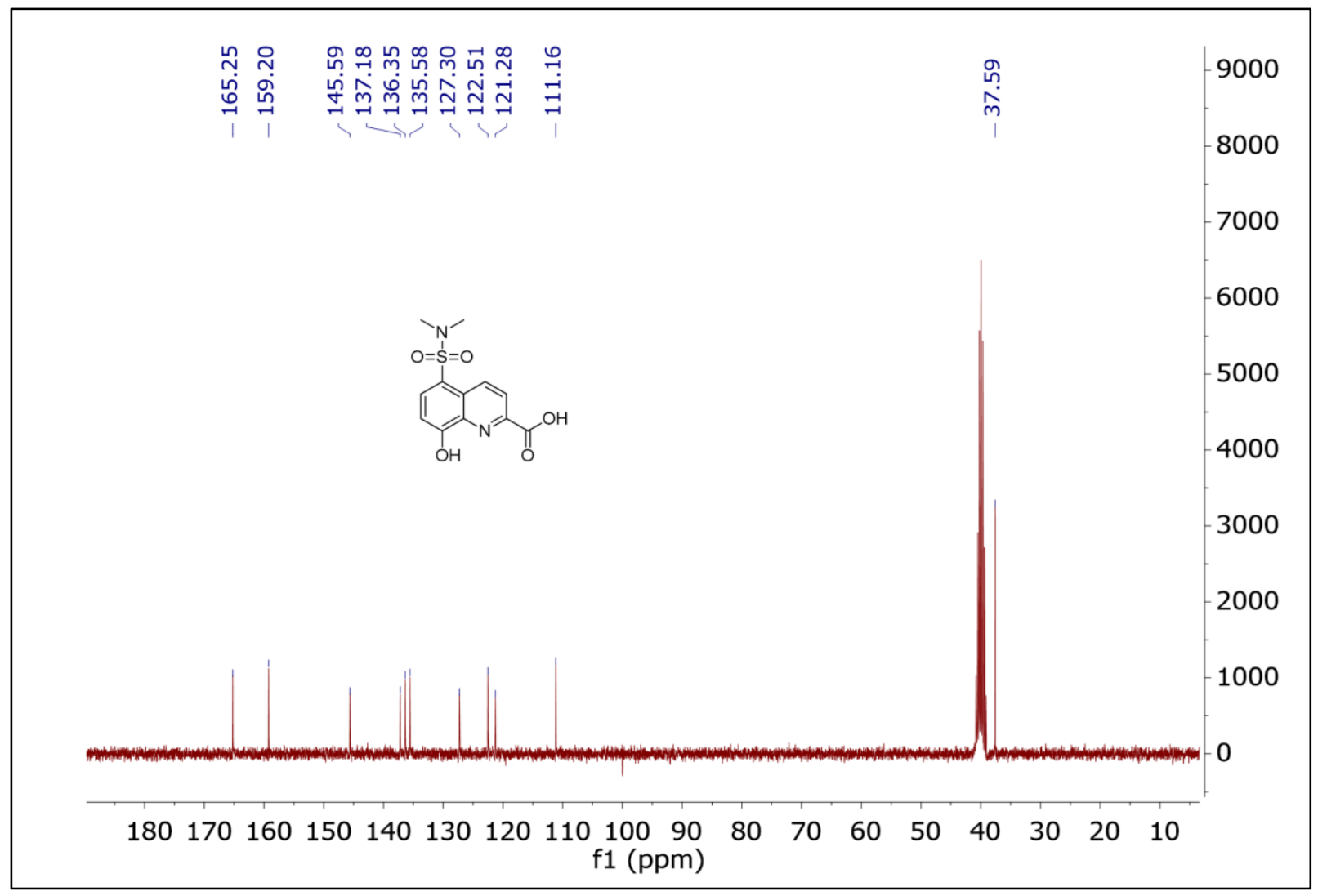

${ }^{13} \mathrm{C}$ NMR chart of 1 in DMSO-d 6 (75 MHz) 


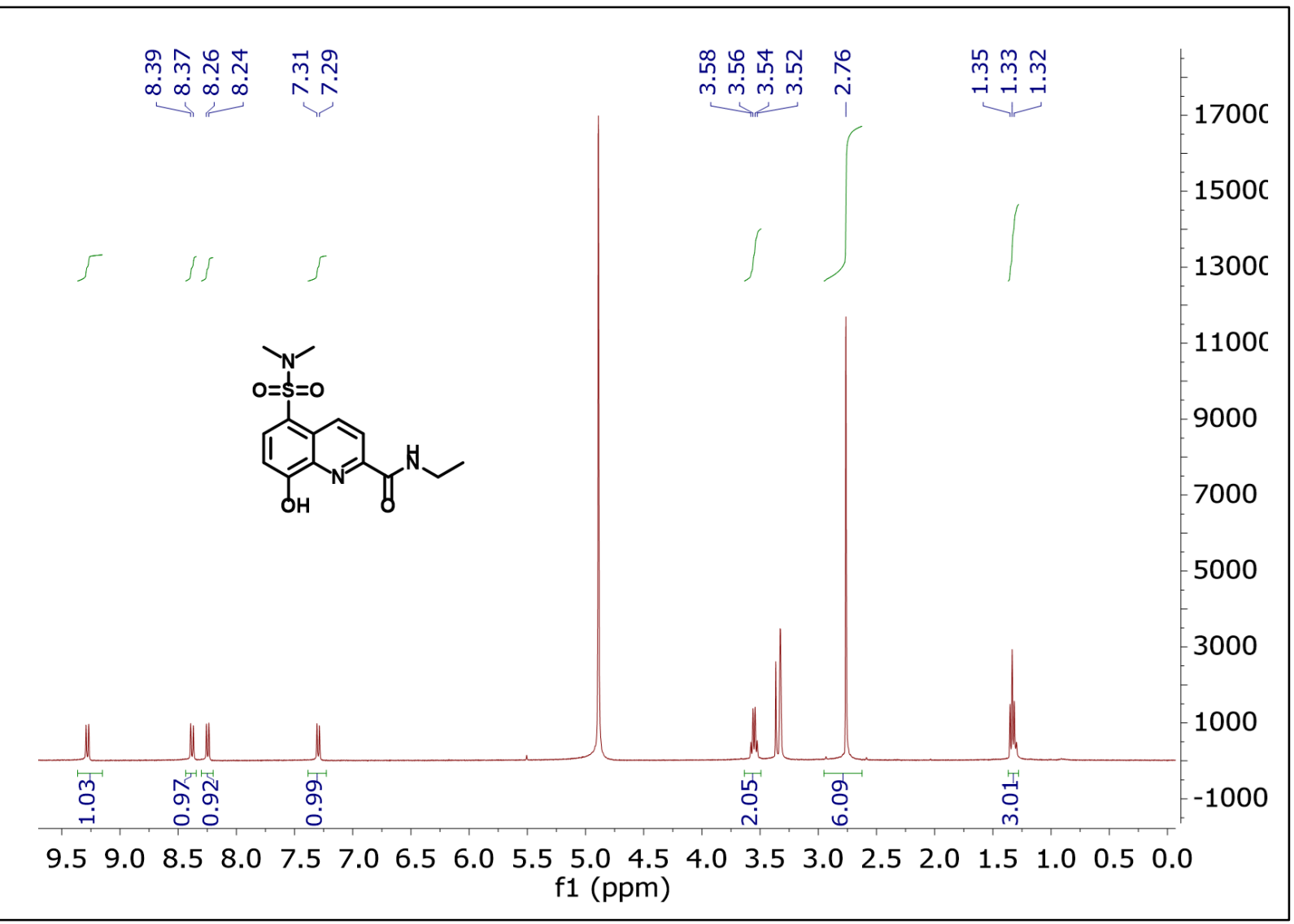

${ }^{1} \mathrm{H}$ NMR chart of 2a in Methanol- $\mathrm{d}_{4}(400 \mathrm{MHz})$ 


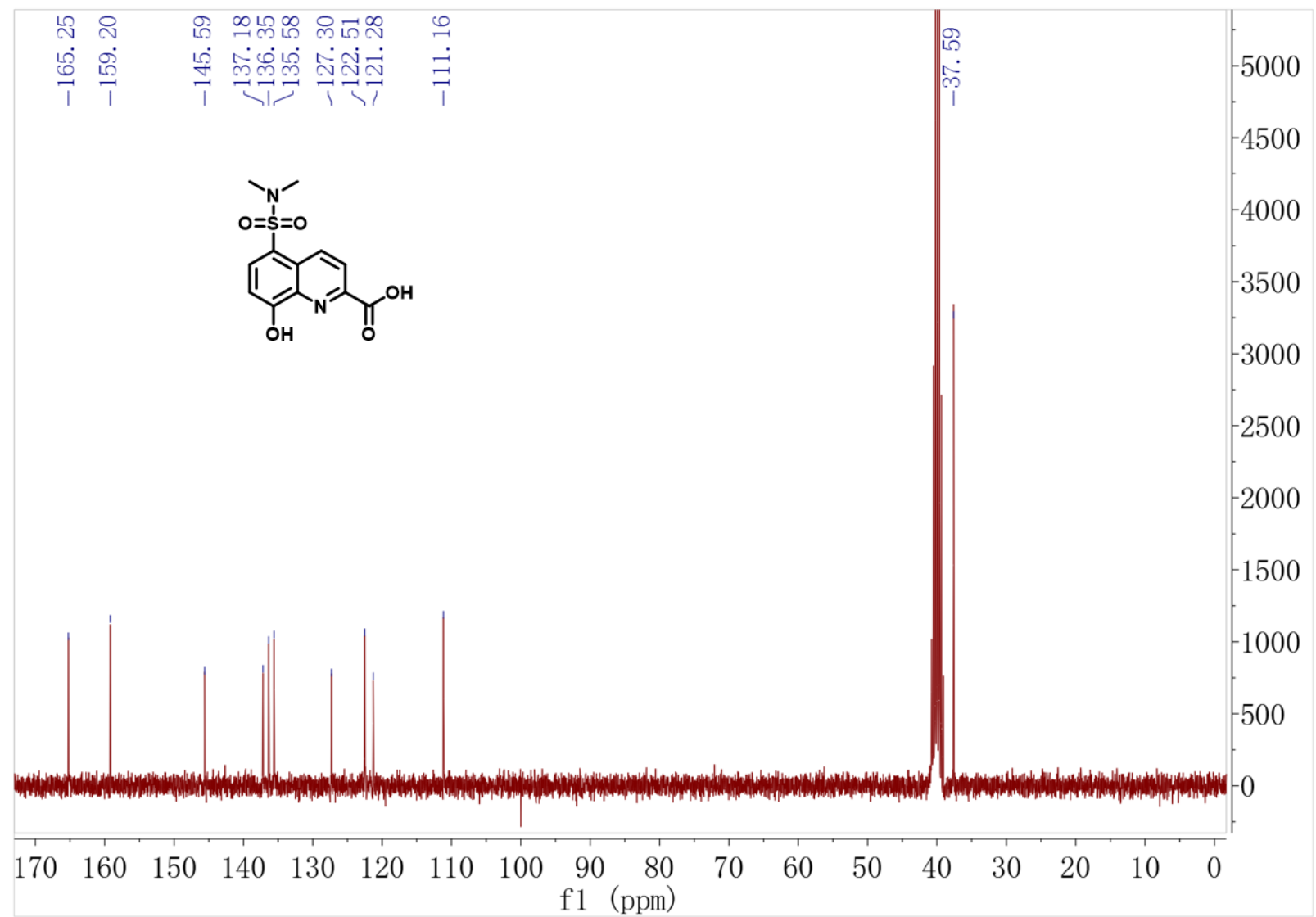

${ }^{13} \mathrm{C}$ NMR chart of $2 \mathbf{a}$ in Methanol- $\mathrm{d}_{4}(101 \mathrm{MHz})$ 


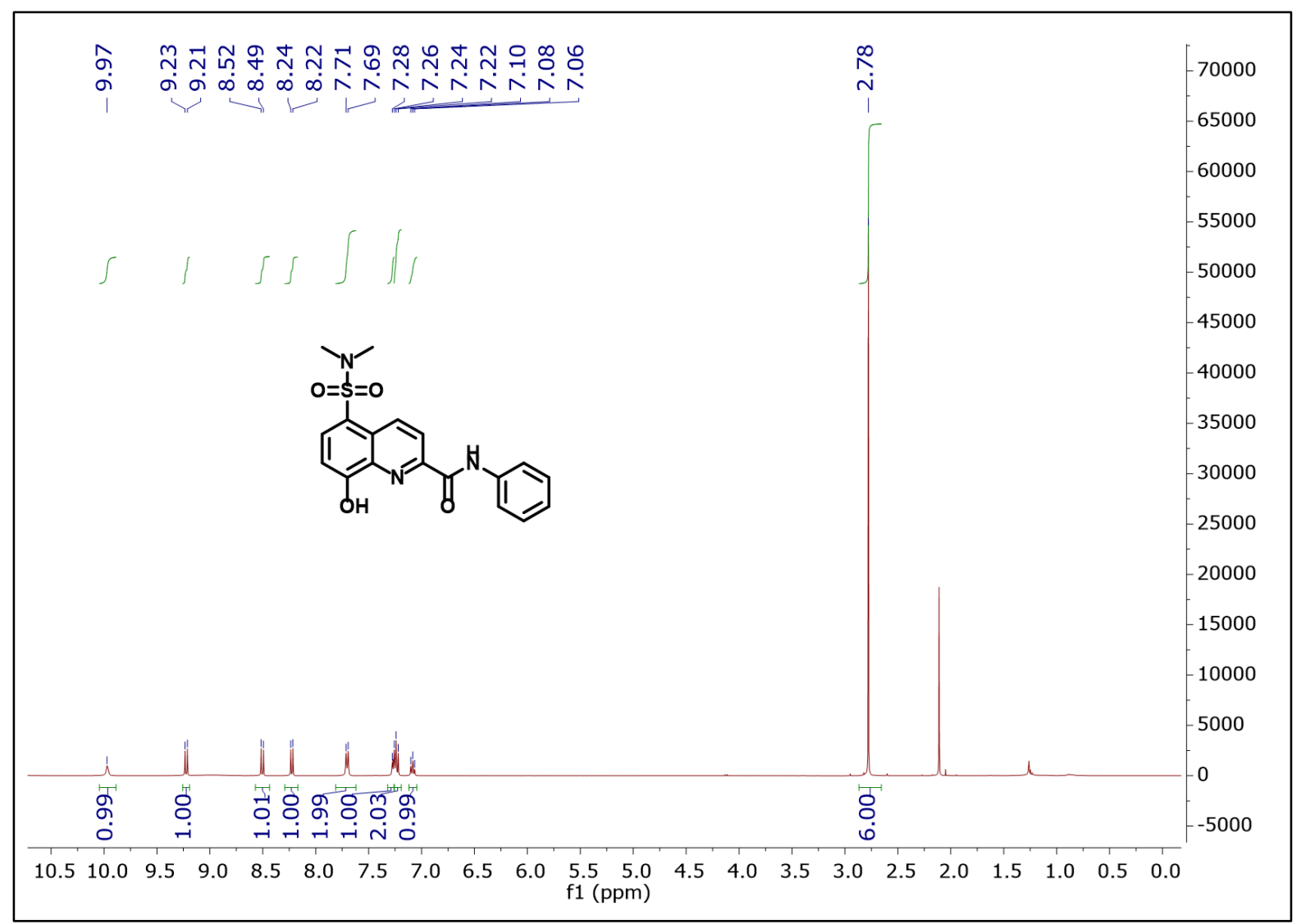

${ }^{1} \mathrm{H}$ NMR chart of $\mathbf{4 a}$ in $\mathrm{CDCl}_{3}(400 \mathrm{MHz})$ 


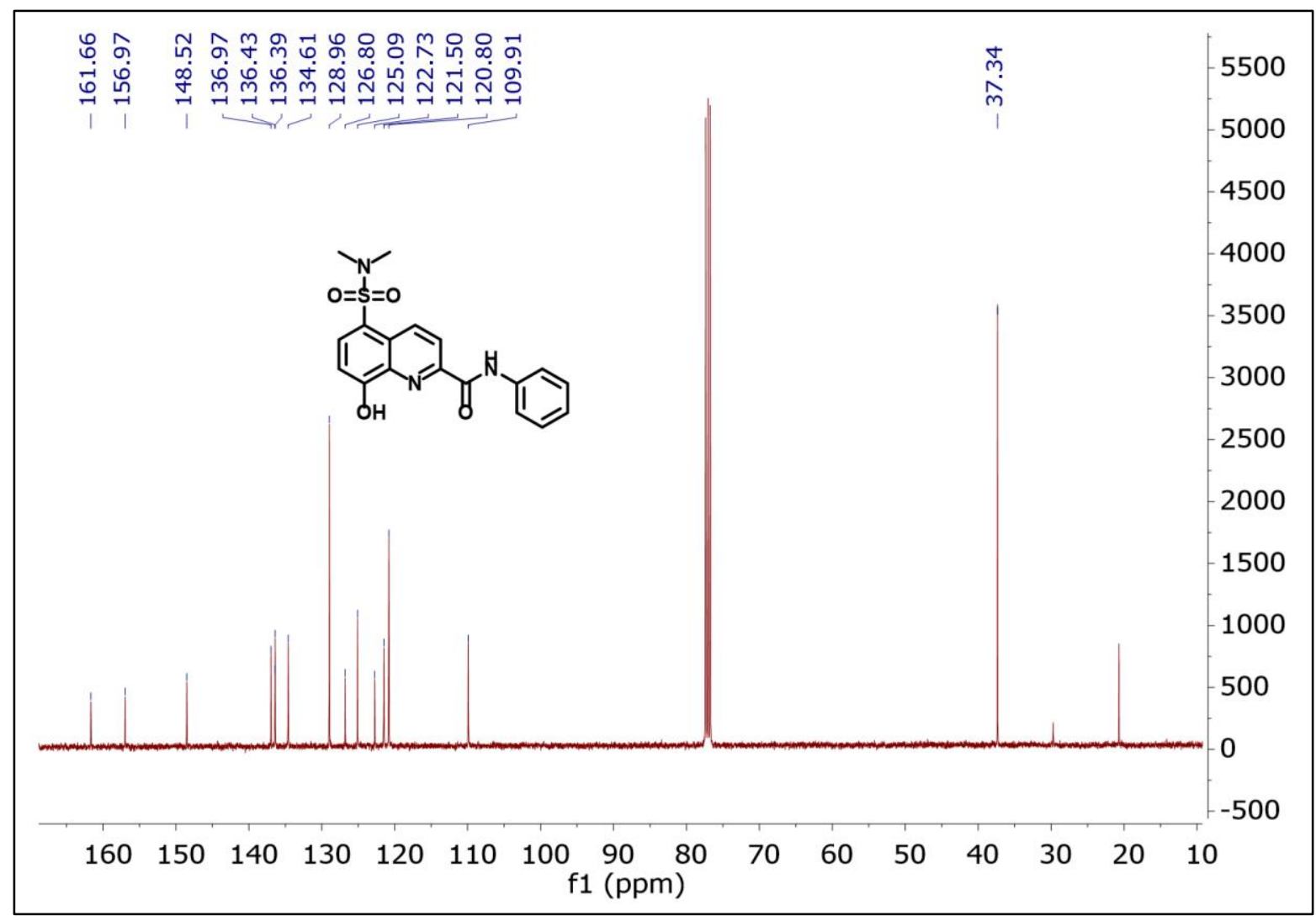

${ }^{13} \mathrm{C}$ NMR chart of $4 a$ in $\mathrm{CDCl}_{3}(101 \mathrm{MHz})$ 


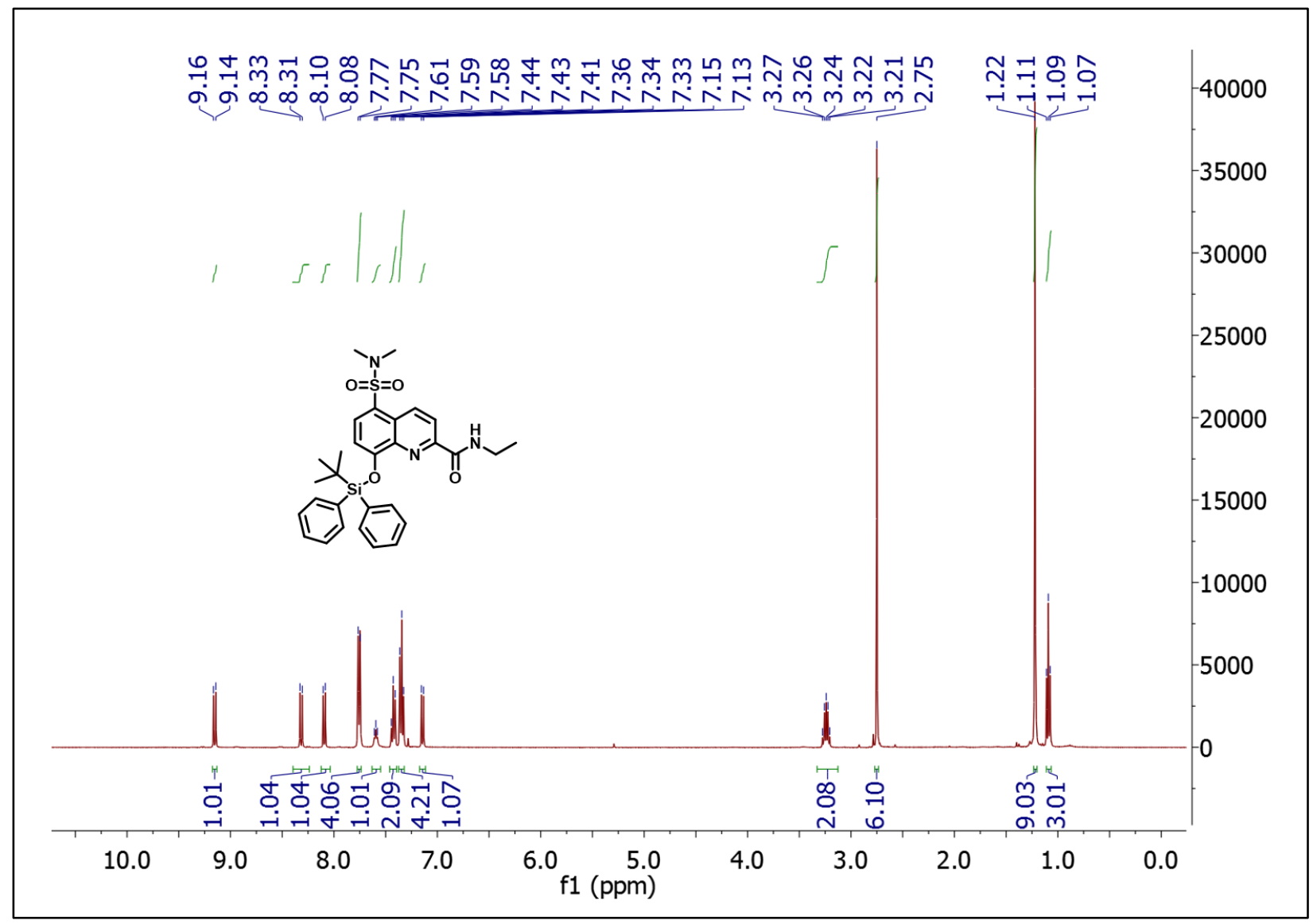

${ }^{1} \mathrm{H}$ NMR chart of 2 in $\mathrm{CDCl}_{3}(400 \mathrm{MHz})$ 


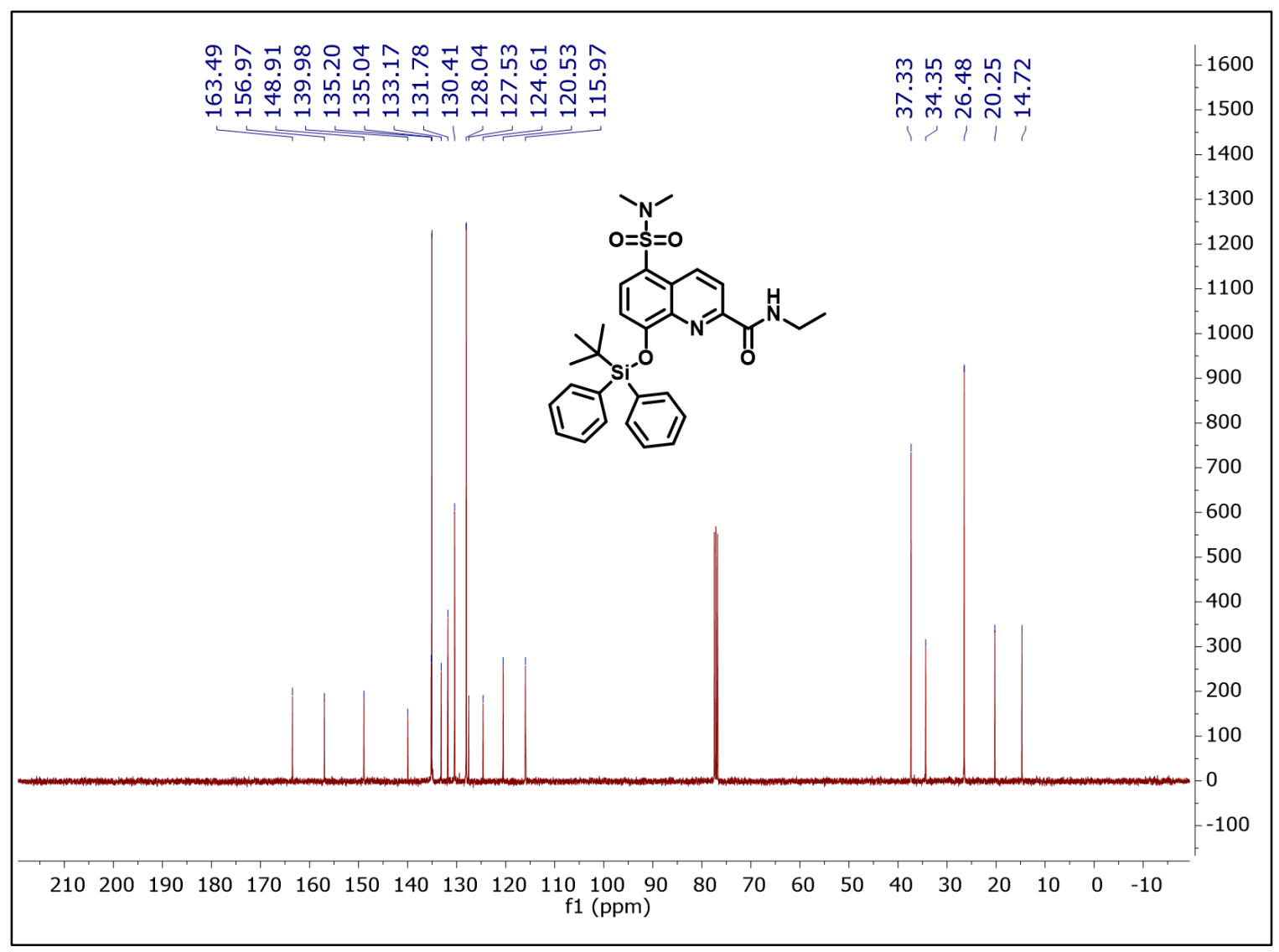

${ }^{13} \mathrm{C}$ NMR chart of 2 in $\mathrm{CDCl}_{3}(101 \mathrm{MHz})$ 


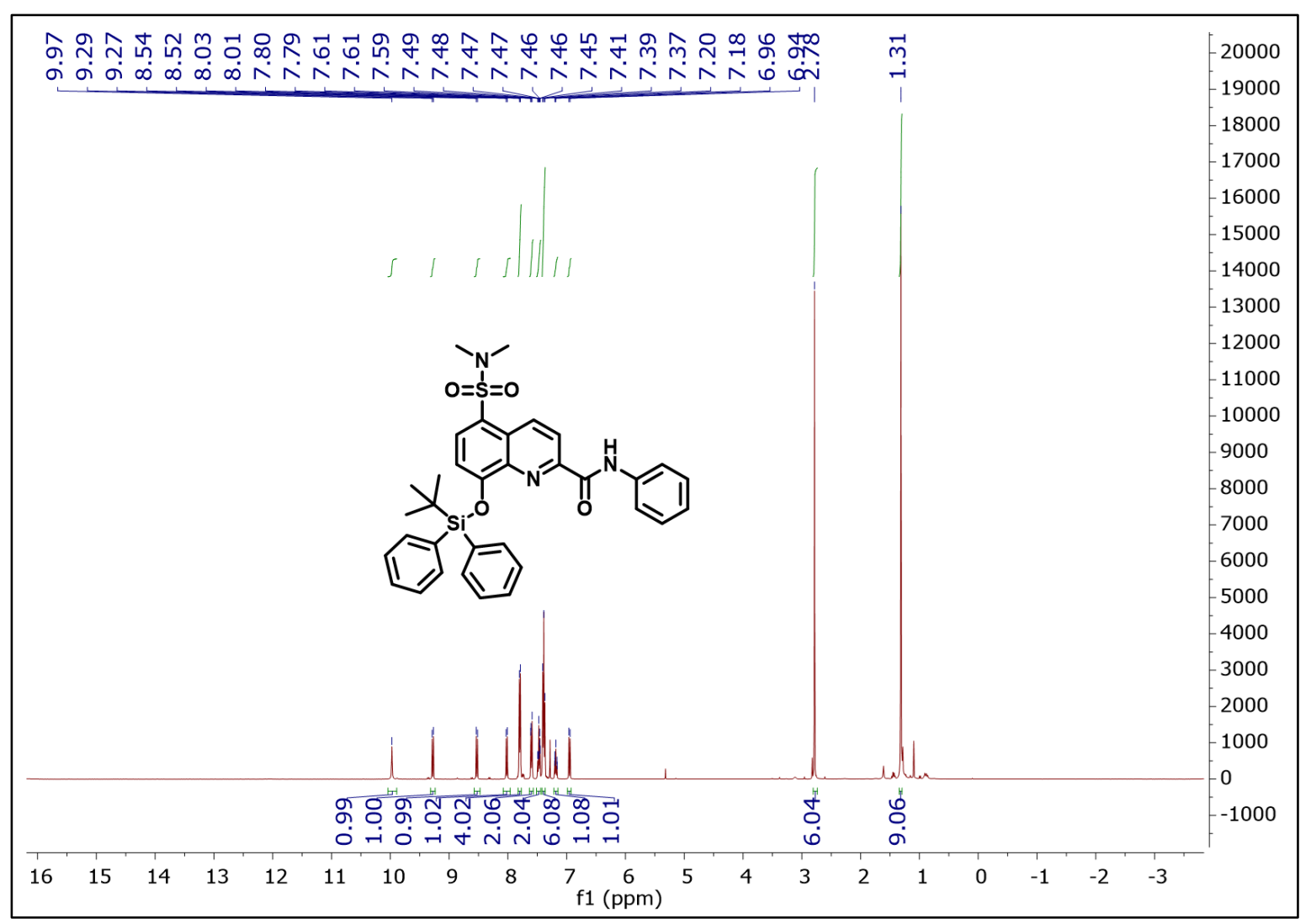

${ }^{1} \mathrm{H}$ NMR chart of 4 in $\mathrm{CDCl}_{3}(400 \mathrm{MHz})$ 


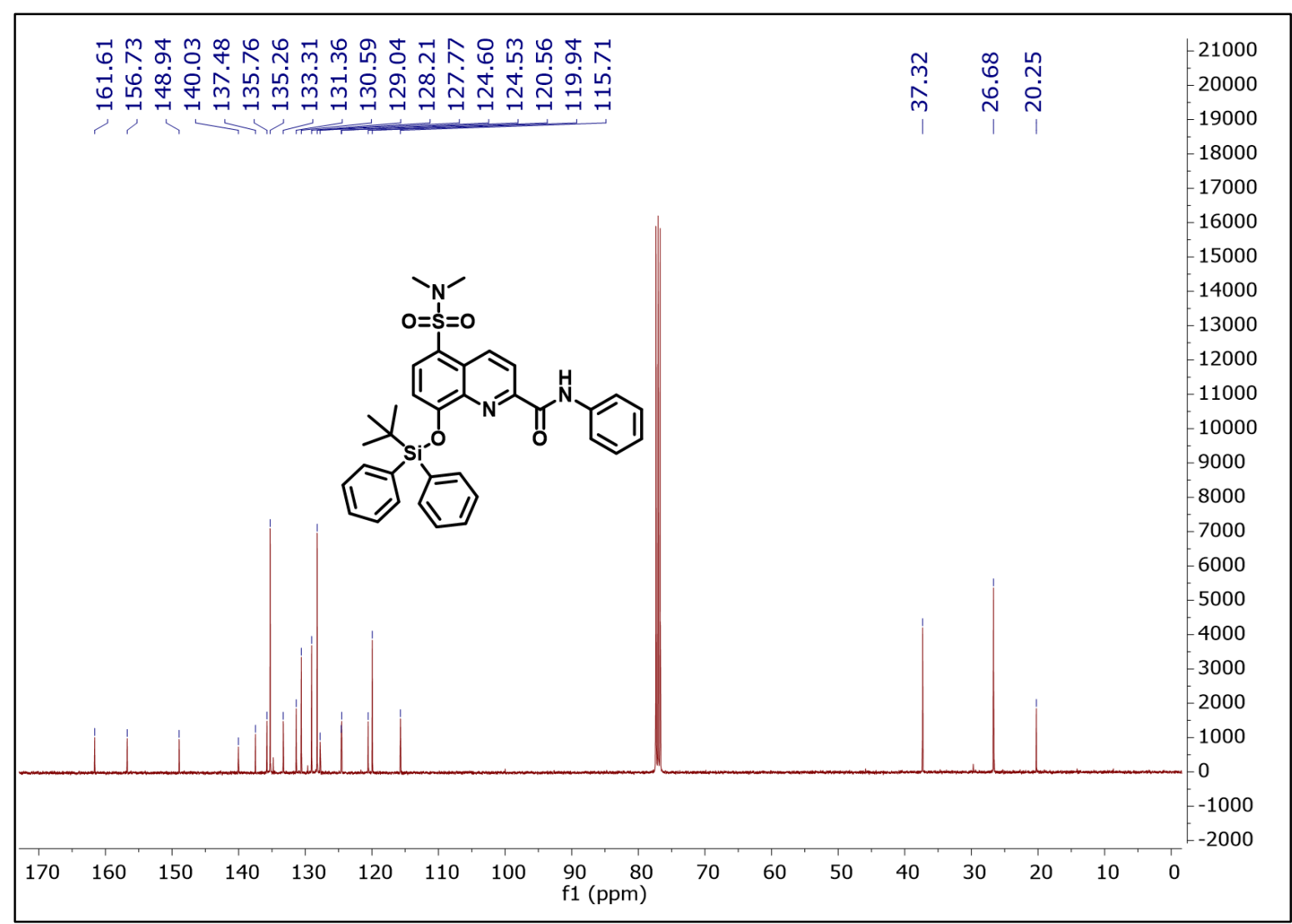

${ }^{13} \mathrm{C}$ NMR chart of 4 in $\mathrm{CDCl}_{3}(101 \mathrm{MHz})$ 


\section{References}

(1) Kim, S. Y.; Park, J.; Koh, M.; Park, S. B.; Hong, J. I. Chem. Commun. 2009, 4735-4737.

(2) Kim, D.; Singha, S.; Wang, T.; Seo, E.; Lee, J. H.; Lee, S. J.; Kim, K. H.; Ahn, K. H. Chem. Commun. 2012, 48, 10243-10245.

(3) Ke, B.; Chen, W.; Ni, N.; Cheng, Y.; Dai, C.; Dinh, H.; Wang, B. Chem. Commun. 2013, 49, 2494-2496.

(4) Zhu, B.; Yuan, F.; Li, R.; Li, Y.; Wei, Q.; Ma, Z.; Du, B.; Zhang, X. Chem. Commun. 2011, 47, 7098-7100.

(5) Li, L.; Ji, Y.; Tang, X. Anal. Chem. 2014, 86, 10006-9.

(6) Ashokkumar, P.; Weisshoff, H.; Kraus, W.; Rurack, K. Angew. Chem. Int. Ed. Engl. 2014, 53, 2225-2229.

(7) Hou, P.; Chen, S.; Wang, H. B.; Wang, J. X.; Voitchovsky, K.; Song, X. Z. Chem. Commun. 2014, 50, 320-322.

(8) Hu, R.; Feng, J. A.; Hu, D. H.; Wang, S. Q.; Li, S. Y.; Li, Y.; Yang, G. Q. Angew. Chem. Int. Edit. 2010, 49, 4915-4918.

(9) Zhang, S. L.; Fan, J. L.; Zhang, S. Z.; Wang, J. Y.; Wang, X. W.; Du, J. J.; Peng, X. J. Chem. Commun. 2014, 50, 14021-14024. 


\section{Appendix B}

Copies of ${ }^{1} \mathrm{H}$ and ${ }^{13} \mathrm{C}$ NMR Spectra. Reprinted with permission from the American Chemical Society.

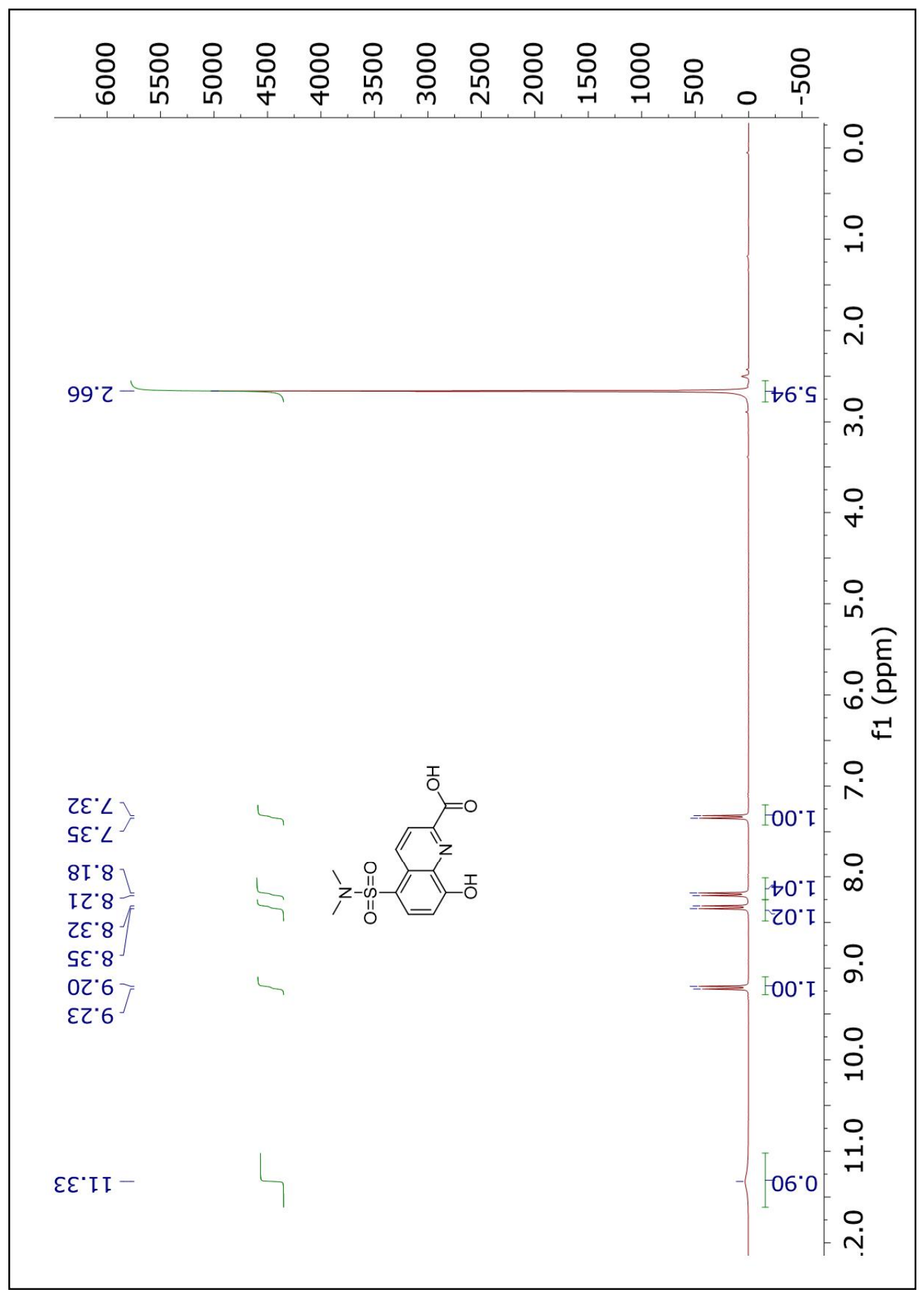


${ }^{1} \mathrm{H}$ NMR chart of 1 in DMSO-d 6 (300 MHz)

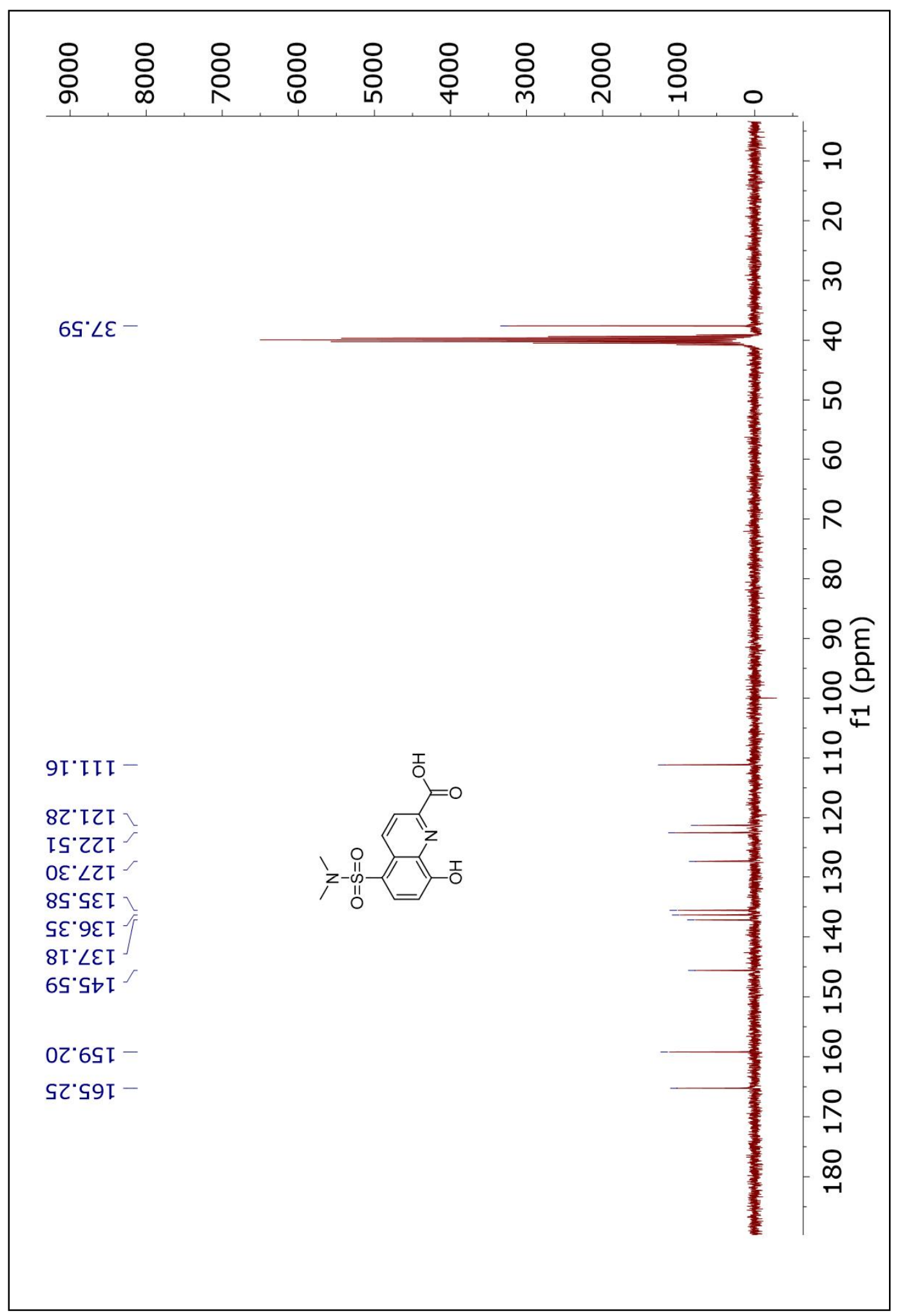

${ }^{13} \mathrm{C}$ NMR chart of $\mathbf{1}$ in DMSO-d 6 (75 MHz) 


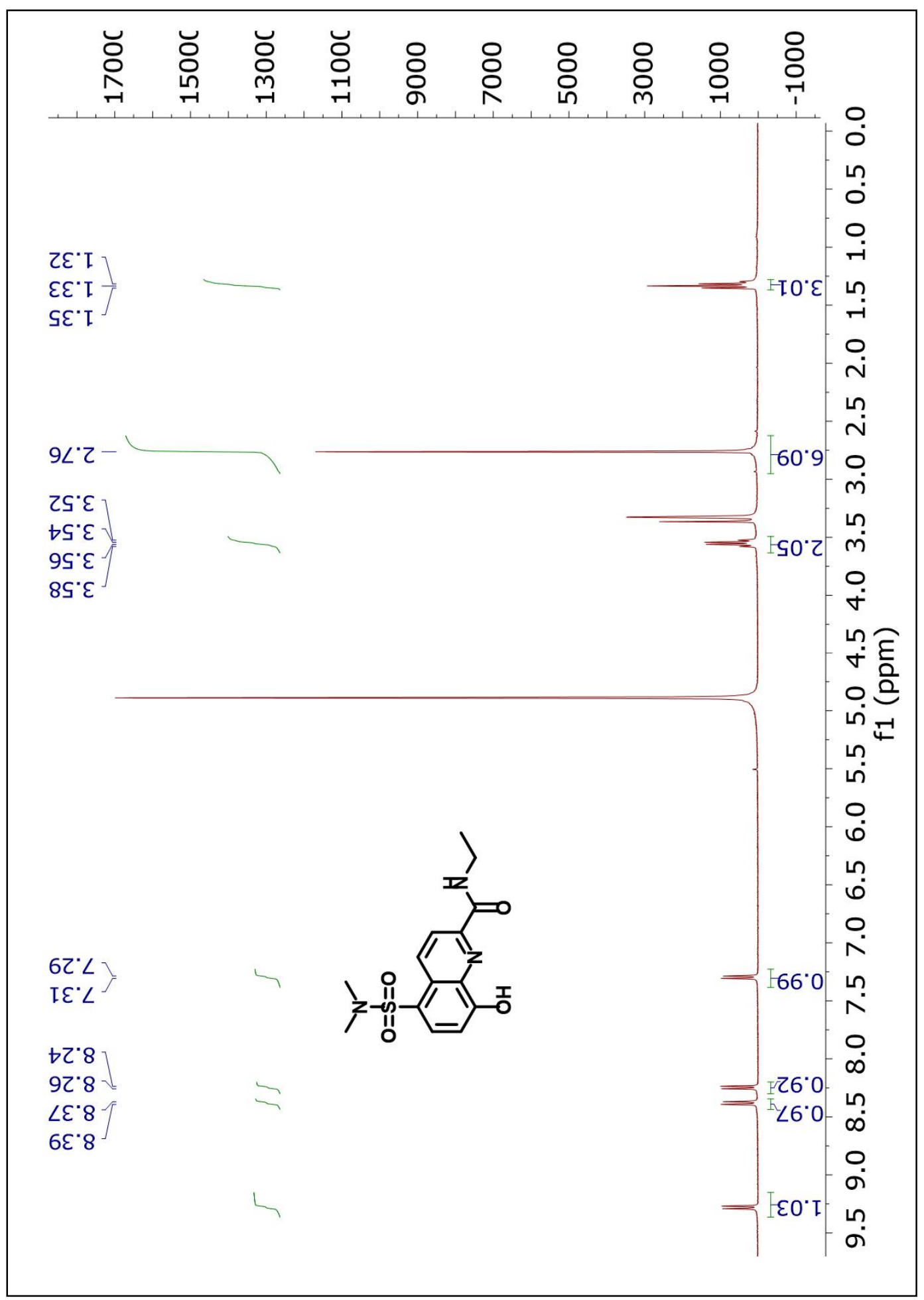

${ }^{1} \mathrm{H}$ NMR chart of $\mathbf{2 a}$ in Methanol-d 4 (400 MHz) 


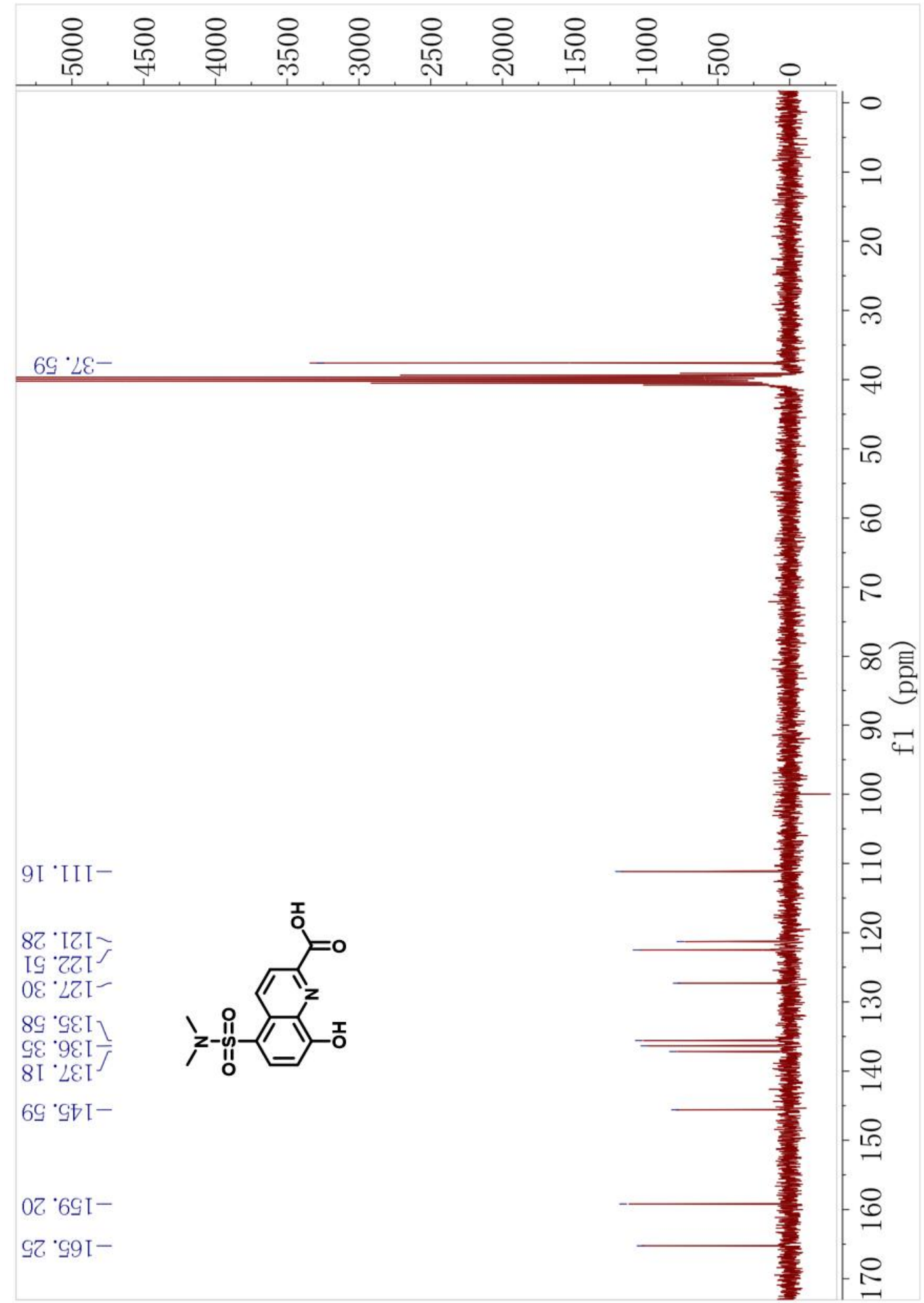

${ }^{13} \mathrm{C}$ NMR chart of 2a in Methanol-d 4 (101 MHz) 


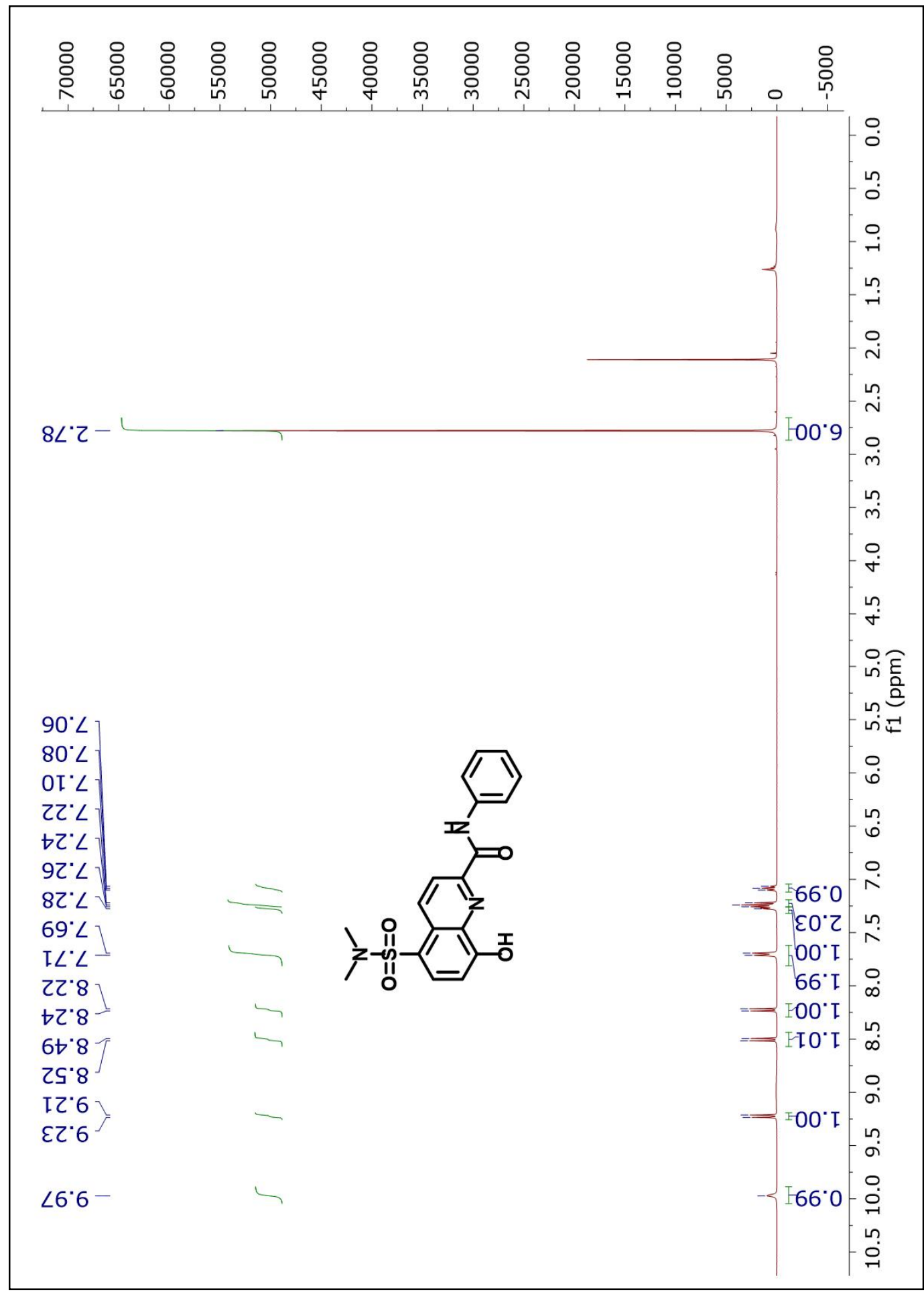

${ }^{1} \mathrm{H}$ NMR chart of $\mathbf{4 a}$ in $\mathrm{CDCl}_{3}(400 \mathrm{MHz})$ 


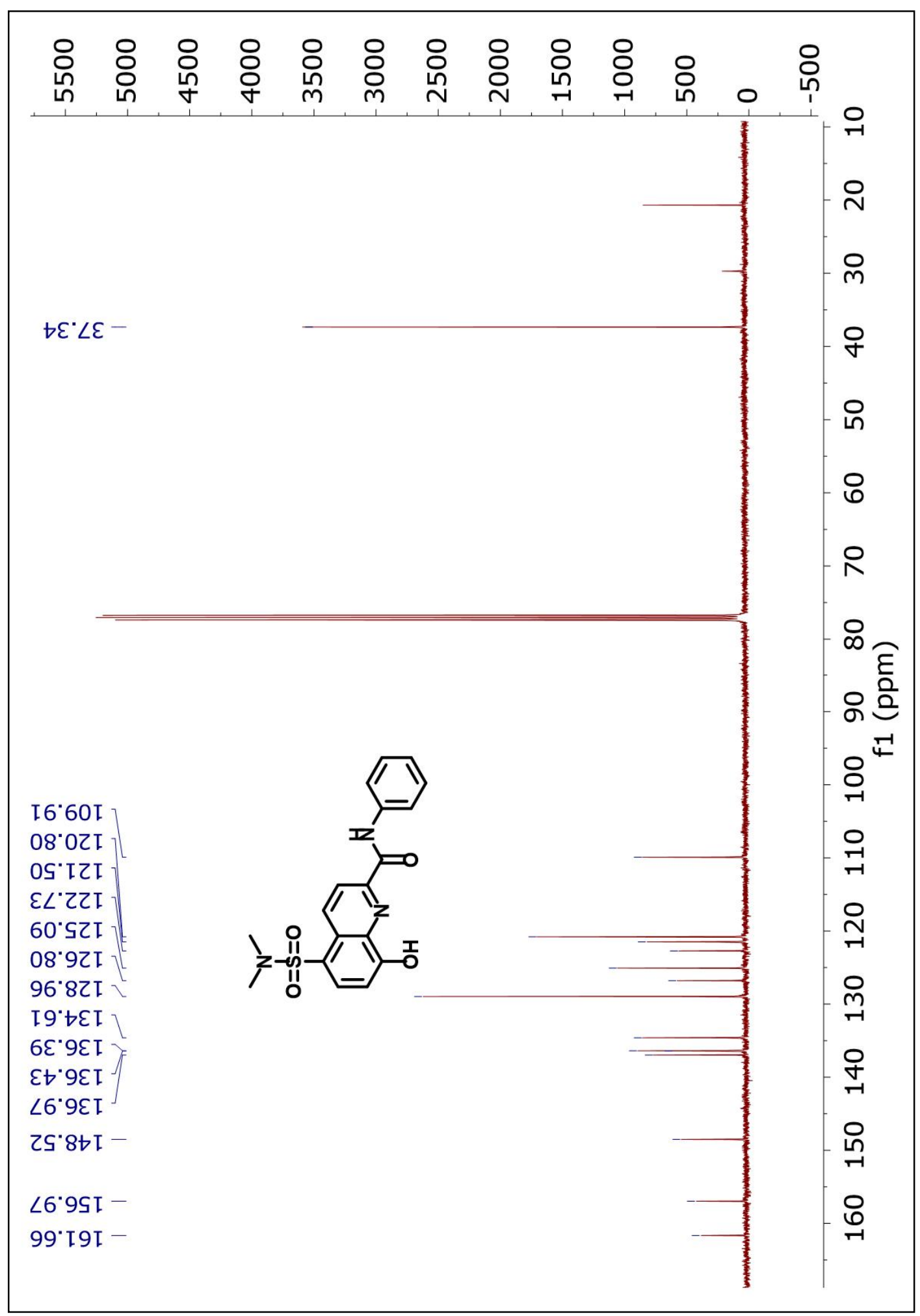

${ }^{13} \mathrm{C}$ NMR chart of $4 \mathbf{a}$ in $\mathrm{CDCl}_{3}(101 \mathrm{MHz})$ 


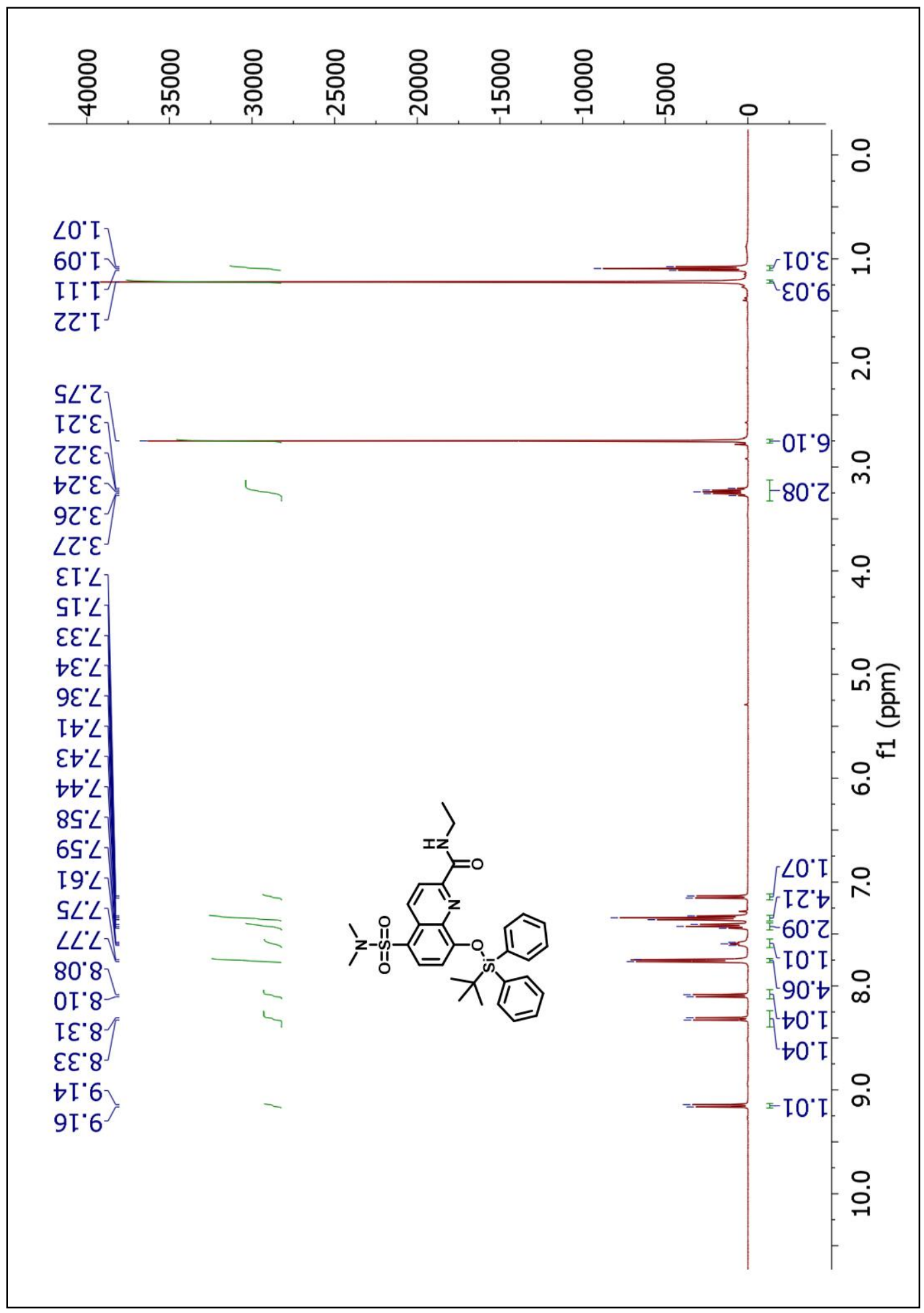

${ }^{1} \mathrm{H} \mathrm{NMR}$ chart of 2 in $\mathrm{CDCl}_{3}(400 \mathrm{MHz})$ 


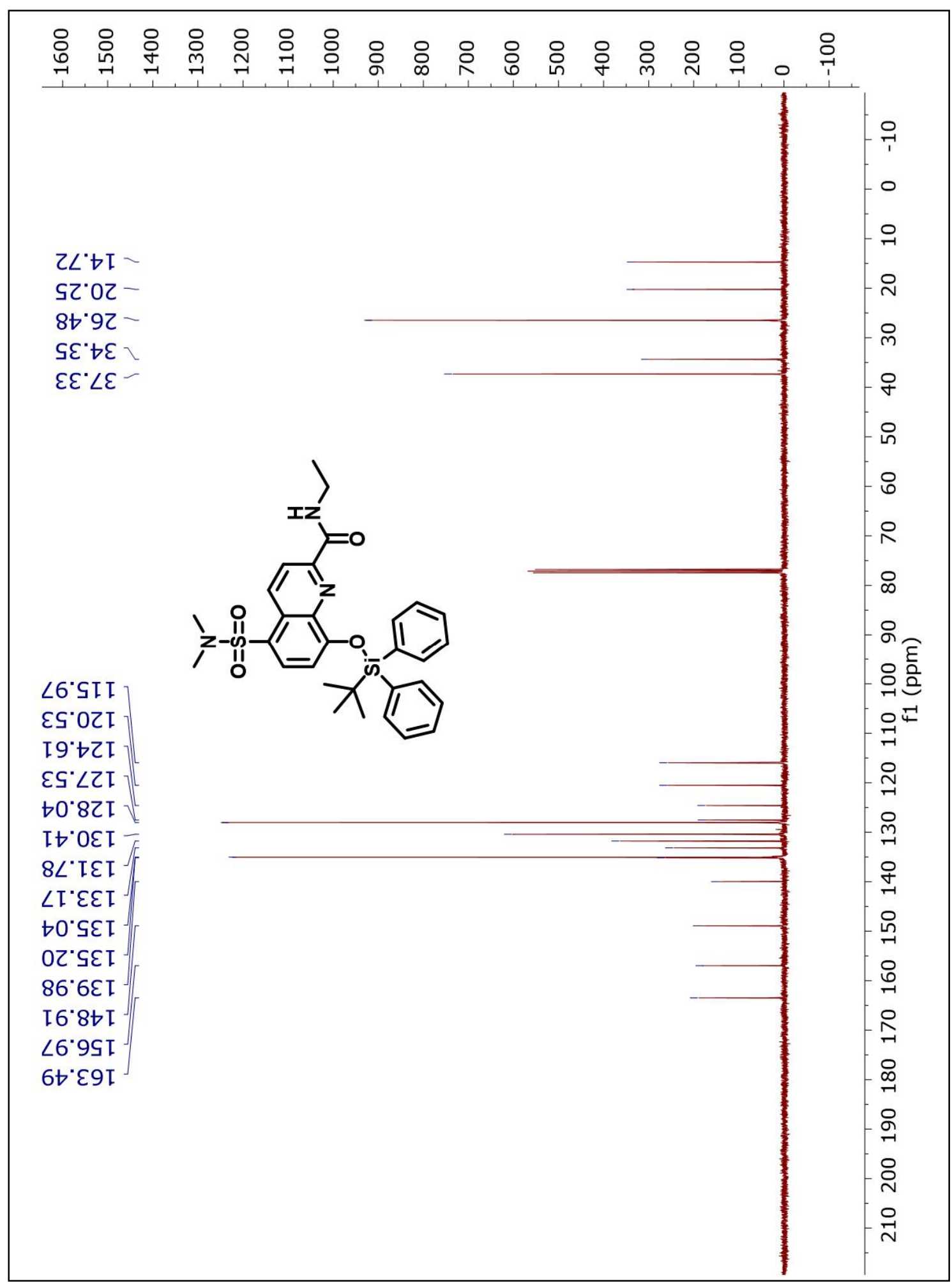

${ }^{13} \mathrm{C}$ NMR chart of 2 in $\mathrm{CDCl}_{3}(101 \mathrm{MHz})$ 


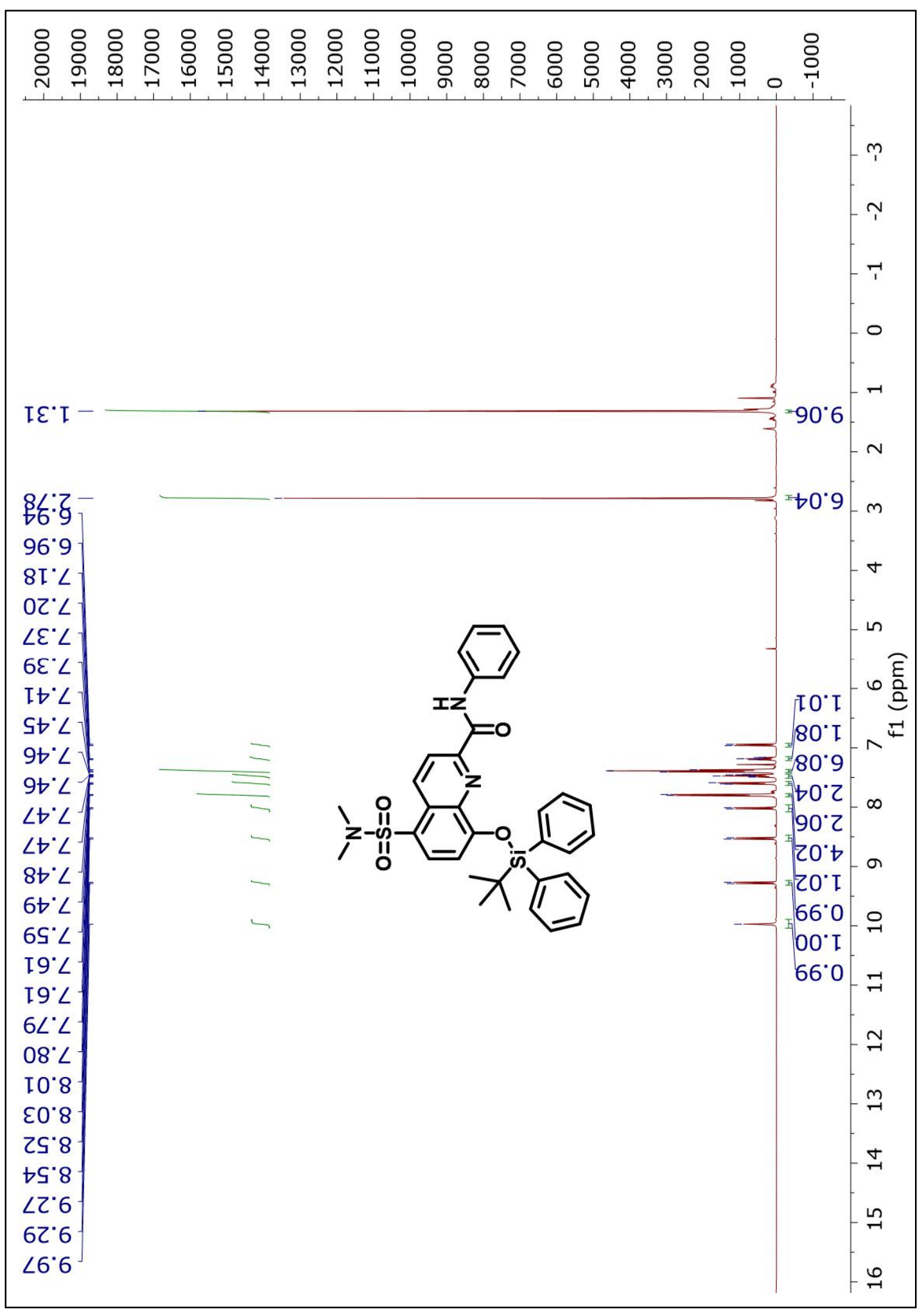

${ }^{1} \mathrm{H}$ NMR chart of 4 in $\mathrm{CDCl}_{3}(400 \mathrm{MHz})$ 


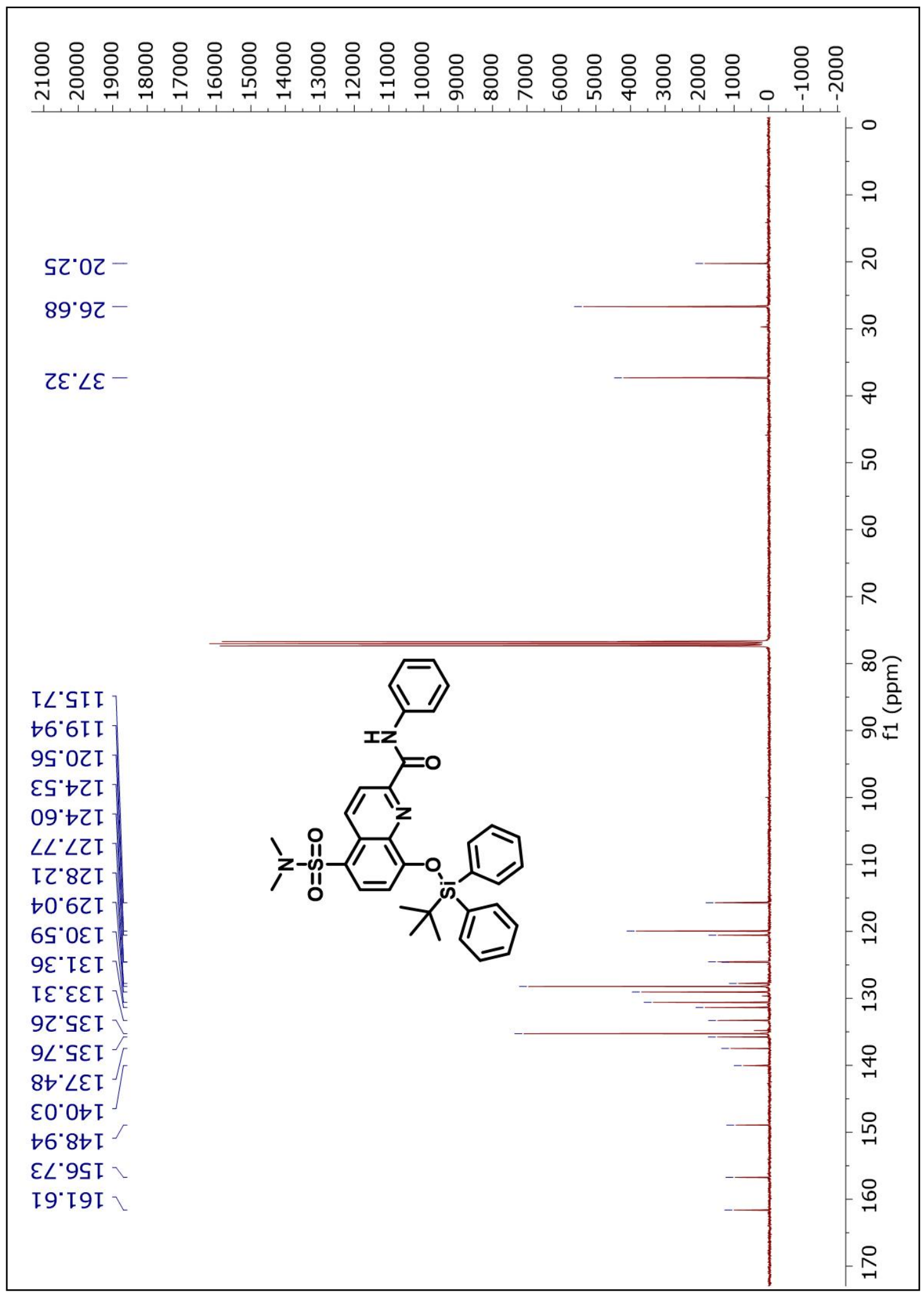

${ }^{13} \mathrm{C}$ NMR chart of 4 in $\mathrm{CDCl}_{3}(101 \mathrm{MHz})$ 


\section{REFERENCES}

1. $\quad$ Birkhed, D. Fluoride toothpaste - Product and behavioural factors. J Dent Res 81, B351-B351 (2002).

2. Campus, G. et al. Laboratory enamel fluoride uptake from fluoride products. $A m J$ Dent 25, 13-16 (2012).

3. Fluoride and the Treatment of Osteoporosis. Lancet 1, 547-547 (1984).

4. Dedeuxchaisnes, C.N., Devogelaer, J.P. \& Stein, F. Fluoride Treatment for Osteoporosis. Lancet 336, 48-49 (1990).

5. Lennon, M.A. One in a million: the first community trial of water fluoridation. World Health Organ 84, 759-764 (2006).

6. Rwenyonyi, C.M., Bjorvatn, K., Birkeland, J.M. \& Haugejordan, O. Altitude as a risk indicator of dental fluorosis in children residing in areas with 0.5 and $2.5 \mathrm{mg}$ fluoride per litre in drinking water. Caries Res 33, 267-274 (1999).

7. $\mathrm{Ba}, \mathrm{Y}$. et al. Serum calciotropic hormone levels, and dental fluorisis in children exposed to different concentrations of fluoride and iodine in drinking water. Chinese Med J-Peking 123, 675-679 (2010).

8. Shashi, A., Singh, J.P. \& Thapar, S.P. Toxic effects of fluoride on rabbit kidney. Fluoride 35, 38-50 (2002).

9. Santoyo-Sanchez, M.P., Silva-Lucero, M.D., Arreola-Mendoza, L. \& Barbier, O.C. Effects of Acute Sodium Fluoride Exposure on Kidney Function, Water Homeostasis, and Renal Handling of Calcium and Inorganic Phosphate. Biol Trace Elem Res 152, 367-372 (2013).

10. Czarnowski, W. et al. The impact of water-borne fluoride on bone density. Fluoride 32, 91-95 (1999).

11. Mousny, M. et al. The genetic influence on bone susceptibility to fluoride. Bone 39, 1283-1289 (2006).

12. Turner, C.H., Dunipace, A.J., Wilson, M. \& Sun, T.C. Fluoride Intake Severely Reduces Bone Strength in Older Rats. J Bone Miner Res 8, S238-S238 (1993).

13. CDC. Recommendations for Using Fluoride to Prevent and Control Dental Caries in the United States. Morbid Mortal Weekly Report 50, 1-42 (2001).

14. Adams, T.K., Capacio, B.R., Smith, J.R., Whalley, C.E. \& Korte, W.D. The application of the fluoride reactivation process to the detection of sarin and soman nerve agent exposures in biological samples. Drug Chem. Toxicol. 27, 77-91 (2004). 
15. Jakubowski, E.M. et al. Quantitation of fluoride ion released sarin in red blood cell samples by gas chromatography-chemical ionization mass spectrometry using isotope dilution and large-volume injection. J. Anal. Toxicol. 28, 357-363 (2004).

16. White, D.J. et al. 19F MAS-NMR and solution chemical characterization of the reactions of fluoride with hydroxyapatite and powdered enamel. Acta Odontol. Scand. 46, 375-389 (1988).

17. Light, T.S. \& Cappuccino, C.C. Determination of fluoride in toothpaste using an lon-selective electrode. J. Chem. Educ. 52, 247-250 (1975).

18. Hara, H., Kobayashi, H., Maeda, M., Ueno, A. \& Kobayashi, Y. Speciation of aluminum in rainwater using a fluoride ion-selective electrode and ion-exchange chromatography with fluorometric detection of the aluminum-lumogallion complex. Anal. Chem. 73, 5590-5595 (2001).

19. Lefler, J.E. \& Ivey, M.M. Ion chromatography detection of fluoride in calcium carbonate. J. Chromatogr. Sci. 49, 582-588 (2011).

20. Chen, C.Y. et al. New chromogenic and fluorescent probes for anion detection: formation of a $[2+2]$ supramolecular complex on addition of fluoride with positive homotropic cooperativity. J. Org. Chem. 73, 900-911 (2008).

21. Cho, E.J. et al. A new fluoride selective fluorescent as well as chromogenic chemosensor containing a naphthalene urea derivative. J. Am. Chem. Soc. 125, 12376-12377 (2003).

22. Fu, L., Jiang, F.L., Fortin, D., Harvey, P.D. \& Liu, Y. A reaction-based chromogenic and fluorescent chemodosimeter for fluoride anions. Chem. Commun. 47, 5503-5505 (2011).

23. Hou, P. et al. An aqueous red emitting fluorescent fluoride sensing probe exhibiting a large Stokes shift and its application in cell imaging. Chem. Commun. 50, 320-322 (2014).

24. Jiang, X., Vieweger, M.C., Bollinger, J.C., Dragnea, B. \& Lee, D. Reactivitybased fluoride detection: evolving design principles for spring-loaded turn-on fluorescent probes. Org. Lett. 9, 3579-3582 (2007).

25. Kim, T.H. \& Swager, T.M. A fluorescent self-amplifying wavelength-responsive sensory polymer for fluoride ions. Angew. Chem. 42, 4803-4806 (2003).

26. Kubo, Y. et al. A colorimetric and ratiometric fluorescent chemosensor with three emission changes: fluoride ion sensing by a triarylborane- porphyrin conjugate. Angew. Chem. 42, 2036-2040 (2003). 
27. Liu, X.Y., Bai, D.R. \& Wang, S. Charge-transfer emission in nonplanar threecoordinate organoboron compounds for fluorescent sensing of fluoride. Angew. Chem. 45, 5475-5478 (2006).

28. Qu, Y., Hua, J. \& Tian, H. Colorimetric and ratiometric red fluorescent chemosensor for fluoride ion based on diketopyrrolopyrrole. Org. Lett. 12, 33203323 (2010).

29. Xiong, L. et al. Sensing in $15 \mathrm{~s}$ for aqueous fluoride anion by water-insoluble fluorescent probe incorporating hydrogel. Anal. Chem. 85, 4113-4119 (2013).

30. Zhang, J.F., Lim, C.S., Bhuniya, S., Cho, B.R. \& Kim, J.S. A highly selective colorimetric and ratiometric two-photon fluorescent probe for fluoride ion detection. Org. Lett. 13, 1190-1193 (2011).

31. Zhou, Y., Zhang, J.F. \& Yoon, J. Fluorescence and colorimetric chemosensors for fluoride-ion detection. Chem. Rev. 114, 5511-5571 (2014).

32. Ashokkumar, P., Weisshoff, H., Kraus, W. \& Rurack, K. Test-strip-based fluorometric detection of fluoride in aqueous media with a BODIPY-linked hydrogen-bonding receptor. Angew. Chem. 53, 2225-2229 (2014).

33. Jacobsen, J.A., Stork, J.R., Magde, D. \& Cohen, S.M. Hydrogen-bond rigidified BODIPY dyes. Dalton Trans. 39, 957-962 (2010).

34. Jiao, Y., Zhu, B., Chen, J. \& Duan, X. Fluorescent sensing of fluoride in cellular system. Theranostics 5, 173-187 (2015).

35. Wang, J., Yang, L., Hou, C. \& Cao, H. A new N-imidazolyl-1,8-naphthalimide based fluorescence sensor for fluoride detection. Org. Biomol. Chem. 10, 62716274 (2012).

36. $\mathrm{Xu}, \mathrm{L}$. et al. A receptor incorporating $\mathrm{OH}, \mathrm{NH}$ and $\mathrm{CH}$ binding motifs for a fluoride selective chemosensor. Org. Biomol. Chem. 10, 4375-4380 (2012).

37. Murphy, C.J. et al. Long-range photoinduced electron transfer through a DNA helix. Science 262, 1025-1029 (1993).

38. Pause, L., Robert, M. \& Saveant, J.M. Stepwise and concerted pathways in photoinduced and thermal electron-transfer/bond-breaking reactions. experimental illustration of similarities and contrasts. J. Am. Chem. Soc. 123, 4886-4895 (2001).

39. Kim, S.K. \& Yoon, J. A new fluorescent PET chemosensor for fluoride ions. Chem. Commun. 770-771 (2002).

40. DiCesare, N. \& Lakowicz, J.R. New sensitive and selective fluorescent probes for fluoride using boronic acids. Anal. Biochem. 301, 111-116 (2002). 
41. Galbraith, E., Fyles, T.M., Marken, F., Davidson, M.G. \& James, T.D. Fluorescent boron bis(phenolate) with association response to chloride and dissociation response to fluoride. Inorg. Chem. 47, 6236-6244 (2008).

42. Guo, Z., Shin, I. \& Yoon, J. Recognition and sensing of various species using boronic acid derivatives. Chem. Commun. 48, 5956-5967 (2012).

43. Huang, S. et al. The progress of selective fluorescent chemosensors by boronic acid. Curr. Med. Chem. 19, 2621-2637 (2012).

44. Swamy, K.M. et al. A new fluorescein derivative bearing a boronic acid group as a fluorescent chemosensor for fluoride ion. J. Org. Chem. 71, 8626-8628 (2006).

45. Rao, M.R., Mobin, S.M. \& Ravikanth, M. Boron-dipyrromethene based specific chemodosimeter for fluoride ion. Tetrahedron 66, 1728-1734 (2010).

46. Fu, L., Jiang, F.L., Fortin, D., Harvey, P.D. \& Liu, Y. A reaction-based chromogenic and fluorescent chemodosimeter for fluoride anions. Chem. Commun. 47, 5503-5505 (2011).

47. Demchenko, A.P. Introduction to fluorescence sensing. (Springer, New York; 2009).

48. Kim, D. et al. In vivo two-photon fluorescent imaging of fluoride with a desilylation-based reactive probe. Chem. Commun. 48, 10243-10245 (2012).

49. Li, Q. et al. Toxicity of sodium fluoride to Caenorhabditis elegans. Biomed. Environ. Sci. 25, 216-223 (2012).

50. Katsura, I., Kondo, K., Amano, T., Ishihara, T. \& Kawakami, M. Isolation, characterization and epistasis of fluoride-resistant mutants of Caenorhabditis elegans. Genetics 136, 145-154 (1994).

51. Kim, S.Y., Park, J., Koh, M., Park, S.B. \& Hong, J.I. Fluorescent probe for detection of fluoride in water and bioimaging in A549 human lung carcinoma cells. Chem. Commun., 4735-4737 (2009).

52. Kim, D. et al. In vivo two-photon fluorescent imaging of fluoride with a desilylation-based reactive probe. Chem. Commun. 48, 10243-10245 (2012).

53. Ke, B. et al. A fluorescent probe for rapid aqueous fluoride detection and cell imaging. Chem. Commun. 49, 2494-2496 (2013).

54. Zhu, B. et al. A highly selective colorimetric and ratiometric fluorescent chemodosimeter for imaging fluoride ions in living cells. Chem. Commun. 47, 7098-7100 (2011). 
55. Li, L., Ji, Y. \& Tang, X. Quaternary ammonium promoted ultra selective and sensitive fluorescence detection of fluoride ion in water and living cells. Anal. Chem. 86, 10006-10009 (2014).

56. Ashokkumar, P., Weisshoff, H., Kraus, W. \& Rurack, K. Test-strip-based fluorometric detection of fluoride in aqueous media with a BODIPY-linked hydrogen-bonding receptor. Angew. Chem. Int. Ed. Engl. 53, 2225-2229 (2014).

57. Hou, P. et al. An aqueous red emitting fluorescent fluoride sensing probe exhibiting a large Stokes shift and its application in cell imaging. Chem. Commun. 50, 320-322 (2014).

58. Zhang, S.L. et al. Lighting up fluoride ions in cellular mitochondria using a highly selective and sensitive fluorescent probe. Chem. Commun. 50, 14021-14024 (2014).

59. Zhou, X., Lai, R., Li, H. \& Stains, C.I. The 8-silyloxyquinoline scaffold as a versatile platform for the sensitive detection of aqueous fluoride. Anal. Chem. 87, 4081-4086 (2015).

60. Pearce, D.A., Jotterand, N., Carrico, I.S. \& Imperiali, B. Derivatives of 8hydroxy-2-methylquinoline are powerful prototypes for zinc sensors in biological systems. J. Am. Chem. Soc. 123, 5160-5161 (2001).

61. Shults, M.D., Pearce, D.A. \& Imperiali, B. Modular and tunable chemosensor scaffold for divalent zinc. J. Am. Chem. Soc. 125, 10591-10597 (2003).

62. Beck, J.R., Peterson, L.B., Imperiali, B. \& Stains, C.I. Quantification of protein kinase enzymatic activity in unfractionated cell lysates using CSox-based sensors. Curr. Protoc. Chem. Biol. 6, 135-156 (2014).

63. Szalewski, D.A., Beck, J.R. \& Stains, C.I. Design, synthesis, and evaluation of a selective chemosensor for leucine-rich repeat kinase 2. Bioorg. Med. Chem. Lett. 24, 5648-5651 (2014).

64. CDC. Recommendations for Using Fluoride to Prevent and Control Dental Caries in the United States. Morbid. Mortal. Weekly Report 50, 1-42 (2001).

65. Williamson, J.E. \& Carter, J.M. in U.S. Geological Survey, Water-Resources Investigations Report, 1-4194 (2001).

66. Korshoj, L.E., Zaitouna, A.J. \& Lai, R.Y. Methylene Blue-Mediated Electrocatalytic Detection of Hexavalent Chromium. Anal. Chem. 87, 2560-2564 (2015). 